\title{
Espelho virtual interativo para simulação de maquiagem
}

Filipe Morgado Simões de Campos

DisSERTAÇÃo APRESENTADA

AO

Instituto DE MATEMÁtica e EstatísticA

DA

Universidade DE SÃo PAUlo

PARA

OBTENÇÃO DO TÍTULO

$\mathrm{DE}$

Mestre EM CiÊNCIAS

Programa: Mestrado em Ciência da Computação

Orientador: Prof. Dr. Carlos Hitoshi Morimoto

São Paulo, Agosto de 2014 


\section{Espelho virtual interativo para simulação de maquiagem}

Esta versão da dissertação contém as correções e alterações sugeridas pela Comissão Julgadora durante a defesa da versão original do trabalho, realizada em 9/9/2014. Uma cópia da versão original está disponível no

Instituto de Matemática e Estatística da Universidade de São Paulo.

Comissão Julgadora:

- Prof. Dr. Carlos Hitoshi Morimoto (Presidente) - IME-USP

- Prof ${ }^{a}$. Dra ${ }^{\mathrm{a}}$. Fátima de Lourdes dos Santos Nunes Marques - EACH-USP

- Prof. Dr. Marcelo Walter - UFRGS 


\section{Agradecimentos}

Gostaria de agradecer à minha família por todo o apoio e educação que me deram desde pequeno e que sem eles não teria chegado onde cheguei. Sou imensamente grato por tudo. Além disso, gostaria de agradecer à minha irmã por ter se disposto a ajudar nas fotografias para os testes e resultados do método de simulação de maquiagem.

Gostaria de agradecer ao Carlos Hitoshi Morimoto por toda sua orientação ao longo dos últimos anos, não só durante o mestrado, mas também durante a iniciação científica. Foi um período bastante importante para mim e sem dúvida você contribuiu muito.

Gostaria de agradecer também aos meus amigos, tanto aos novos amigos que tive o prazer de conhecer no IME quanto aos antigos amigos, por todo o apoio, companheirismo e incentivo.

Por fim, gostaria de agradecer a todos os professores que participaram da qualificação e da defesa com seus comentários úteis e construtivos que me permitiram melhorar a qualidade da dissertação. 


\section{Resumo}

Campos, F. M. S. Espelho virtual interativo para simulação de maquiagem. 2014. 77 f. Dissertação (Mestrado) - Instituto de Matemática e Estatística, Universidade de São Paulo, São Paulo, 2014.

Este trabalho tem como objetivo desenvolver um espelho virtual interativo para simulação de maquiagem com a intenção de melhorar a experiência do usuário durante a experimentação de produtos de maquiagem, tornando essa tarefa mais rápida (aplicação e remoção da maquiagem simulada ocorre de forma instantânea) e barata (sem gasto de produtos).

A interação com o simulador foi baseada na metáfora de um espelho. A interface do sistema permite a escolha da maquiagem e sua livre aplicação sobre a imagem da própria pessoa. O sistema renderiza em tempo real o vídeo resultante da simulação exibido no espelho sem a necessidade de marcas fiduciais na face ou a criação de um modelo 3D da face antes do uso do sistema. A interface proposta é composta por um monitor sensível a toque e uma câmera RGBD. A câmera RGBD facilita o rastreamento de características faciais do usuário e fornece a imagem a ser utilizada no espelho virtual. A interação ocorre por meio do toque no monitor, permitindo que o usuário escolha a maquiagem e também faça sua aplicação. A simulação da maquiagem considera produtos comuns que modificam propriedades da superfície da pele como cor e textura, sob condições controladas de iluminação.

O método permite a livre aplicação de tipos diferentes de maquiagem (base, batom e sombra) em qualquer área do rosto de forma independente (flexibilidade), não necessita de equipamentos especiais e pode ser computado em tempo real. Para isso, a imagem é decomposta em camadas de cor e textura que podem ser tratadas independentemente, por meio de filtros e transformações no espaço de cor. Um protótipo em tempo real foi desenvolvido utilizando um Microsoft Kinect, que demostra a viabilidade do método.

Palavras-chave: simulação de maquiagem, interação humano computador, processamento de imagens. 


\section{Abstract}

Campos, F. M. S. Interactive virtual mirror for makeup simulation. 2014. 77 f. Dissertação (Mestrado) - Instituto de Matemática e Estatística, Universidade de São Paulo, São Paulo, 2014.

The objective of this thesis is to develop an interactive virtual mirror for makeup simulation to improve user experience when trying different makeup products.

The interaction with the simulator was based on the metaphor of a mirror. The system interface allows the user to choose and to apply makeup over its own image. The system renders the video displayed in the mirror in real time without the need of fiducial markers on the user's face or the creation of a 3D face model before the use of the system. The proposed interface consists of a touch-sensitive monitor and a RGBD camera. The latter makes the tracking of facial features easier and also provides the image used in the virtual mirror and the former allows the interaction with the system that is touch based. Under controlled lighting conditions, the makeup simulation considers common products that modify skin texture and color.

Our method allows the application of different makeup products (foundation, lipstick, eyeshadow) independently and in any face location (flexibility), do not require special equipment and can be computed in real time. The simulation algorithm decomposes the image into layers of color and texture that can be treated independently by filters and color space transformations. A prototype that runs in real time has been developed using a Microsoft Kinect, which demonstrates the feasibility of the method.

Keywords: makeup simulation, human computer interaction, image processing. 


\section{Sumário}

$\begin{array}{ll}\text { Lista de Figuras } & \text { ix }\end{array}$

Lista de Tabelas $\quad$ xiii

1 Introdução $\quad 1$

1.1 Motivação . . . . . . . . . . . . . . . . . . . 1

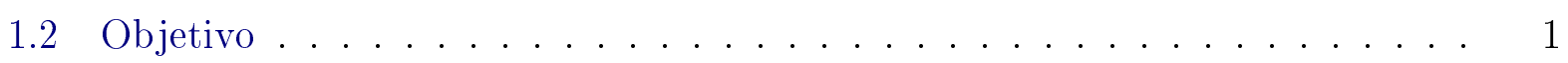

1.3 Definição do problema . . . . . . . . . . . . . . . . 2

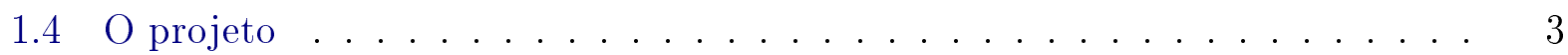

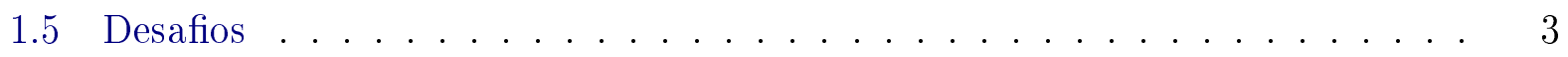

1.6 Contribuições . . . . . . . . . . . . . . . . . . 3

1.7 Organização do trabalho . . . . . . . . . . . . . . . . 4

2 Fundamentos $\quad 5$

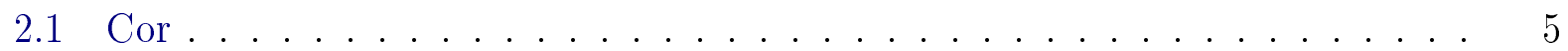

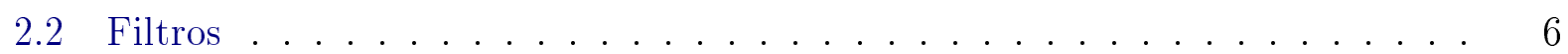

2.3 Operações morfológicas . . . . . . . . . . . . . . . . . . 6

2.4 Superfície especular e lamberciana . . . . . . . . . . . . . . . 6

2.5 Maquiagem . . . . . . . . . . . . . . . . . . 7

2.6 Base, batom e sombra .................... 7

3 Estado da Arte $\quad 9$

3.1 Trabalhos acadêmicos . . . . . . . . . . . . . . . 9

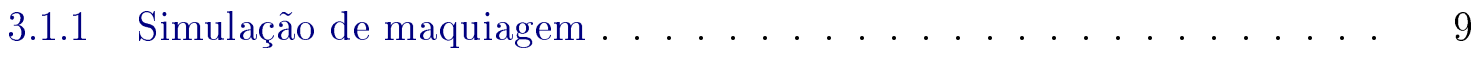

3.1.2 Interação humano computador . . . . . . . . . . . . . . 22

3.1 .3 Sugestão de maquiagem . . . . . . . . . . . . . . . . 28

3.1.4 Reconstrução facial e interação da luz com a pele . . . . . . . . . . 30

3.1.5 Rastreamento de faces . . . . . . . . . . . . . . . . . 31

3.2 Trabalhos não acadêmicos . . . . . . . . . . . . . . . . 31

3.2 .1 Shiseido . . . . . . . . . . . . . . . . . 31

3.2 .2 Natura . . . . . . . . . . . . . . . . . . . 31

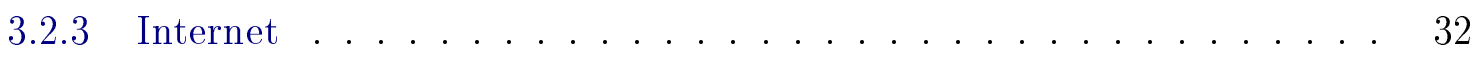


3.2.4 Softwares de rastreamento facial . . . . . . . . . . . . . 32

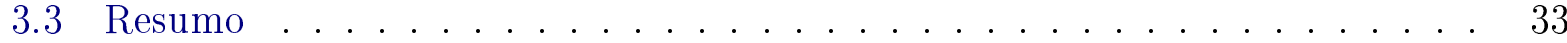

3.3 .1 Simulação de maquiagem . . . . . . . . . . . . . . 33

3.3 .2 Interação humano computador . . . . . . . . . . . . . . . . . . 34

4 Sistema Proposto $\quad 37$

4.1 Contextualização . . . . . . . . . . . . . . . . . . . 37

4.2 Arquitetura . . . . . . . . . . . . . . . . . 38

4.3 Interação . . . . . . . . . . . . . . . . . . . . . . 38

4.4 Simulação de maquiagem . . . . . . . . . . . . . . . . . . 40

5 Prototipação $\quad 45$

5.1 Interação . . . . . . . . . . . . . . . . . . . . . . 46

5.1 .1 Triangularização e Modelo de face . . . . . . . . . . . . . 47

5.1 .2 Simulação de maquiagem . . . . . . . . . . . . . . . . . . 49

5.1 .3 Interface e maquilets . . . . . . . . . . . . . . . . . . . 49

5.2 Simulação de maquiagem . . . . . . . . . . . . . . . . 50

5.2 .1 Simulação de maquiagem - Textura . . . . . . . . . . . . . 52

5.2 .2 Simulação de maquiagem - Cor . . . . . . . . . . . . . . 55

5.2 .3 Desempenho . . . . . . . . . . . . . . . . 55

6 Resultados $\quad 59$

6.1 Interação . . . . . . . . . . . . . . . . . . . . 59

6.2 Simulação de maquiagem . . . . . . . . . . . . . . . . . 60

$\begin{array}{lll}7 & \text { Conclusão } & 69\end{array}$

$\begin{array}{ll}\text { Referências Bibliográficas } & 73\end{array}$ 


\section{Lista de Figuras}

3.1 As duas imagens à esquerda ilustram as imagens chamadas de $A$ (modelo sem maquiagem) e $A^{*}$ (modelo com maquiagem) utilizadas para gerar o resultado na imagem mais à direita. As imagens à direita são $B$ (alvo sem maquiagem) e $B^{*}$ (alvo com maquiagem aplicada por meio da transferência de maquiagem proposta pelo artigo). Retirado de Tong et al. (2007). . . . . . . . . . . .

3.2 Mapa de maquiagem $C_{i}$ computado para os três exemplos de maquiagem $A_{i}^{*}$, $i=1,2$ e 3 . Para proporcionar uma melhor visualização, foi adicionado a cada pixel o valor 127. Retirada de Tong et al. (2007). . . . . . . . . . . . . .

3.3 À esquerda, pode-se ver que sardas e sinais da pele na imagem modelo maquiada, $A_{4}^{*}$, não foram transferidas para a imagem alvo $B_{4}^{*}$. À direita, pode-se observar a imagem original do olho da face alvo, $B$, a preservação das cores e densidade da sobrancelha, $B_{1}^{*}$, e um exemplo com maquiagem cobrindo a sobrancelha $B_{3}^{*}$ (as imagens modelo da maquiagem, $A_{1}^{*}$ e $A_{3}^{*}$, para esses resultados, $B_{1}^{*}$ e $B_{3}^{*}$, podem ser observadas na figura 3.2$)$. Retirada de Tong et al. (2007).

3.4 Exemplos de transferência de maquiagem. A face alvo, $B$, usada é a mesma apresentada na figura 3.1. (a) Faces modelo antes da maquiagem, $A_{i}$. (b) Faces modelo após maquiagem, $A_{i}^{*}$. (c) Faces alvo após aplicação da maquiagem, $B_{i}^{*}$. Retirada de Tong et al. (2007). . . . . . . . . . . . . . .

3.5 (a) Imagem alvo. (b) Imagem modelo com o estilo de maquiagem a ser transferido, retirada da mesma fonte utilizada no artigo anterior, (Nars, 2004). (c) Resultado da transferência. Retirada de Guo e Sim (2009). . . . . . . . . 15

3.6 A imagem ilustra o processo criado para a abordagem apresentada em Guo e Sim (2009). $W$ denota a deformação, $\nabla$ denota a edição por gradiente, + denota a soma ponderada e $\alpha$ denota a média ponderada. Nessa imagem os valores da camada de detalhe da pele, $\mathcal{I}_{d}$ e $\mathcal{E}_{d}$, estão exagerados quatro vezes para facilitar sua visualização. A abordagem desse artigo consiste de quatro passos: alinhamento entre faces, decomposição em camadas, transferência da maquiagem, junção das camadas. Retirada de Guo e Sim (2009). . . . . . . 15

3.7 Comparação entre os resultados de Guo e Sim (2009) e de Tong et al. (2007). Retirada de Guo e Sim (2009). . . . . . . . . . . . . . . . 
3.8 Foto retocada, (a) Imagem modelo tirada de forma profissional em um estúdio com a intenção de proporcionar o retoque desejado na imagem alvo. (b) e (d) Fotos da mesma pessoa de (a), tiradas de forma amadora. (c) e (e) O resultado do retoque de (b) e (d), respectivamente. Retirada de Guo e Sim (2009). . .

3.9 (a) Imagem de uma pintura usada como imagem exemplo. (b) Foto da pessoa alvo. (c) Resultado da maquiagem com os detalhes faciais de (a). (d) Resultado da maquiagem com os detalhes faciais de (b). Retirada de Guo e Sim (2009).

3.10 Comparativo entre o resultado da simulação (direita) e a maquiagem real (esquerda). Retirada de Huang et al. (2013). . . . . . . . . . . . . . 22

3.11 Interface gráfica do sistema proposto em Kim e Choi (2008). . . . . . . . . 22

3.12 Essa imagem ilustra o sistema proposto pelos autores e destaca os equipamentos utilizados para seu funcionamento. Retirada de Iwabuchi et al. (2009). 23

3.13 Exemplo de configuração de um espelho virtual baseado em um espelho semireflexivo. Retirada de Makino et al. (2005). . . . . . . . . . . . . . .

3.14 Sistema proposto em Rahman et al. (2010). Destaque para os equipamentos utilizados em seu funcionamento. . . . . . . . . . . . . . 26

3.15 Sistema proposto em Hanafusa et al. (2010). Destaque para os equipamentos utilizados em seu funcionamento. . . . . . . . . . . . .

3.16 A imagem ilustra a interface gráfica do sistema proposto em Hanafusa et al.

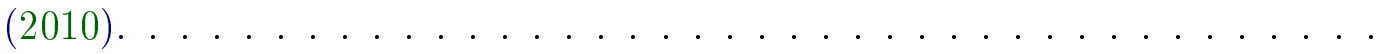

3.17 A imagem ilustra o sistema proposto destacando os equipamentos utilizados. Retirada de Nakagawa et al. (2011). . . . . . . . . . . . . . . . .

3.18 A imagem ilustra o quiosque do sistema proposto. Retirada de Jain e Bhatti

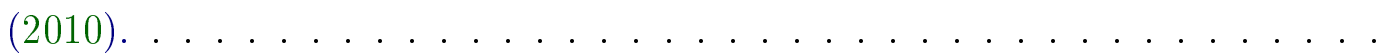

3.19 A imagem ilustra as etapas do sistema proposto. Retirada de Jain e Bhatti

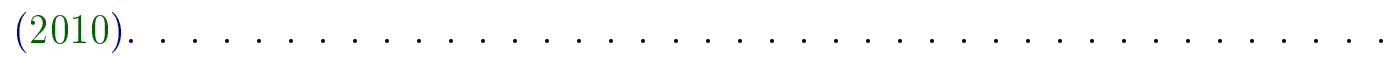

3.20 A imagem ilustra o cenário de captura da face utilizando o sistema da Dynamixyz. Imagem retirada do site da Dynamixyz. . . . . . . . . . . . . . 33

4.1 Arquitetura geral. . . . . . . . . . . . . . . . . . 39

4.2 À esquerda a região do espelho e à direita a região dos controles. . . . . . . . 40

4.3 Fluxo da simulação de maquiagem - Textura. . . . . . . . . . . . . . . . 42

4.4 Divisão da imagem da face em cinco faixas de frequência a serem tratadas independentemente. . . . . . . . . . . . . . . . . 42

4.5 Fluxo da simulação de maquiagem - Cor. . . . . . . . . . . . . . 43

5.1 Pontos fortes e fracos dos protótipos da Interação e da Simulação de Maquiagem, bem como seu elo de ligação para junção dos dois protótipos em um só, quando a capacidade computacional do hardware permitir. . . . . . . . . . 
5.2 (a) triangularização obtida apenas com as funções do SDK do Kinect, vista frontal; (b) triangularização obtida apenas com as funções do SDK do Kinect, vista lateral; (c) triangularização final, vista frontal; (d) triangularização final, vista lateral. . . . . . . . . . . . . . . . . . . . . 4 48

5.3 Um exemplo de subdivisão de um triângulo ABC . . . . . . . . . . . . . . . 48

5.4 (a) Exemplo de máscara para o protótipo da interação criada a partir do toque do usuário na imagem da face; (b) Mesma máscara de (a) após operação de dilatação e suavização; (c) Resultado da aplicação de maquiagem para o protótipo da interação considerando a $m_{\text {asc }}$ apresentada em (b). . . . . . . .

5.5 Disposição dos equipamentos do protótipo da interação exibindo também a região de espelho e a região de controles da interface. O teclado não é necessário para a utilização do sistema, é usado apenas durante o uso comum do computador. . . . . . . . . . . . . . . . . . .

5.6 Exemplos de máscaras, $m_{a s c}$, para a aplicação de cada produto de maquiagem no protótipo da simulação de maquiagem. (a) exemplo de máscara para a aplicação de base; (b) exemplo de máscara para a aplicação de sombra; (c) exemplo de máscara para a aplicação de batom. . . . . . . . . . . . . . . .

5.7 (a) camada de frequência intermediária $1, C_{f 1}$; (b) camada de frequência intermediária 1, $C_{f 1}$, após suavização; (c) camada de frequência intermediária 2, $C_{f 2} ;(\mathrm{d})$ camada de frequência intermediária $2, C_{f 2}$, após suavização; (e) camada de frequência intermediária $3, C_{f 3}$; (f) camada de frequência intermediária $3, C_{f 3}$, após suavização; $(\mathrm{g})$ camada de alta frequência, $C_{f A}$; (h) camada residual, $C_{f B}$; (i) esquerda: resultado da simulação levando em conta apenas o módulo Textura, direita: imagem original. . . . . . . . . . . .

5.8 Resultado da simulação utilizando os espaços de cor HSL, RGB e La*b*. Para facilitar a visualização das diferenças entre os resultados dos três espaços de cor, foram recortados da imagem do resultado de cada uma delas a região entre o olho direito e o cabelo. (a) resultado para a simulação utilizando o espaço de cor HSL; (b) resultado para a simulação utilizando o espaço de cor RGB e (c) resultado para a simulação utilizando o espaço de cor La*b*. . . .

5.9 Camadas geradas utilizando o espaço de cor La*b* e resultados após média ponderada. (a) camada referente ao canal $\mathrm{a}^{*}, C_{a^{*}}$; (b) resultado da camada referente ao canal a* após média ponderada; (c) camada referente ao canal $\mathrm{b}^{*}, C_{b^{*}}$; (d) resultado da camada referente ao canal b* após média ponderada; (e) camada referente ao canal $\mathrm{L}, C_{L} \ldots \ldots \ldots$

6.1 (a) Representa o estado inicial da interface quando o simulador é iniciado; (b) Exibe a interface quando o usuário toca na tela para escolher o produto de maquiagem a ser aplicado; (c) Exibe a interface e as opções disponíveis para a aplicação de batom. . . . . . . . . . . . . . . . . 
6.2 (a) Exibe a interface e as opções disponíveis para a aplicação de batom ou sombra; (b) Exibe a interface e as opções disponíveis para a suavização de batom ou sombra; (c) Exibe a interface e as opções disponíveis para a remoção de batom ou sombra. . . . . . . . . . . . . . . . . .

6.3 (a) Imagem da face sem maquiagem; (b) Resultado para a base aplicada apenas na metade da face do lado esquerdo da imagem; (c) Resultado para a aplicação de base em toda face; (d) Resultado para a aplicação de batom; (e) Resultado para a aplicação de base, batom e sombra; (f) Resultado para aplicação de base na metade visível da face, porém aplicando o produto algumas vezes em uma mesma região da face tornando a maquiagem mais intensa nesse local. . . . . . . . . . . . . . . . . . . . . . .

6.4 (a) Imagem original, $I$; (b) Resultado apenas para o módulo Textura do algoritmo de simulação; (c) Comparativo entre $I$ e o resultado em (b), lado direito: imagem original, lado esquerdo: resultado do módulo Textura; (d) Resultado do módulo Textura e Cor. . . . . . . . . . . . . . . . . . . .

6.5 Resultado da simulação para intensidades diferentes de suavização. Parâmetros se referem ao tamanho do kernel utilizado na suavização. (a) Imagem original; (b) Suavização utilizada nas outras imagens deste trabalho. Parâmetros: 5-9-17 para $C_{f 1}, C_{f 2}$ e $C_{f 3}$ respectivamente; (c) Suavização um pouco mais intensa. Parâmetros: 5-13-25 para $C_{f 1}, C_{f 2}$ e $C_{f 3}$ respectivamente; (d) Suavização ainda mais intensa, começando a perder seu aspecto natural. Parâmetros: 7-17-37 para $C_{f 1}, C_{f 2}$ e $C_{f 3}$ respectivamente. . . . . . . . . .

6.6 Resultado da simulação para batom, sombra e base. (a) Imagem original; (b) Resultado da simulação; (c) Comparativo, lado esquerdo: original, lado direito: maquiada. . . . . . . . . . . . . . . . .

6.7 Comparativo entre o resultado da simulação e maquiagem real. (a) Imagem sem maquiagem; (b) Resultado da simulação de maquiagem; (c) Maquiagem real; (d) Comparativo, lado esquerdo: simulada, lado direto: real . . . . . . . . 


\section{Lista de Tabelas}

3.1 Comparativo entre os métodos para simulação de maquiagem. . . . . . . . . 34

3.2 Primeiro comparativo entre os trabalhos sobre interação no contexto de simulação de maquiagem. N.E. significa não especificado no artigo. . . . . . . . . 35

3.3 Segundo comparativo entre os trabalhos sobre interação no contexto de simulação de maquiagem. . . . . . . . . . . . . . . . . 35

5.1 Desempenho do algoritmo de simulação de maquiagem com e sem paralelização em CPU para uma imagem de 1018x990 pixels. . . . . . . . . . . . . . 56 


\section{Capítulo 1}

\section{Introdução}

\subsection{Motivação}

A maquiagem faz parte do dia a dia das pessoas, mas experimentar e escolher tais produtos para cada ocasião pode ser um processo demorado e complexo. Um simulador de maquiagem pode ajudar uma pessoa a realizar essas tarefas de forma mais prática.

Computacionalmente, simular maquiagem continua sendo um problema desafiador como pode ser observado nos artigos apresentados no capítulo 3. Comercialmente, este trabalho pode ser o início da base tecnológica para o desenvolvimento de um produto inovador para o mercado de cosméticos que nacionalmente fatura US $\$ 42$ bilhões tornando-se o terceiro maior do mundo e, mantendo o ritmo de crescimento atual, será o segundo maior mercado mundial até 2017 (DCI, 2013).

\subsection{Objetivo}

Esse trabalho tem como objetivo desenvolver um ambiente virtual interativo para simulação de maquiagem que permita a escolha dos produtos e aplicação desses na imagem do usuário. Tal simulador deve possibilitar que o usuário experimente um produto de maquiagem de forma mais fácil e conveniente do que utilizando os cosméticos reais, podendo observar os resultados de forma mais rápida (sem a necessidade de preparação, além da aplicação e remoção da maquiagem ocorrerem instantaneamente) e barata (não é necessário comprar o produto ou gastar produtos já existentes).

Existem diversos cenários em que esse ambiente virtual pode ser útil. No ambiente doméstico, quando o usuário for se maquiar ele pode testar combinações de todas as maquiagens que possui antes de definir quais serão as maquiagens escolhidas para a ocasião. Além disso, ele também poderia testar outras maquiagens que ainda não possui, mas que combinam com as que o usuário já tem, realizando uma compra online para utilizar na próxima ocasião.

Em uma loja de produtos de maquiagem, a simulação pode ser útil para mostrar o resultado de diversos produtos, demonstrar como estes podem ser combinados entre si e 
ensinar ao cliente o correto uso e respectivas combinações.

Já em um salão de beleza, pode-se mostrar para o cliente como ele ficará após a aplicação das maquiagens que o maquiador está considerando, com o intuito de verificar sua satisfação antes de ser maquiado.

O ambiente virtual também pode ser usado na Internet para que o usuário possa criar novos estilos de maquiagem com a colaboração de amigos em redes sociais.

É importante ressaltar que este projeto não tem como objetivo fazer com que o simulador tome o lugar de maquiadores, especialistas em maquiagem ou outros profissionais da área, pelo contrário, maquiagem é uma arte e precisa de pessoas envolvidas para que continue a ser bem sucedida. O ambiente virtual seria apenas uma ferramenta para auxiliar esses profissionais e seus clientes.

\subsection{Definição do problema}

Para criar o ambiente virtual do simulador de maquiagem desejado, podemos considerar duas grandes questões a serem resolvidas: a interação com esse sistema e o algoritmo responsável pela simulação da maquiagem.

Com relação à interação, o sistema deve possibilitar que o usuário se maqueie de forma semelhante ao que ele já faz com produtos reais e em um ambiente familiar. Dado que um dos locais mais comuns para aplicar maquiagem é em frente ao espelho, este foi escolhido como metáfora para a interação do simulador. Assim, o sistema funciona permitindo a escolha da maquiagem e também sua aplicação sobre a imagem da face do usuário como se ele estivesse maquiando seu reflexo no espelho. Para que a aplicação da maquiagem seja semelhante ao que é realizado com produtos reais, o simulador deve oferecer a liberdade para que o usuário aplique a maquiagem que ele desejar em qualquer região de sua face.

Por se tratar de um espelho, a imagem a ser exibida deve corresponder ao reflexo da imagem da pessoa no espelho e portanto deve ser um vídeo e não uma imagem fixa. Isso gera dois problemas a serem resolvidos: o posicionamento da maquiagem virtual na face do usuário deve acompanhar o movimento da face (sem a necessidade de intervenção humana para marcação de pontos faciais) e também deve ser realizado em tempo real de forma que a taxa de quadros por segundo do vídeo não seja afetada.

Com relação ao algoritmo para a simulação de maquiagem, ele deve ser capaz de simular como a face do usuário ficará após a aplicação da maquiagem. Tal simulação deve mimetizar as alterações das propriedades ópticas e de textura da pele de forma convincente, já que o usuário espera ver sua imagem como se ele estivesse se vendo em um espelho. Além disso, o método deve ser capaz de ser processado em tempo real para que possa ser utilizado em vídeo, deve ser flexível para permitir a aplicação independente de diversas maquiagens por qualquer região da face do usuário e não deve requisitar o uso de equipamentos especiais que encareceriam a solução. 


\subsection{O projeto}

Este projeto consiste em um espelho virtual interativo para simulação de maquiagem. Com relação à interface, foi criada uma interface que é composta por um monitor sensível a toque fazendo o papel de espelho e, posicionado acima dele, um sensor RGBD para capturar o vídeo do usuário. A interação com o sistema ocorre por meio do toque no monitor, permitindo a escolha da maquiagem desejada e também sua aplicação na imagem do espelho. A interface permite que o usuário possa aplicar a maquiagem da forma desejada em sua face criando efeitos diversos, por exemplo, intensificando determinadas regiões ou passando mais de um produto de maquiagem na mesma região. Além disso, uma vez que a maquiagem for aplicada, o sistema é capaz de manter seu posicionamento durante a movimentação da face do usuário sem que isso interfira na fluidez da imagem do espelho e sem a necessidade de marcadores.

Para a simulação de maquiagem, o método desenvolvido simula a aplicação de sombra, base e batom que podem ser aplicados individualmente em qualquer região da imagem da face. Além dessa flexibilidade, o algoritmo é capaz de ser computado em tempo real, não necessita de equipamentos especiais para seu funcionamento e apresenta resultados convincentes.

\subsection{Desafios}

Os desafios desse projeto são:

- realismo. A simulação de maquiagem deve alterar de forma adequada as propriedades ópticas e de textura da pele para que seu resultado seja convincente;

- tempo real. A simulação de maquiagem deve ser computada rápida o suficiente para que ela possa ser usada como um reflexo de espelho;

- flexibilidade. A interação com o simulador deve ser natural, se assemelhando com o que as pessoas já estão acostumadas ao interagir com um espelho comum, porém permitindo escolher e experimentar diversos produtos com praticidade;

- baixo custo. O sistema não deve utilizar equipamentos de alto custo.

\subsection{Contribuições}

As principais contribuições deste trabalho são:

- proposta de um modelo de interação para um simulador de maquiagem;

- um método para simular a aplicação de maquiagens em faces em tempo real. 
O modelo de interação proposto neste trabalho contempla uma interface que faz alusão a um espelho para aplicar independentemente os produtos de maquiagem desejados em qualquer região da face tocada no espelho. Por estar maquiando a imagem do usuário, o sistema deve realizar a simulação em um vídeo da imagem do usuário e deve manter o correto posicionamento da maquiagem conforme o usuário movimenta a face em frente ao espelho sem o uso de marcadores. Como descrito no capítulo 3, foi encontrado apenas um trabalho de Interação Humano Computador que faz alusão ao espelho e simula maquiagem (Rahman et al., 2010). Nesse trabalho o reflexo do espelho é um modelo 3D do usuário que mimetiza seus movimentos e a maquiagem é simulada nesse modelo. Além disso, existe a necessidade de marcadores para o adequado funcionamento do sistema. Ou seja, o usuário precisa passar por algumas etapas preparatórias antes de iniciar o uso do sistema como criar seu modelo 3D, que não será tão realista quanto a imagem da câmera, e posicionar marcadores.

O método para simulação de maquiagem em faces proposto neste trabalho se diferencia dos demais trabalhos apresentados no capítulo 3, pois tais trabalhos não apresentam ao mesmo tempo as quatro características do nosso método, que são: flexibilidade (permitir aplicar cada maquiagem individualmente em qualquer região da face), tempo real (rápido o suficiente para aplicar maquiagem em um vídeo), baixo custo (não necessita de equipamentos especiais) e realismo (resultado da simulação é convincente).

\subsection{Organização do trabalho}

Esse trabalho está organizado da seguinte forma: no capítulo 2 são abordados conceitos úteis para a compreensão do texto da dissertação, no capítulo 3 os trabalhos acadêmicos e não acadêmicos relacionados ao tema dessa dissertação são apresentados e discutidos, no capítulo 4 são explicados o modelo de interação e o método de simulação de maquiagem propostos, no capítulo 5 são apresentados maiores detalhes relativos à prototipação do projeto, no capítulo 6 são expostos os resultados obtidos e no capítulo 7 a conclusão do trabalho é apresentada. 


\section{Capítulo 2}

\section{Fundamentos}

Para a leitura desta dissertação é necessário o entendimento de alguns conceitos relacionados ao processamento de imagens, visão computacional, computação gráfica e maquiagem, apresentados nas seções a seguir.

\subsection{Cor}

Para representar as cores que nossos olhos são capazes de observar em objetos reais, foram criados espaços de cor para padronizar tais representações nas imagens observadas por meio de dispositivos eletrônicos.

Um espaço de cor amplamente utilizado em monitores, televisores e câmeras digitais é o RGB. Ele é um espaço de cor aditivo e a cor de cada pixel é representada por três valores, um associado ao vermelho $(\mathrm{R})$, outro ao verde $(\mathrm{G})$ e outro para o azul (B). Ao combinar diferentes valores para o vermelho, verde e azul pode-se obter muitas outras cores. Como exemplo, comumente são utilizados 8 bits para cada um dos canais de cor, o que permite 256 valores distintos para cada um deles. Assim, pode-se criar 16.777.216 tons de cores diferentes. O RGB é baseado em um sistema de coordenadas cartesiano com três eixos, cada um relativo a uma das componentes ( $\mathrm{R}, \mathrm{G}$ e B).

O espaço de cor HSL, ao contrário do RGB que é um espaço de cor prático para ser utilizado por hardware, é uma forma de descrever a cor de uma maneira mais intuitiva para o ser humano. Seus canais representam a matiz (H, do inglês hue), saturação (S, em inglês saturation) e luminosidade (L, em inglês lightness). A matiz é o atributo de cor relacionado com o principal comprimento de onda que define a cor dominante percebida pelo observador, a saturação está relacionada com a pureza da cor representada e a luminosidade está relacionada à intensidade de luz indo do preto ao branco. O HSL forma um sistema de coordenadas cilíndricas.

O espaço de cor $\mathrm{La}^{*} \mathrm{~b}^{*}$ foi criado para se aproximar da visão humana. Ele se aproxima de uma representação de cores perceptualmente uniforme e a componente L se aproxima da percepção humana de luminosidade. Perceptualmente uniforme significa que a mudança de 
uma mesma quantidade do valor de cor deve produzir uma mudança da percepção visual da cor de mesma intensidade. Outra característica importante desse espaço de cor é que ele é independente de dispositivo, ou seja, as cores podem ser definidas independentemente de sua natureza de criação ou do dispositivo em que elas serão exibidas. Assim pode-se usá-lo como uma referência, como por exemplo para conversões entre espaços de cor RGB e CMYK (comumente usado para impressão), já que a possibilidade de cores que podem ser criadas com o La*b* engloba tanto as que podem ser geradas com o RGB quanto com o CMYK.

Para mais detalhes sobre cores e espaços de cor, pode-se ler o capítulo 6 de Gonzalez e Woods (2006).

\section{$2.2 \quad$ Filtros}

Filtros são aplicados em imagens para transformá-las de alguma forma. Existem diversos tipos de filtros, mas esta seção abordará o filtro gaussiano e o filtro bilateral.

O filtro gaussiano pode ser entendido como um filtro passa baixa, ou seja, ele permite que as baixas frequências permaneçam na imagem, enquanto que as altas frequências (detalhes) são removidas. O filtro recebe esse nome pois sua computação é realizada por meio de uma convolução com uma função gaussiana.

O filtro bilateral por ser utilizado para realizar uma suavização na imagem que preserve as bordas, o que não acontece no filtro gaussiano. Então, regiões de borda são preservadas enquanto que outras regiões são suavizadas.

Mais detalhes sobre filtros podem ser obtidos, por exemplo, no capítulo 4 de Gonzalez e Woods (2006).

\subsection{Operações morfológicas}

Existem diversas operações morfológicas que podem ser criadas a partir de operações mais básicas. As duas operações fundamentais, a erosão e a dilatação, bastam para o entendimento dessa dissertação. Demais detalhes sobre morfologia matemática podem ser obtidos no capítulo 9 de Gonzalez e Woods (2006).

O efeito principal da erosão em uma imagem binária é contrair as fronteiras dos objetos, de modo que tais áreas sejam encolhidas e eventuais buracos no interior delas sejam expandidos. Em contrapartida, a dilatação é a operação oposta à erosão causando uma expansão dessas fronteiras e o preenchimento de buracos existentes no seu interior.

\subsection{Superfície especular e lamberciana}

Uma superfície lamberciana, ou difusa, é aquele que reflete a luz uniformemente em todas as direções devido a microirregularidades na superfície do material. Já a superfície especular 
apresenta comportamento diferente concentrando a reflexão dos raios de luz na direção da reflexão ideal exibindo um brilho ou pontos brilhantes característicos.

A inclusão dessas componentes na renderização da imagem é importante para aumentar o realismo da simulação, como descrito por Phong e pode ser lido com mais detalhes no capítulo 14 de Foley et al. (1990).

\subsection{Maquiagem}

No contexto deste trabalho, podemos definir maquiagem como a responsável pela mudança da aparência facial de quem a utiliza. Estas mudanças são alcançadas por meio de alterações de propriedades óticas e de textura da pele, normalmente com o objetivo de tornar a face visualmente mais saudável e mais atraente.

Dessa forma, ao utilizarmos maquiagem estamos alterando o comportamento da interação da luz com a pele em sua reflexão, refração ou espalhamento dos raios de luz. A combinação certa dos produtos, suas cores e locais de aplicação geram regiões de realce e sombra que podem mudar bastante a forma como percebemos a aparência da face de uma pessoa.

\subsection{Base, batom e sombra}

Nesta dissertação, são considerados três tipos de maquiagem: base, sombra e batom. Cada uma possui suas características próprias e consequentemente alteram a pele de forma particular.

A base é utilizada para uniformizar o tom de pele do rosto, corrigir alterações de cores e melhorar o relevo da pele disfarçando pequenas imperfeições. Para suavizar pintas, acne, olheiras ou manchas no rosto o procedimento correto seria utilizar um corretivo além da base, então não se deve esperar que toda base seja capaz de esconder todo e qualquer detalhe ou alteração do tom de pele. Existem diversos tipos de base, como spray, líquida, cremosa e bastão, porém não vamos nos ater às especificidades de cada um desses tipos e sim ao comportamento geral da base. Assim, este trabalho considera como base, um produto que possui como característica suavizar os detalhes faciais e homogeneizar os tons de pele de quem a utiliza, porém sem que ocorra um cobertura total da pele.

A sombra é utilizada para colorir as pálpebras. Também existem tipos diferentes de sombra, como em pó, cremosa e líquida, cada uma com suas próprias características. Porém, da mesma forma que foi feito para a base, este trabalho considera a característica geral da sombra e assim sua simulação se restringirá a introduzir cor na região aplicada.

O batom, além de colorir os lábios, pode ter função hidratante e até protetora contra o sol. Também pode-se encontrar diversos tipos de batons, alguns mais cremosos, outros mais brilhantes, mais opacos, criando um aspecto plastificado ou com maior cobertura dos detalhes do lábio. Da mesma forma que as maquiagens anteriores, vamos nos ater ao comportamento 
mais comum do batom e assim esse trabalho considera apenas a introdução de cor nos lábios. 


\section{Capítulo 3}

\section{Estado da Arte}

Este capítulo está dividido em duas partes. A primeira trata sobre os trabalhos acadêmicos que mais se assemelham ao objetivo dessa dissertação. Em sequência, são apresentados os trabalhos não acadêmicos que estão ou estiveram presentes no mercado e são de interesse deste trabalho.

\subsection{Trabalhos acadêmicos}

Esta seção está dividida em cinco subseções. Elas contemplam as referências para outros estudos relativos ao tema central desse trabalho, como também outros artigos de temas complementares.

\subsubsection{Simulação de maquiagem}

Alguns métodos já foram propostos com objetivos relacionados à simulação de maquiagem. Eles podem ser divididos em dois grupos: transferência de maquiagem e aplicação de maquiagem. Em geral, trabalhos de transferência de maquiagem se baseiam em entender o que corresponde à maquiagem em uma imagem de uma face já maquiada para transferir tal maquiagem para uma outra face. Tipicamente, tais trabalhos têm como limitações iguais condições de iluminação e pose da face entre as imagens. Além disso, as possibilidades de maquiagem estão restritas às faces exemplos já maquiadas. Os trabalhos de aplicação, apesar de terem objetivos semelhantes a este artigo, tratam a aplicação da maquiagem de forma simples, não obtendo um realismo adequado ou então necessitam de equipamentos especiais para seu funcionamento.

\section{Transferência de maquiagem}

Seja $A^{*}$ a imagem contendo uma face $F$ com maquiagem $M ; A$ a imagem contendo $F$, porém sem maquiagem e $B$ uma outra imagem contendo uma face $G$, possivelmente de 
outra pessoa e sem maquiagem. A transferência de maquiagem é definida como o processo de compor uma imagem $B^{*}$ com a face $G$ maquiada da mesma forma que $F$ em $A^{*}$.

O artigo de transferência de maquiagem de Tong et al. (2007) assume como problema a ser resolvido a transferência de maquiagem a partir de duas imagens modelos de uma mesma pessoa, uma sem e outra com maquiagem, para uma outra imagem de uma pessoa qualquer (alvo). O artigo tem como objetivo criar um procedimento para realizar tal transferência levando em conta a contribuição da maquiagem a ser aplicada e também das pequenas variações ou imperfeições da geometria da pele do modelo para a pessoa alvo. Tal procedimento também é a contribuição proposta pelo artigo.

Quando Tong et al. (2007) citam variações ou imperfeições da pele, eles querem dizer que se deve realizar apenas a transferência da maquiagem da face modelo para a face alvo, ou seja, sardas, pintas e manchas da face das imagens modelo não devem ser carregadas para a imagem da face alvo, porém essas mesmas características, se presentes na face alvo, devem ser preservadas. Além disso, diferenças de tom de pele e pelos faciais devem ser trabalhados adequadamente para apresentarem resultados realistas e o procedimento a ser criado deve ser flexível o suficiente para que se possa ajustar a intensidade da maquiagem aplicada ou até mesmo combinar estilos diferentes de maquiagem.

De forma geral, o procedimento para a transferência de maquiagem começa com o cálculo relativo à mudança de cor e iluminação entre as imagens modelo com e sem maquiagem. Na sequência, as diferenças de tom e textura de pele são tratadas e por fim a maquiagem é aplicada e ajustada na face alvo.

O processo pode ser dividido da seguinte forma:

- pré-processamento;

- mapeamento da maquiagem;

- correção de aparência;

- transferência dos olhos.

As imagens exemplo usadas no artigo foram fotografadas cuidadosamente para que as condições de iluminação e pose sejam as mesmas para todas as fotos. Exemplos de imagens como essas podem ser observados na figura 3.1.

Para o pré-processamento, o primeiro passo é a remoção da sobrancelha e cílios, seguido pelo preenchimento desses locais em que os pelos faciais estavam presentes. Na sequência, são extraídas as variações ou imperfeições faciais e por último a face é deformada para se acomodar em um modelo de face canônico.

Para realizar a remoção, usou-se o método proposto por Chuang et al. (2001). Já para preencher os buracos gerados pela remoção da sobrancelha e cílios, foi utilizado um algoritmo de síntese de textura baseado em corte de grafos proposto por Kwatra et al. (2003) que utiliza regiões próximas ao local do buraco para repará-lo. 


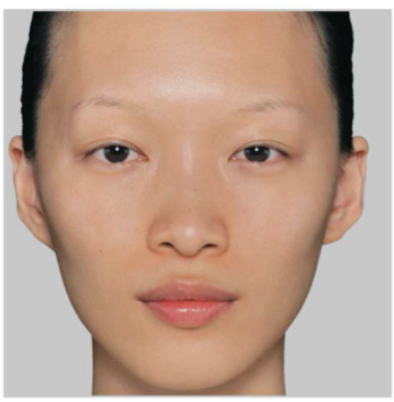

$\mathcal{A}$

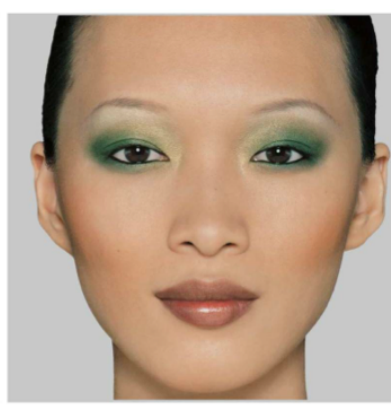

$\mathcal{A}^{*}$

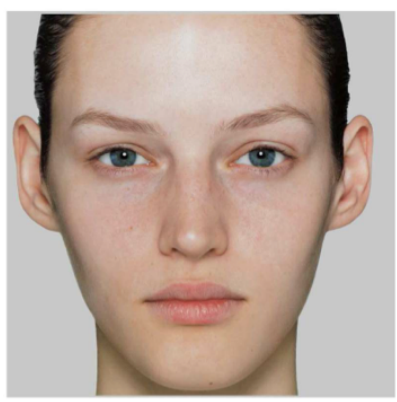

$\mathcal{B}$

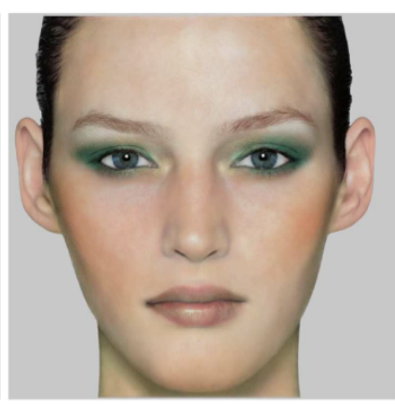

$\mathcal{B}^{*}$

Figura 3.1: As duas imagens à esquerda ilustram as imagens chamadas de A(modelo sem maquiagem) e $A^{*}$ (modelo com maquiagem) utilizadas para gerar o resultado na imagem mais à direita. As imagens à direita são B(alvo sem maquiagem) e $B^{*}$ (alvo com maquiagem aplicada por meio da transferência de maquiagem proposta pelo artigo). Retirado de Tong et al. (2007).

Com relação à remoção das imperfeições faciais, ela é realizada para todas as imagens (A, A* e B) antes de ser computada a transferência da maquiagem, já que elas não são realmente parte da maquiagem e, portanto, não devem contribuir para ela. Para esse processo, é utilizada uma parte da região da face da pessoa que contenha tais variações e utiliza-se o método Independent Component Analysis (ICA) proposto por Tsumura et al. (2003), para obter uma matriz de separação que seja capaz de distinguir os pigmentos existentes na face de uma pessoa, já que são esses os responsáveis por tornar visíveis certas manchas da face.

Para finalizar o pré-processamento, todas as faces $\left(A, A^{*}\right.$ e $\left.B\right)$ são distorcidas para se adequarem a um modelo canônico seguindo o método descrito por Bookstein (1989), thinplate-splines. Vale ressaltar que os pontos de correspondência entre as imagens são marcados manualmente e totalizam 84 pontos. O objetivo desse passo é criar uma geometria da face que seja invariante à pessoa para que a maquiagem possa ser transferida de uma pessoa para outra independentemente da geometria do rosto de cada um.

Para o mapeamento da maquiagem, sua transferência é computada pixel a pixel a partir das três imagens $\left(\mathrm{A}, \mathrm{A}^{*}\right.$ e $\left.\mathrm{B}\right)$ compartilhando a mesma geometria 2D. A transferência representa a mudança de cor e refletância da pele criada pela maquiagem após esta ser aplicada.

Tong et al. (2007) assumem que a pele da face seria uma superfície lamberciana (superfície que reflete a luz uniformemente em todas as direções) e utilizam a ideia de uma representação intrínseca para a imagem da face (Barrow e Tenenbaum, 1978). Assim, a imagem da face foi modelada como um produto, pixel a pixel, de duas imagens intrínsecas, uma representando a refletância e a outra representado a iluminação.

Então, a partir de imagens da face da mesma pessoa, com e sem maquiagem, sob mesmas condições de iluminação e pose, a mudança da aparência da pele devido à aplicação da maquiagem foi modelada da seguinte forma:

$$
c_{p}=a_{p}^{*} / a_{p}
$$


onde, $a_{p}$ e $a_{p}^{*}$ são, respectivamente, a intensidade do pixel $p$ antes e depois da maquiagem e a coleção dos valores de $c_{p}$ formam $C$, o mapa de maquiagem que pode ser observado na imagem 3.2.

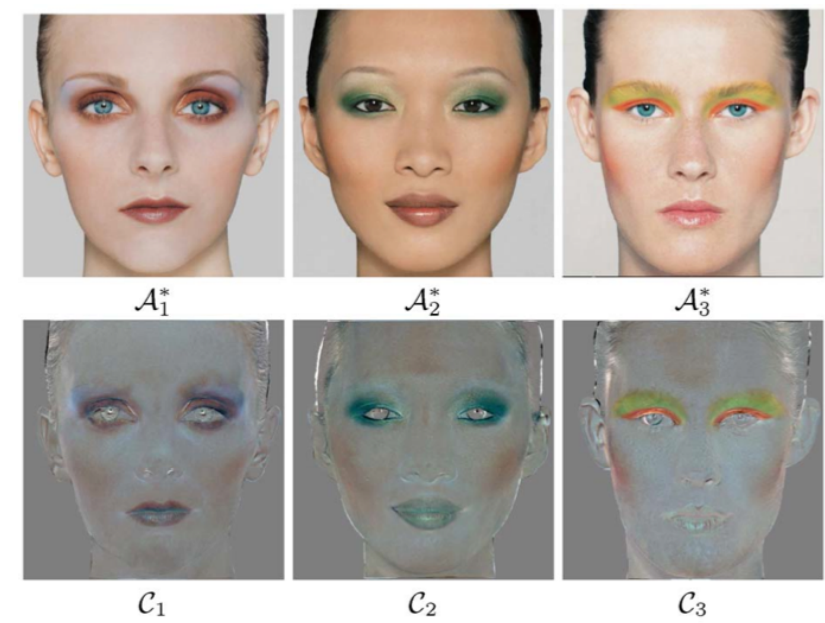

Figura 3.2: Mapa de maquiagem $C_{i}$ computado para os três exemplos de maquiagem $A_{i}^{*}, i=1,2$ e 3. Para proporcionar uma melhor visualização, foi adicionado a cada pixel o valor 127. Retirada de Tong et al. (2007).

A aplicação do mapa na face alvo $B$ para chegar em $B^{*}$ é feita seguindo:

$$
b_{p}^{*}=c_{p} b_{p}
$$

onde a coleção dos valores de $b_{p}^{*}$ formam $B^{*}$. Após a aplicação do mapa de maquiagem, as variações ou imperfeições faciais extraídas anteriormente são novamente combinadas à imagem.

Na correção de aparência, para chegar na imagem final, inicialmente os autores calcularam o valor de cada pixel da imagem da seguinte forma:

$$
b_{p}^{*}=b_{p}\left(\gamma\left(c_{p}-1\right)+1\right)
$$

onde $b_{p}^{*}$ é a cor calculada para cada pixel $p, b_{p} \in B$ e $c_{p} \in C$ são, respectivamente, as cores da face alvo e do mapa de maquiagem. $\gamma \in[0,1]$ representa a quantidade de maquiagem a ser aplicada, assim, para $\gamma=1$ voltamos à equação 3.2 e para $\gamma=0$ a equação se torna $b_{p}^{*}=b_{p}$, ou seja, a maquiagem não é aplicada.

No entanto, a aplicação de maquiagem pode causar pequenas mudanças na geometria da face que podem resultar em diferenças de aparência que não são incorporadas por C, já que ele representa apenas mudanças relativas a cor e refletância. Então, para corrigir os problemas de aparência que surgem dessas pequenas alterações da geometria da face, Tong et al. (2007) assumiram que o operador Laplaciano poderia capturar tais mudanças combinando $a_{p}^{*}$ e $b_{p}$ para cada pixel $p$. Dessa forma, temos:

$$
\Delta\left(b_{p}^{*}\right)=\Delta\left(\beta b_{p}+(1-\beta) a_{p}^{*}\right)
$$


onde $\Delta$ denota o operador Laplaciano e $\beta$ pondera a intensidade da mudança geométrica que será transferida de $b_{p}$ e $a_{p}^{*}$.

Para a transferência dos olhos, Tong et al. (2007) comentam que maquiagens mais fortes nas sobrancelhas e cílios precisam ser tratadas com algoritmos mais complicados que não foram usados nesse artigo. Eles apenas transferiram as sobrancelhas e cílios da imagem original que tinha sido extraída antes $(B)$ para a nova imagem maquiada $\left(B^{*}\right)$.

Com relação aos resultados, eles foram analisados de forma qualitativa pelos autores. Eles comentam que foram feitos testes com várias pessoas de diferentes características faciais (cor de pele, textura da pele, cor de pelos) e geometrias faciais diferentes entre a face modelo e a face alvo. Alguns resultados podem ser visualizados nas imagens 3.3 e 3.4.
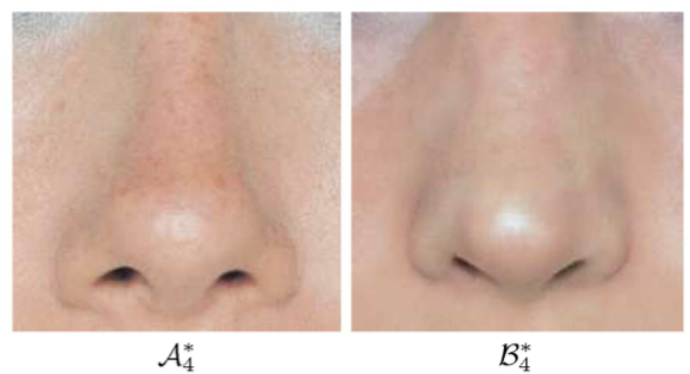

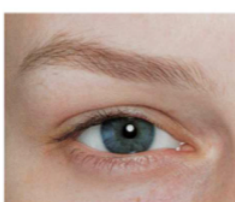

$\mathcal{B}$ : eye

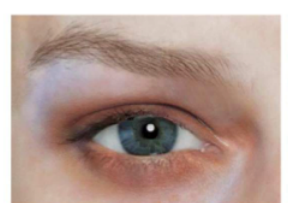

$\mathcal{B}_{1}^{*}$ : eye

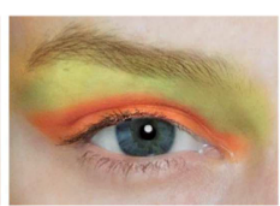

$\mathcal{B}_{3}^{*}$ : eye

Figura 3.3: $\grave{A}$ esquerda, pode-se ver que sardas e sinais da pele na imagem modelo maquiada, $A_{4}^{*}$, não foram transferidas para a imagem alvo $B_{4}^{*}$. $\grave{A}$ direita, pode-se observar a imagem original do olho da face alvo, $B$, a preservação das cores e densidade da sobrancelha, $B_{1}^{*}$, e um exemplo com maquiagem cobrindo a sobrancelha $B_{3}^{*}$ (as imagens modelo da maquiagem, $A_{1}^{*}$ e $A_{3}^{*}$, para esses resultados, $B_{1}^{*}$ e $B_{3}^{*}$, podem ser observadas na figura 3.2). Retirada de Tong et al. (2007).

O artigo de Guo e Sim (2009) assume como problema a ser resolvido a aplicação de maquiagem em uma face tomando como base as maquiagens aplicadas em outra imagem. Então, o artigo tem como objetivo apresentar uma abordagem para transferir a maquiagem de uma imagem de uma pessoa com maquiagem para outra imagem de uma outra pessoa sem maquiagem. A principal diferença com relação ao artigo anterior consiste na necessidade de apenas uma imagem modelo e não duas imagens modelo, uma sem e outra com maquiagem. A abordagem que foi apresentada usando apenas uma imagem modelo é a contribuição do artigo e a figura 3.5 ilustra as imagens de entrada e o resultado do método.

Guo e Sim (2009) ressaltam que a abordagem proposta por eles é análoga à maquiagem no mundo real, já que eles preservam a estrutura da face e modificam a cor e detalhes da pele, ou seja, transferem a parte relevante da maquiagem da textura da pele da face exemplo para a face alvo. Tal processo é realizado decompondo a imagem exemplo $\mathcal{I}$ e a imagem alvo $\mathcal{E}$ em três camadas, para então transferir informação de cada camada de uma face para a camada correspondente da outra face. As camadas utilizadas são:

- estrutura da face: disposição das características faciais como olhos, boca e nariz. Denotada por $s$; 


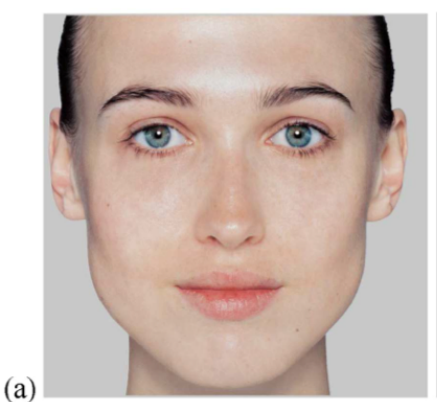

(a)

$\mathcal{A}_{5}$

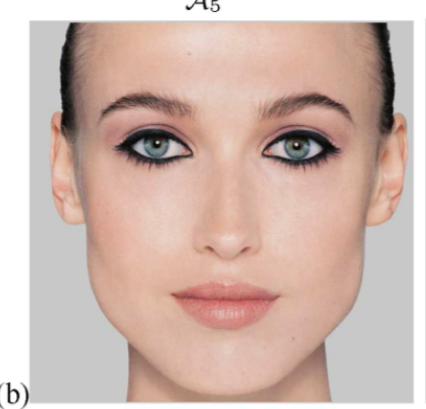

$\mathcal{A}_{5}^{*}$

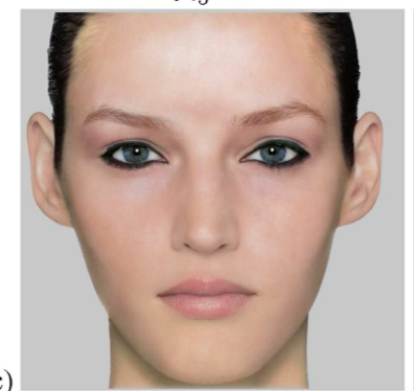

$\mathcal{B}_{5}^{*}$

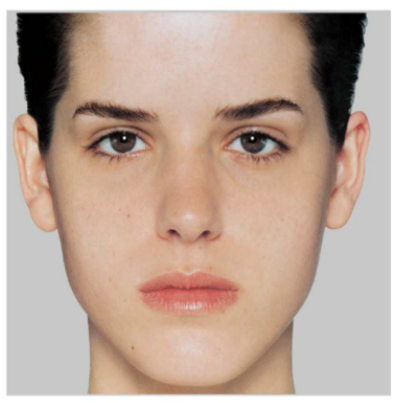

$\mathcal{A}_{6}$

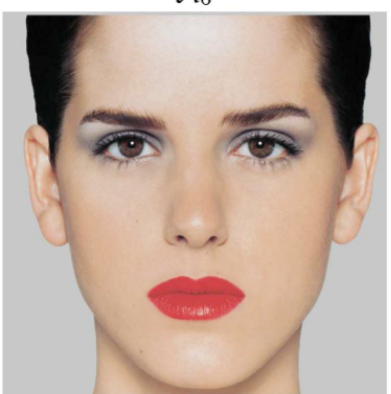

$\mathcal{A}_{6}^{*}$

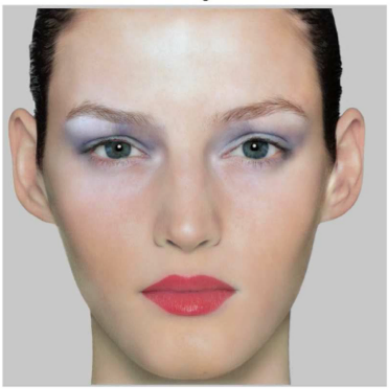

$\mathcal{B}_{6}^{*}$

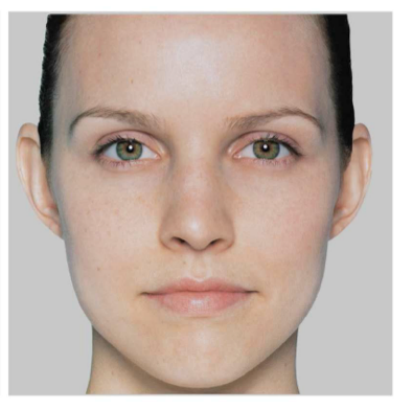

$\mathcal{A}_{7}$

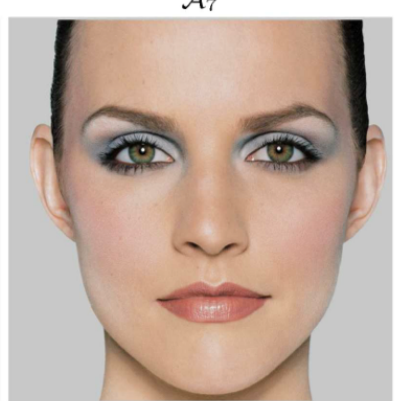

$\mathcal{A}_{7}^{*}$

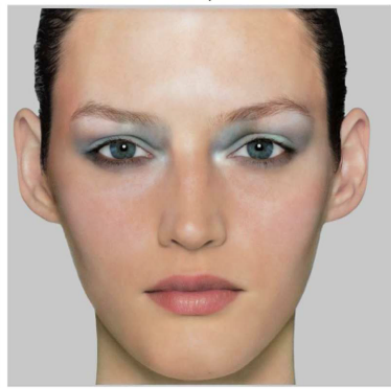

$\mathcal{B}_{7}^{*}$

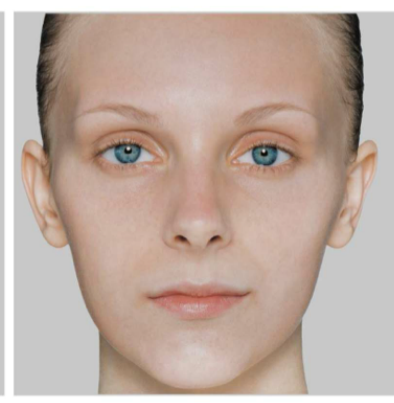

$\mathcal{A}_{8}$

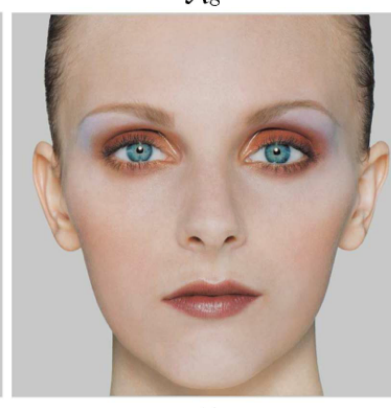

$\mathcal{A}_{8}^{*}$

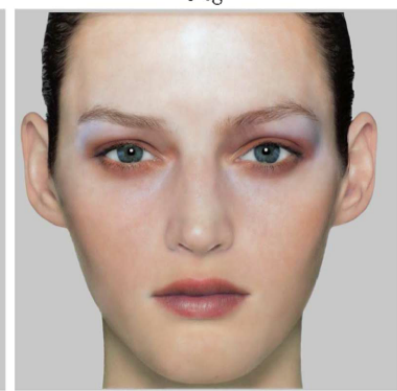

$\mathcal{B}_{8}^{*}$

Figura 3.4: Exemplos de transferência de maquiagem. A face alvo, B, usada é a mesma apresentada na figura 3.1. (a) Faces modelo antes da maquiagem, $A_{i}$. (b) Faces modelo após maquiagem, $A_{i}^{*}$. (c) Faces alvo após aplicação da maquiagem, $B_{i}^{*}$. Retirada de Tong et al. (2007).

- detalhes da pele: contém a textura da pele incluindo falhas, sinais e rugas. Denotada por $d$;

- cor: representa a cor de forma isolada com relação às outras camadas. Denotada por ${ }_{c}$.

O processo proposto, que pode ser visualizado na figura 3.6, foi dividido em quatro etapas listadas como segue:

- alinhamento entre faces;

- decomposição em camadas;

- transferência da maquiagem;

- junção das camadas. 


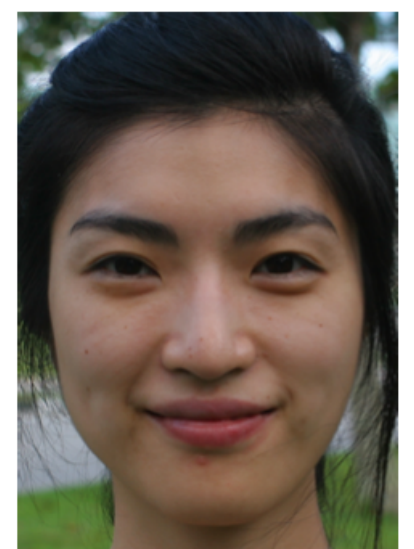

(a)

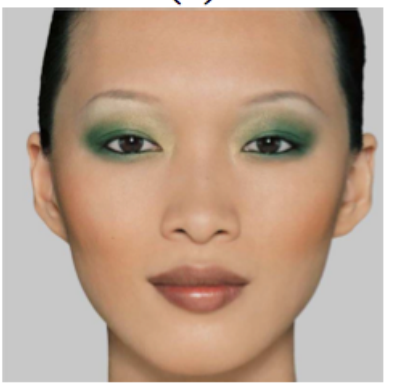

(b)

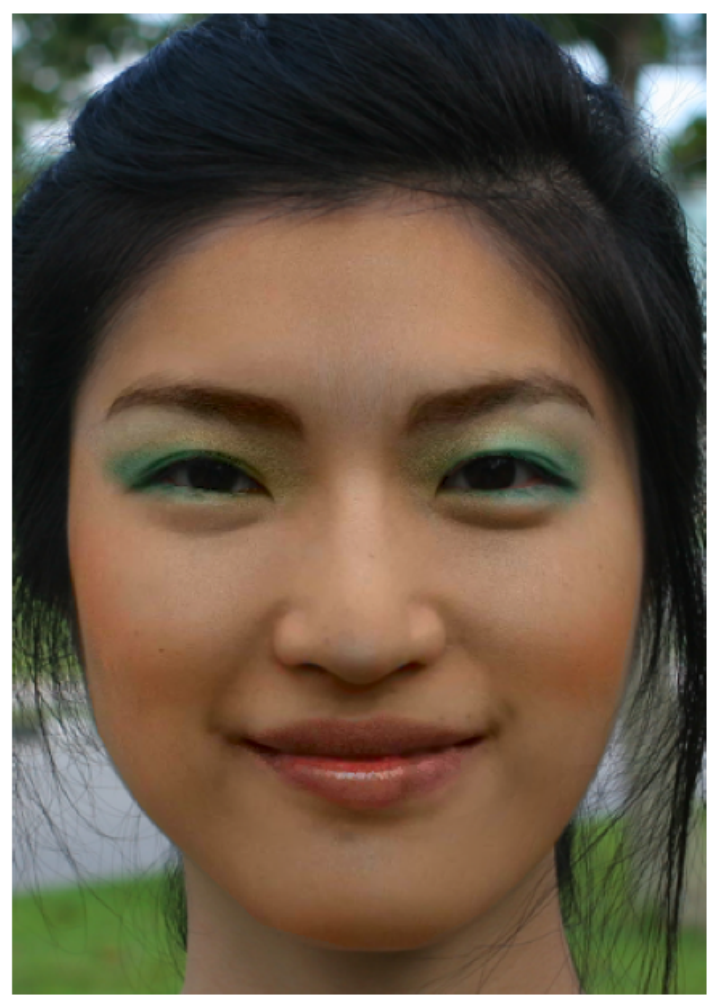

(c)

Figura 3.5: (a) Imagem alvo. (b) Imagem modelo com o estilo de maquiagem a ser transferido, retirada da mesma fonte utilizada no artigo anterior, (Nars, 2004). (c) Resultado da transferência. Retirada de Guo e Sim (2009).

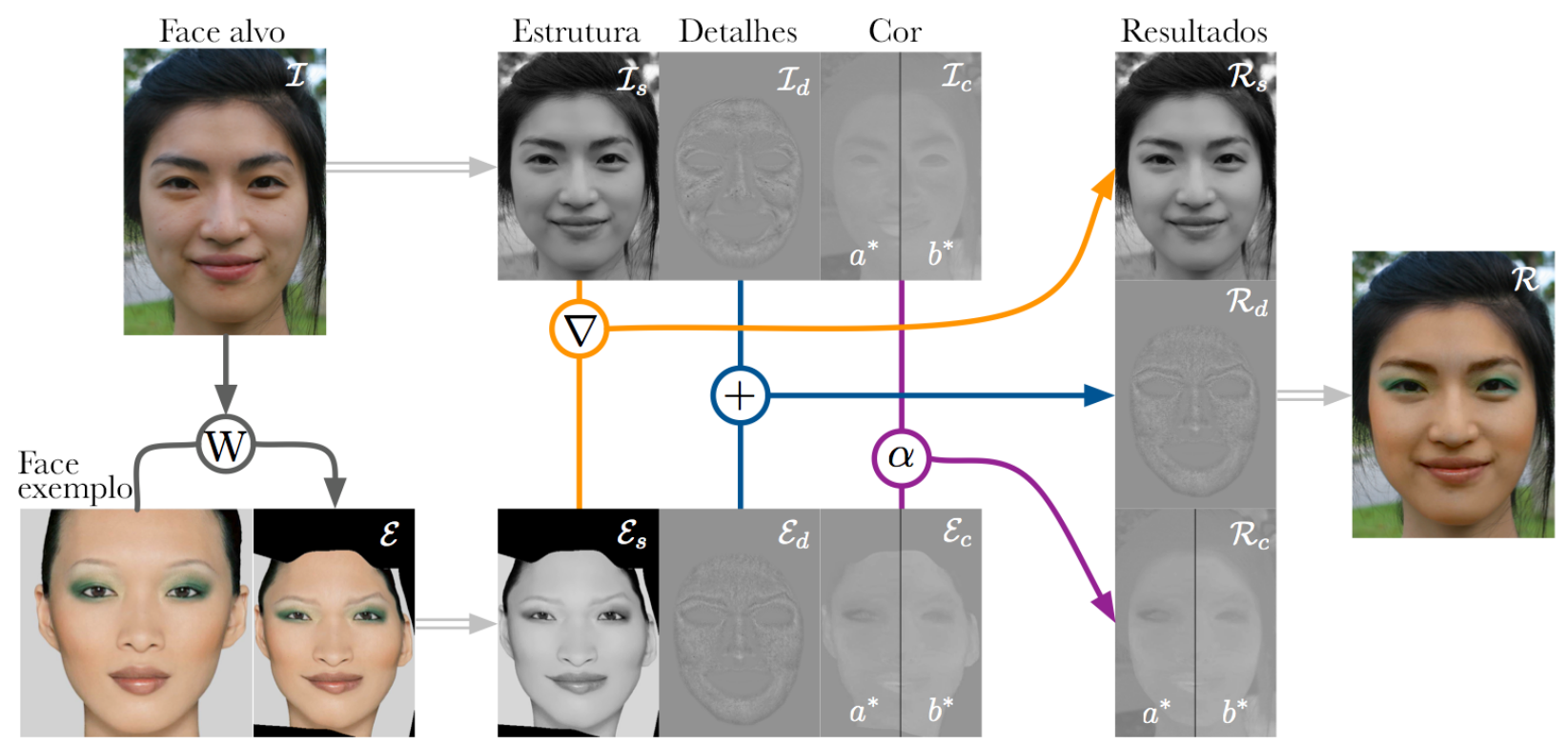

Figura 3.6: A imagem ilustra o processo criado para a abordagem apresentada em Guo e Sim (2009). $W$ denota a deformação, $\nabla$ denota a edição por gradiente, + denota a soma ponderada e $\alpha$ denota a média ponderada. Nessa imagem os valores da camada de detalhe da pele, $\mathcal{I}_{d}$ e $\mathcal{E}_{d}$, estâo exagerados quatro vezes para facilitar sua visualização. A abordagem desse artigo consiste de quatro passos: alinhamento entre faces, decomposição em camadas, transferência da maquiagem, junção das camadas. Retirada de Guo e Sim (2009). 
Para o alinhamento entre faces, o primeiro passo é obter os pontos de controle para então alinhar a face. Os pontos são obtidos usando um método estendido do Active Shape Model (ASM), Milborrow e Nicolls (2008). Com os pontos, a imagem modelo, $\mathcal{E}$, é deformada para coincidir com a imagem alvo, $\mathcal{I}$, utilizando o mesmo método do artigo anterior, Thin Plate Splines, criado por Bookstein (1989).

Ainda com relação a essa etapa, Guo e Sim (2009) comentam que o ASM estendido apresentou problemas de precisão com relação ao posicionamento de alguns pontos devido às alterações causadas pela maquiagem. Assim, o sistema ainda precisa de auxílio humano para refinar a localização dos seus 83 pontos.

Outro ponto abordado pelo artigo é a divisão da face de acordo com os pontos do ASM em algumas classes. Os pontos encontrados definem algumas características faciais como as sobrancelhas, nariz, narinas, lábios, cavidade de boca e o resto da face. Assim, foram criadas três classes que são tratadas de formas diferentes ao aplicar a maquiagem. A primeira classe, $\mathcal{C}_{1}$, é a região com pele da face excluindo as regiões $\mathcal{C}_{2}$ e $\mathcal{C}_{3}$, essa região segue o processo ilustrado na figura 3.6. A segunda classe, $\mathcal{C}_{2}$, corresponde à região dos lábios e tem tratamento específico devido a sua variabilidade de pessoa para pessoa e sua característica altamente deformável. A terceira classe, $\mathcal{C}_{3}$, corresponde aos olhos e a cavidade da boca, ela não recebe maquiagem.

O procedimento para a decomposição em camadas começa com a decomposição das imagens $\mathcal{I}$ e $\mathcal{E}$ (depois de deformada) em duas camadas, cor e luminosidade. Em seguida, a luminosidade é decomposta na camada da estrutura da face e na camada de detalhes da pele.

Para criar as camadas de cor e luminosidade, converte-se as imagens para o espaço de cor $\mathrm{La}^{*} \mathrm{~b}^{*}$, utilizando $L^{*}$ para a luminosidade e $a^{*}$ e $b^{*}$ para cor. Segundo os autores, esse espaço de cor foi escolhido por desempenhar melhor se comparado a outros espaços de cor quando se deseja separar luminosidade de cor e também por ser perceptualmente uniforme.

Segundo Guo e Sim (2009), a divisão da camada de luminosidade em estrutura da face e detalhes da pele já foi abordada em outros trabalhos como em Eisemann e Durand (2004) e Zhang et al. (2008). Assim, a ideia principal é realizar uma suavização que preserve as bordas na camada de luminosidade para obter a camada da estrutura da face. Para a camada de detalhes, é realizada uma subtração da camada de luminosidade pela camada de estrutura da face. Para a suavização, foi utilizado o método weighted-least-squares (WLS) proposto por Farbman et al. (2008) no lugar do filtro bilateral, já que ele tem um melhor desempenho computacional.

A transferência de maquiagem foi dividida em quatro procedimentos: transferência dos detalhes da pele, de cor, de destaque e sombreamento e da maquiagem dos lábios.

Para a transferência dos detalhes da pele, a camada de detalhe da pele resultante, $\mathcal{R}_{d}$, é calculada por meio de uma soma ponderada seguindo a equação:

$$
\mathcal{R}_{d}=\delta_{\mathcal{I}} \mathcal{I}_{d}+\delta_{\mathcal{E}} \mathcal{E}_{d}
$$


para $0 \leq \delta_{\mathcal{I}}, \delta_{\mathcal{E}} \leq 1$ sendo que $\delta_{\mathcal{I}}$ e $\delta_{\mathcal{E}}$ controlam a contribuição de cada componente. $\mathrm{O}$ valor padrão para essas variáveis usadas no artigo foram $\delta_{\mathcal{I}}=0$ e $\delta_{\mathcal{E}}=1$. Assim, ocultam-se os detalhes da pele da face original e são introduzidos os detalhes faciais correspondentes à face maquiada da imagem modelo. Caso queira-se preservar detalhes da face em $\mathcal{I}$, podese fazer $\delta_{\mathcal{I}}>0$. Vale comentar que a soma das duas variáveis não precisa ser 1 , já que a imagem final pode ser criada com a quantidade que se queira de detalhes da pele de cada imagem, porém não se deve usar valores pequenos para essas variáveis, já que a pele ficaria sem detalhes resultando em uma aparência artificial.

Para a transferência de cor, a camada de cor resultante, $\mathcal{R}_{c}$, é computada por meio de uma média ponderada da seguinte forma:

$$
\mathcal{R}_{c}(p)=\left\{\begin{array}{cc}
(1-\gamma) \mathcal{I}_{c}(p)+\gamma \mathcal{E}_{c}(p) & \text { para } \mathrm{p} \in \mathcal{C}_{3} \\
\mathcal{I}_{c}(p) & \text { caso contrário }
\end{array}\right.
$$

onde $p$ é um pixel da imagem e $\gamma$ controla o peso de cada imagem na composição final. $\mathrm{O}$ valor usado na imagem da figura 3.5 foi 0,8 . O método para a simulação de maquiagem a ser apresentado nesse trabalho, para o procedimento relacionado à simulação de cor, também utiliza uma média ponderada com os canais $\mathrm{a}^{*} \mathrm{e} \mathrm{b}^{*}$.

Para a transferência de destaque e sombreamento, será trabalhada a camada da estrutura da face já que nela residem os efeitos de destaque e sombreamento, sendo esses importantes no contexto da maquiagem. Como essa camada contém informações que são inerentes da pessoa alvo, não se pode simplesmente copiar $\mathcal{E}_{s}$ para $\mathcal{I}_{s}$ ou combiná-las. Assim, para conseguir realizar a transferência, Guo e Sim (2009) adaptaram um método de edição baseado em gradiente. A ideia principal é adicionar apenas grandes mudanças de $\mathcal{E}_{s}$ para $\mathcal{I}_{s}$. Ao assumir isso, o artigo considera iluminação uniforme na imagem $\mathcal{E}$, caso contrário essa também seria transportada para a imagem final. A edição de imagem baseada em gradiente foi calculada da seguinte forma:

$$
\nabla \mathcal{R}_{s}(p)=\left\{\begin{array}{cc}
\nabla \mathcal{E}_{s}(p) & \text { se } \beta(p)\left\|\nabla \mathcal{E}_{s}(p)\right\|>\left\|\nabla \mathcal{I}_{s}(p)\right\| \\
\nabla \mathcal{I}_{s}(p) & \text { caso contrário }
\end{array}\right.
$$

Para a transferência da maquiagem nos lábios, segundo Guo e Sim (2009), esse tipo de maquiagem tem características diferentes das abordadas nos outros processos, já que ao invés de ocultar os detalhes ele preserva ou realça a textura dos lábios. Nesse procedimento diferenciado, para cada pixel $p$ em $\mathcal{I}$, uma busca é realizada pelo pixel $q$ em $\mathcal{E}$, tal que $\mathcal{E}(q)$ e $\mathcal{I}(p)$ sejam o mais similar possível enquanto $q$ e $p$ seja o mais próximo possível. Seja $\mathcal{M}$ a região dos lábios após a aplicação da maquiagem, para cada pixel $p \in \mathcal{C}_{2}$ tem-se:

$$
\mathcal{M}(p)=\mathcal{E}(\widetilde{q})
$$


onde

$$
\widetilde{q}=\arg \max _{q \in \mathcal{C}_{2}}\{G(|q-p|), G(|\mathcal{E}(q)-\mathcal{I}(p)|)\}
$$

onde $G$ denota a função Gaussiana e para $|\mathcal{E}(q)-\mathcal{I}(p)|$ é utilizada a diferença entre os valores de pixel apenas no canal $L^{*}$ após uma equalização de histograma realizada separadamente para $\mathcal{E}$ e $\mathcal{I}$.

Para o resultado final, a região dos lábios do canal $L^{*}$ de $\mathcal{M}$ é substituída na mesma região para o canal $L^{*}$ de $\mathcal{R}$, o mesmo acontecendo para os outros canais $a^{*}$ e $b^{*}$.

Com relação aos resultados, eles foram analisados de forma qualitativa e comparados com os resultados do artigo anterior. Segundo Guo e Sim (2009), os resultados apresentam cores mais vivas e são mais fiéis ao estilo de maquiagem da imagem modelo quando comparados com o trabalho anterior (Tong et al., 2007). Além disso, também é comentado que a abordagem proposta nesse artigo obteve melhores resultados quanto à preservação da estrutura facial após a aplicação da maquiagem, como pode ser visto na figura 3.7, além de melhores resultados para os lábios, já que obtiveram sua textura preservadas mesmo com o destaque criado pela aplicação da maquiagem. Vale acrescentar também que as manchas, descolorações e clareamentos na pele, comentadas pelos autores do artigo anterior, ficam bem mais visíveis agora quando é possível ver os resultados dos dois artigos lado a lado na figura 3.7 .

Outros resultados podem ser visualizados nas figuras 3.8 e 3.9. A primeira, chamada pelos autores de foto retocada, ilustra uma possibilidade um pouco diferente de uso da abordagem proposta quando uma pessoa poderia usar como imagem modelo uma boa fotografia dela mesma (com ou sem maquiagem) e como imagem alvo uma foto mais amadora, para que essa última fosse retocada para ficar mais parecida com a boa fotografia. A segunda, ilustra outro exemplo diferente em que a imagem modelo seria uma imagem de um quadro ou desenho, nesse caso, melhores resultados foram obtidos com $\delta_{\mathcal{I}}=1$ e $\delta_{\mathcal{E}}=0$ para evitar que os detalhes da face da pintura fossem transportados para a imagem final.

Ainda se referindo ao artigo de Tong et al. (2007), os autores ressaltam que a diferença entre os dois artigos é que essa nova abordagem aprende os efeitos da maquiagem após sua aplicação na pele, enquanto que o trabalho anterior aprende a maneira com que a maquiagem altera os pixels da imagem.

Scherbaum et al. (2011) descrevem um sistema que consiga sugerir o estilo de maquiagem que um especialista em maquiagem escolheria para uma determinada face. Para isso, foi construído um banco de dados de imagens de pessoas sem e com maquiagem feita por um profissional para que fosse possível aprender como esse profissional trabalha cada face e também o efeito causado pela maquiagem em cada uma delas. A aplicação da maquiagem é simulada em um modelo 3D criado a partir de padrões de luz aplicados na face da pessoa. Para esse procedimento, a imagem da face é quebrada em várias camadas, são elas: cor difusa em RGB, posição em 3D, normal em 3D, especularidade, brilho e espalhamento. 

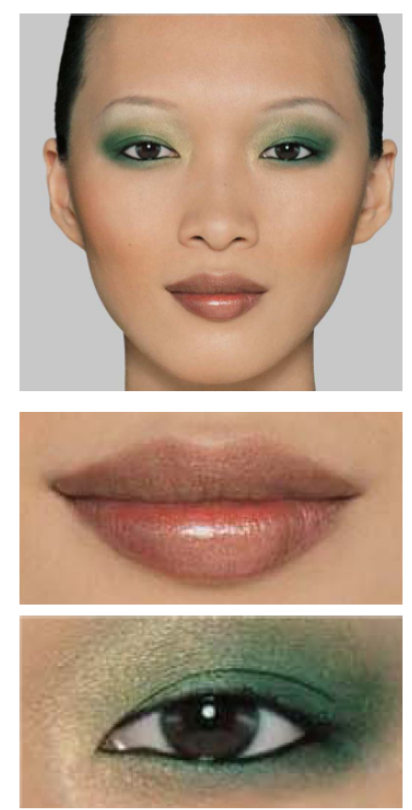

Imagem modelo, $\mathcal{E}$
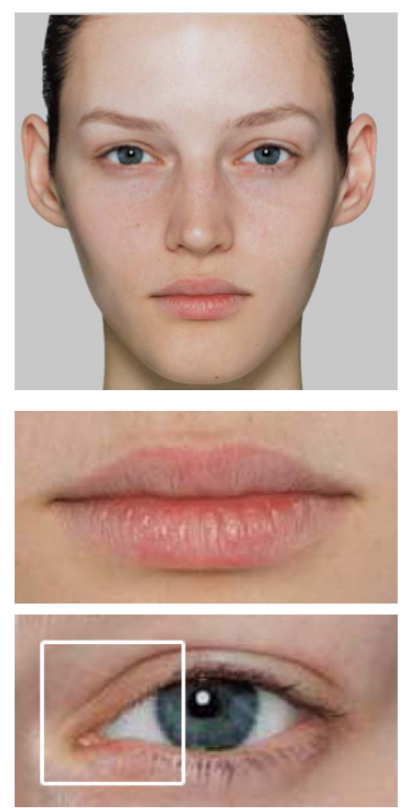

Imagem alvo, $\mathcal{I}$
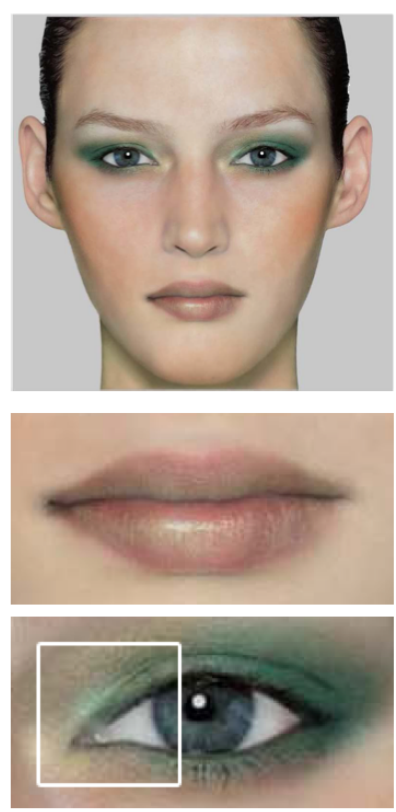

Resultados de Tong et al.
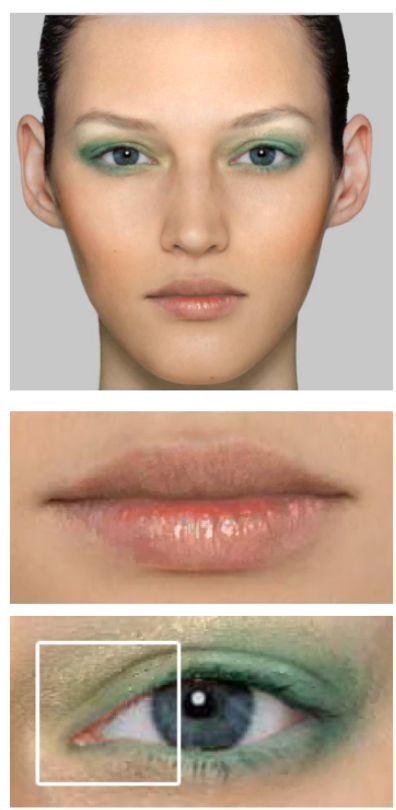

Resultado de Guo e Sim

Figura 3.7: Comparação entre os resultados de Guo e Sim (2009) e de Tong et al. (2007). Retirada de Guo e Sim (2009).

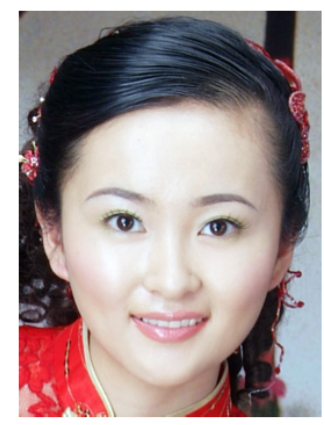

(a)

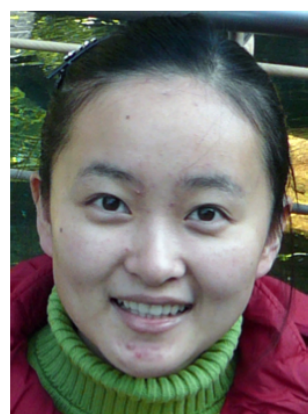

(b)

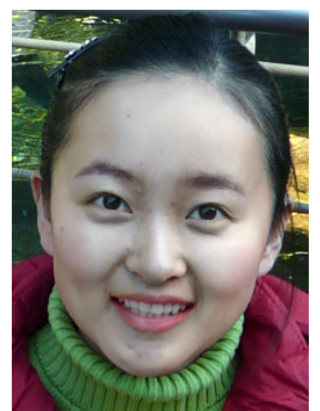

(c)

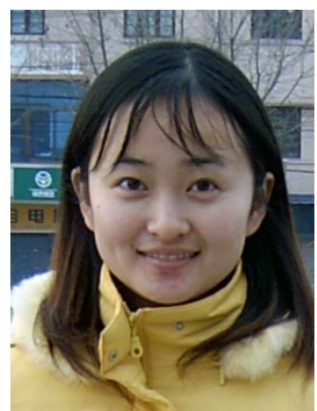

(d)

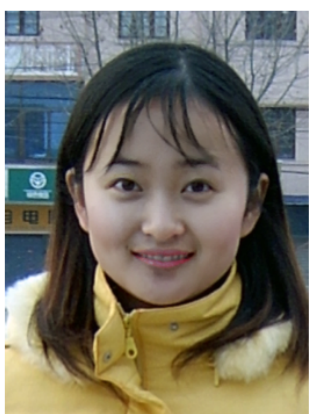

(e)

Figura 3.8: Foto retocada, (a) Imagem modelo tirada de forma profissional em um estúdio com a intenção de proporcionar o retoque desejado na imagem alvo. (b) e (d) Fotos da mesma pessoa de (a), tiradas de forma amadora. (c) e (e) O resultado do retoque de (b) e (d), respectivamente. Retirada de Guo e Sim (2009).

Entretanto, todas elas só podem ser obtidas com o método utilizado para a criação do modelo 3D limitando a aplicação do método. De forma semelhante ao trabalho de Tong et al. (2007), é necessário um par de imagens modelo de uma mesma pessoa $i$ com $(Y)$ e sem $(X)$ maquiagem e a mudança da aparência entre as duas faces é considerada maquiagem, denotada por $M_{i, X \rightarrow Y}$. Tal valor é computado como uma razão da seguinte forma:

$$
M_{i, X \rightarrow Y}=A_{i, X} / A_{i, Y}
$$

Para aplicar a maquiagem, usa-se:

$$
A_{i, Y}=A_{i, X} * M_{i, X \rightarrow Y}
$$




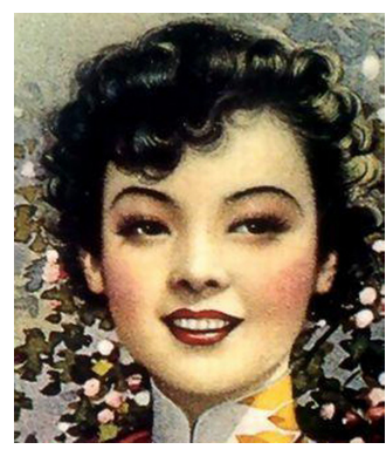

(a)

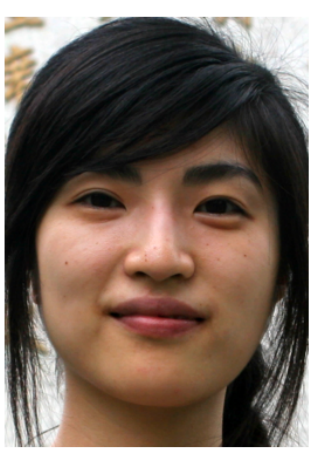

(b)

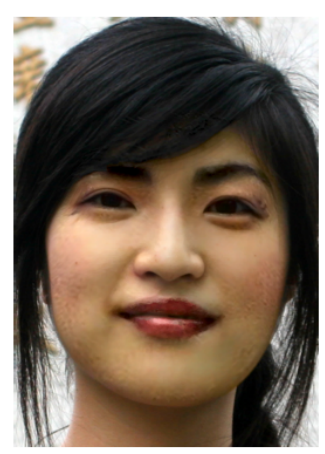

(c)

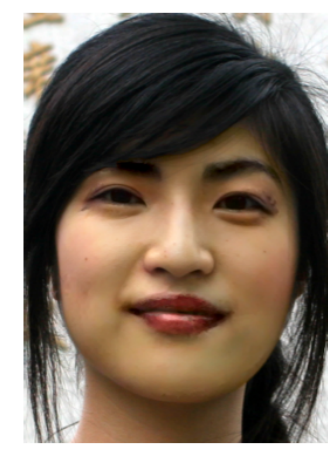

(d)

Figura 3.9: (a) Imagem de uma pintura usada como imagem exemplo. (b) Foto da pessoa alvo. (c) Resultado da maquiagem com os detalhes faciais de (a). (d) Resultado da maquiagem com os detalhes faciais de (b). Retirada de Guo e Sim (2009).

Para Scherbaum et al. (2011) a mudança na camada de cor difusa é a mais importante e é utilizada a equação 3.11 nos três canais do espaço de cor RGB. Já para as camadas de especularidade e brilho foi realizada uma soma e para a camada de espalhamento uma multiplicação monocromática. Outro ponto a ser dito, como os autores não tomaram cuidado com rugas, manchas e afins antes de iniciar o processo de maquiagem, ao transferir a maquiagem de uma pessoa para outra, essas características faciais também são transferidas. Para sanar esse problema, foi utilizado Principal Component Analysis, PCA, juntamente com a abordagem de Eigenfaces (Turk e Pentland, 1991). Assim, foram criadas eigen-maquiagens, sendo que as que obtiveram os maiores autovalores correspondem às variações responsáveis pela maquiagem e as com os menores autovalores correspondem às variações devido aos detalhes faciais citadas. Utilizou-se então apenas as que tiveram os dez maiores autovalores. Além disso, diferentemente de outros artigos, esse assume que a maquiagem não tem efeito geométrico na pele.

\section{Aplicação de maquiagem}

Dhall et al. (2009) aplicam maquiagem automaticamente baseado no gênero e cor de pele da pessoa. Apenas sobre o escopo da aplicação da maquiagem, primeiramente a face é segmentada na imagem por cor de pele, então usa-se Viola-Jones (Viola e Jones, 2001) para encontrar a região aproximada dos olhos e da boca e, por fim, usa-se Active Shape Models (Cootes et al., 1995) para segmentar com mais precisão essas regiões. Para aplicar a maquiagem nas regiões encontradas, primeiramente o artigo aplica uma suavização Gaussiana seguida de uma dilatação, com o objetivo de remover pequenas marcas e sinais na pele, para então aplicar a maquiagem na face modificando os valores de matiz e saturação do espaço de cor HSV para que eles sejam os mesmos dos padrões adequados para cada gênero e cor de pele que os autores têm guardados em um banco de dados. Para a maquiagem nos lábios, utiliza-se para cada pixel no espaço de cor RGB a seguinte equação:

$$
\text { novoRG } B=\text { antigoRGB } *(\max -\alpha)+\operatorname{labio} R G B * \alpha
$$


onde labioRGB é a cor que os lábios devem ter e tal valor é retirado do mesmo banco de dados citado anteriormente, o que também vale para o valor de $\alpha$. O valor de max não foi especificado no artigo.

Kim e Choi (2008) criaram um sistema interativo para aplicar maquiagem em um modelo 3D com feedback háptico e visão estéreo. No que diz respeito à aplicação da maquiagem, ela é feita combinando as cores da textura da pele capturada pelos escâneres 3D utilizados no projeto e as cores da maquiagem desejada. Esse procedimento foi definido pela média ponderada, conforme equação 3.13

$$
C=C_{b}(1-\beta)+C_{p} \beta
$$

onde $C$ é a cor resultante, $C_{b}$ é a cor da pele da face, $C_{p}$ é a cor da maquiagem e $\beta$ é a intensidade da pressão feita no dispositivo háptico.

Existe ainda mais um tipo de artigo que trata sobre aplicação de maquiagem. Este se baseia em modelos físicos para simular o comportamento da interação da luz com a pele.

O trabalho de Huang et al. (2013) tem como objetivo simular de forma realista a renderização de pele com cosmético aplicada a ela. Para isso, foi proposta uma abordagem baseada em modelos físicos que simulam o comportamento da luz ao interagir com a pele. As contribuições do artigo são o método para realizar essa simulação e o desenvolvimento de um sistema para simulação de maquiagem que permita ao usuário modificar o estilo da maquiagem aplicada em tempo real.

O método proposto se baseia em combinar o modelo de Kubelka-Munk (Kortüm e Lohr , 1969) com uma abordagem de renderização de pele chamada screen-space (Jimenez et al. , 2009). O modelo de Kubelka-Munk é usado para calcular a transmitância total quando a luz passa através de camadas de cosméticos e o screen-space é usado para simular o espalhamento dos raios de luz dentro da pele humana. Os parâmetros do modelo de Kubelka-Munk são adquiridos medindo as propriedades ópticas dos cosméticos a serem simulados. Para o screen-space, também é necessário medir algumas características da pele como coeficiente de espalhamento e de absorção.

O método foi implementado utilizando GPU e os modelos da face de possíveis usuários foram construídos utilizando um equipamento especial chamado Light Stage X. Foram obtidos aproximadamente 170 quadros por segundo para um frame buffer de 1280x720 pixels utilizando um computador com processador Intel Core i5 750 2,67GHz e placa de vídeo NVIDIA GTX 260. O resultado da simulação comparado com a maquiagem real pode ser visto na figura 3.10 .

O uso desse método para essa dissertação fica comprometido devido à necessidade de medir propriedades ópticas da pele e das maquiagens a serem simuladas para que seus respectivos modelos possam ser criados. Tais medidas necessitam de equipamentos especiais que são caros e não estão disponíveis para o projeto. 


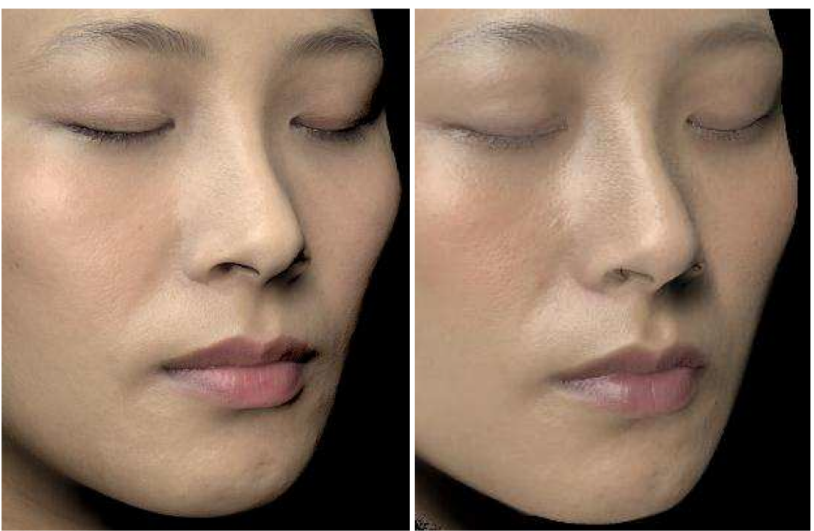

Figura 3.10: Comparativo entre o resultado da simulação (direita) e a maquiagem real (esquerda). Retirada de Huang et al. (2013).

\subsubsection{Interação humano computador}

Abaixo serão comentados os trabalhos que ainda pertencem ao tema de simulação de maquiagem, mas que possuem enfoque ou que se preocuparam com a interface do simulador de uma forma diferenciada dos demais artigos.

Kim e Choi (2008) se propõe a criar um sistema interativo para aplicar maquiagem em um modelo 3D com feedback háptico e visão estéreo. Então, o usuário veste um óculos especial para enxergar seu próprio modelo 3D em um monitor estéreo e utiliza um dispositivo háptico para interagir com o modelo, sendo que esse dispositivo faz o papel de, por exemplo, um pincel de maquiagem utilizado na aplicação do cosmético. O modelo 3D da face da pessoa é adquirido com escâneres 3D comerciais que capturam a nuvem de pontos e a textura da face.

O sistema simula aplicação de base, maquiagens coloridas e brilho labial utilizando a pressão feita no dispositivo háptico para determinar a quantidade de maquiagem a ser aplicada. Com a interface gráfica ilustrada na figura 3.11, o usuário pode utilizar uma esponja para passar a base, um pincel colorido para as maquiagens coloridas, o aplicador de brilho labial para o gloss e um removedor de maquiagem para retirar a maquiagem aplicada. Além da maquiagem o usuário pode melhorar a textura de sua face alterando brilho, contraste, realizando suavização, remoção de ruído e tom de pele.

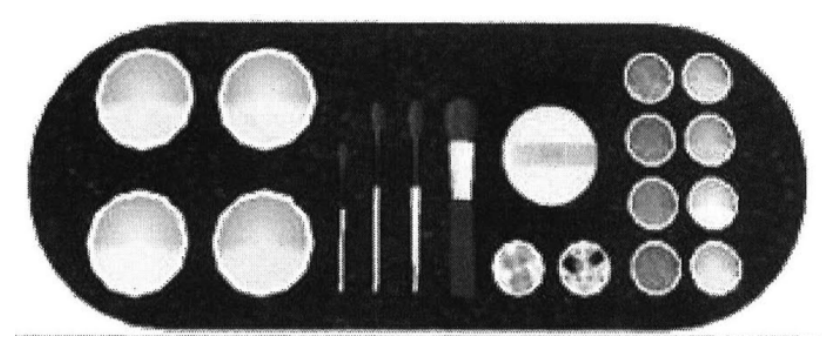

Figura 3.11: Interface gráfica do sistema proposto em Kim e Choi (2008).

No artigo de Iwabuchi et al. (2009), os autores se propõem a criar um espelho inteligente de maquiagem com o objetivo de tornar o processo de aplicação desses produtos mais fácil e 
divertido. Tal sistema não contempla simulação de maquiagem, ele seria apenas um espelho com funcionalidades a mais do que um espelho comum. Esse trabalho foi motivado por um problema identificado pelos autores por meio de uma pesquisa realizada no Japão, indicando que $63.5 \%$ das mulheres achavam o processo de aplicação de maquiagem problemático e muitas delas gostariam de uma ferramenta que fizesse com que essa experiência fosse mais fácil e divertida.

A figura 3.12 ilustra o sistema proposto pelos autores que é constituído por um monitor que exibe a imagem da pessoa como se fosse um espelho, duas câmeras posicionadas acima desse monitor, uma de baixa resolução usada apenas para encontrar os marcadores nos objetos utilizados ao aplicar maquiagem real e outra de alta resolução utilizada na imagem exibida para o usuário para chegar o mais próximo possível da imagem real do espelho. Além disso, também foram usados um sensor de proximidade na parte superior do monitor, sensores infravermelhos de distância acoplados na lateral do monitor e um computador para processar as imagens e controlar o sistema.

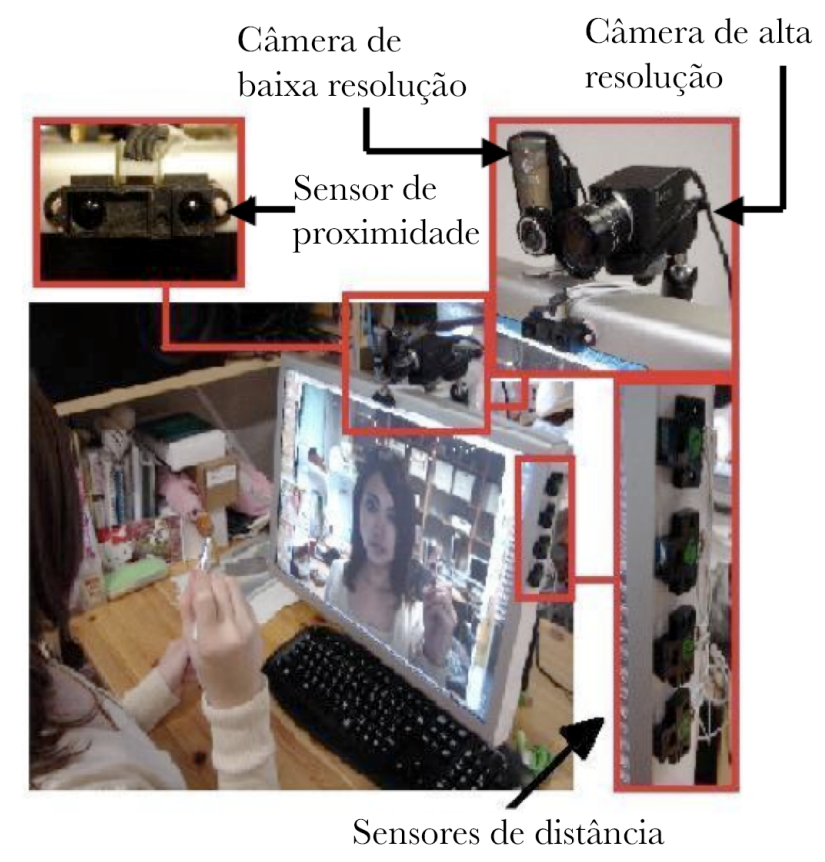

Figura 3.12: Essa imagem ilustra o sistema proposto pelos autores e destaca os equipamentos utilizados para seu funcionamento. Retirada de Iwabuchi et al. (2009).

A partir dessa configuração e de dicas de especialistas sobre maquiagem, foram feitas algumas considerações que direcionaram o desenvolvimento do projeto. Dentre elas, notouse que:

- a direção do olhar do usuário não está alinhada com a imagem do espelho inteligente. Isso ocorre devido ao posicionamento da câmera que está acima do monitor, atrapalhando o realismo e a metáfora de espelho;

- a resolução da imagem exibida no monitor deve ser a mais alta possível para que se tenha a mesma sensação de um espelho real; 
- a imagem exibida no espelho inteligente pode apresentar defasagem com a realidade devido ao atraso ocorrido pelo processamento das imagens;

- a imagem pode ficar fora de foco se o usuário se mover consideravelmente para frente ou para trás, caso a câmera não tenha mecanismo de foco automático;

- é interessante a existência de um mecanismo que possibilite um zoom na face da pessoa para simular o comportamento comum do usuário quando ele se aproxima do espelho para enxergar detalhes;

- para avaliar a maquiagem aplicada, é interessante que o usuário se observe da mesma forma com que outra pessoa o observaria frontalmente (imagem não invertida) e também de outros pontos de vista como lateral, por baixo, em diagonal e etc;

- a aparência da maquiagem pode mudar de acordo com o tipo de fonte de luz que ilumina o ambiente.

Assim, o espelho desenvolvido contempla algumas funcionalidades que o diferenciam de um espelho comum, como:

- a habilidade de possibilitar zoom em partes específicas da face quando detectado um marcador colorido nos objetos utilizados para aplicar a maquiagem;

- a funcionalidade de lente de aumento que é ativada automaticamente quando o usuário se aproxima ou se afasta levemente do monitor. Quanto mais ele se aproxima, maior é o fator de aumento aplicado na imagem e quanto mais ele se afasta, menor o fator;

- a possibilidade de exibir a face em vários ângulos diferentes. Isso é feito congelando por alguns segundos a imagem de determinado ponto de vista para que o usuário possa observá-la;

- a possibilidade de exibir a face como se outra pessoa a estivesse observando;

- simular condições de iluminação diferentes. Seis modos foram desenvolvidos: modo de maquiagem, modo escritório, modo nublado, modo céu aberto, modo pôr do sol avermelhado e modo luz de velas;

- a possibilidade de gravar imagens da face com maquiagem e comparar essas imagens com outras já gravadas anteriormente;

- compartilhar as imagens gravadas com amigos que podem votar positivamente ou negativamente. 
Exceto pelos dois primeiros itens, os outros são ativados aproximando a mão do sensor de proximidade no topo do monitor. Entretanto, o artigo não apresenta detalhes da interação para ativar e desativar cada uma dessas funcionalidades.

Com relação à questão do posicionamento da câmera que leva ao problema da diferença da direção do olhar, o trabalho de Makino et al. (2005) cita uma possível configuração que resolveria esse problema. Utiliza-se um espelho semi-reflexivo que permita a reflexão da imagem do usuário para que a câmera a capte, mas também permitia que o usuário consiga ver o monitor através desse espelho, como ilustrado na figura 3.13. Isso seria algo parecido com o que se tem em programas de televisão ou em discursos, teleprompter. O problema dessa configuração é o custo do equipamento.

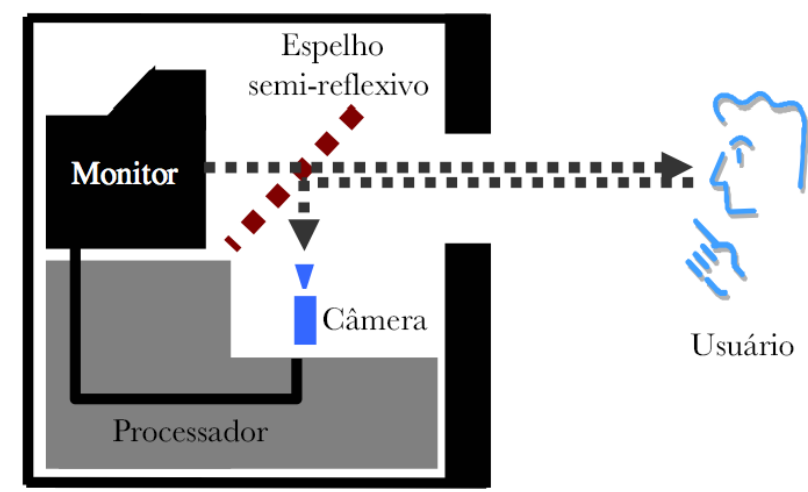

Figura 3.13: Exemplo de configuração de um espelho virtual baseado em um espelho semi-reflexivo. Retirada de Makino et al. (2005).

No artigo de Rahman et al. (2010), os autores se propõem a desenvolver uma interface para um espelho inteligente de maquiagem que torne o momento da escolha desses produtos algo mais conveniente e eficiente. Assim, foi desenvolvido um sistema chamado pelos autores de sensory augmented smart interaction mirror (SIM), que contempla um monitor fazendo o papel de espelho juntamente com a simulação da maquiagem escolhida pelo usuário, além da sugestão de outros produtos de maquiagem como, por exemplo, com menor preço, baseado no histórico de produtos provados. Vale comentar que a imagem da face da pessoa que aparece no espelho é um modelo 3D dela que mimetiza em tempo real os movimentos feitos pelo usuário ao utilizar o sistema. Tal modelo precisa ser criado antes de se utilizar o SIM.

O problema encontrado pelos autores e que motivou o projeto é que selecionar produtos de maquiagem é uma tarefa desafiadora. Segundo Rahman et al. (2010), isso acontece pois existem diversos tipos de maquiagens e ocorreu uma grande aumento no número de fabricantes criando então uma infinidade de produtos que podem ser escolhidos. Além disso, para selecionar os produtos deve-se atentar para as cores que melhor combinam com o tipo e cor de pele e a ocasião em que a maquiagem será utilizada, o que torna o processo ainda mais complexo e cansativo.

Para seu funcionamento, o sistema possui uma câmera comum para capturar a imagem do usuário e uma câmera infravermelha utilizada para rastrear a face (são colocados dois 
emissores de infravermelho, um em cada orelha do usuário) e as mãos do usuário (são colocados emissores de infravermelho nos produtos). Para obter a informação de que produto o usuário deseja aplicar, todos os produtos utilizados no sistema possuem um marcador RFID. Assim, quando o usuário quer usar o produto, ele o aproxima do leitor RFID para que o sistema saiba qual a textura adequada para essa maquiagem. Além disso, foi utilizado um monitor de 21 polegadas para fazer o papel de espelho, como ilustrado na figura 3.14.

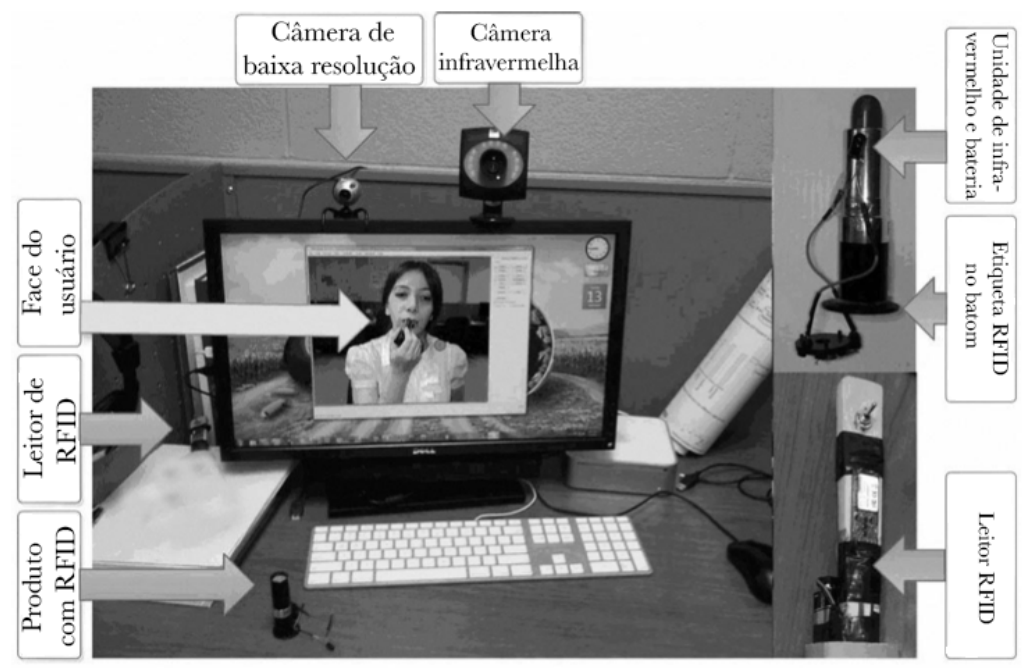

Figura 3.14: Sistema proposto em Rahman et al. (2010). Destaque para os equipamentos utilizados em seu funcionamento.

O artigo de Hanafusa et al. (2010) se propõe a desenvolver um sistema de maquiagem que tenha uma interface adequada para portadores de deficiência visual. Assim, foi desenvolvido um sistema que ensina deficientes visuais a aplicar maquiagem, verifica se o batom foi aplicado corretamente e também verifica o formato da sobrancelha após a maquiagem. O problema que levou os pesquisadores a desenvolverem esse trabalho se baseia no fato de que os deficientes visuais se sentem inseguros quanto ao resultado da aplicação da maquiagem feita por eles, já que não podem enxergar os resultados.

A parte do sistema que ensina os deficientes a aplicar a maquiagem funciona com o computador lendo os passos necessários para a aplicação daquele tipo de maquiagem. Por meio da caixa de som do computador, o usuário escuta a leitura dos passos e os executa, podendo pedir para o sistema repetir a instrução ou passar para a seguinte com o auxílio de um teclado. Para verificar a correta aplicação da maquiagem o sistema compara a imagem depois da aplicação do produto com uma imagem capturada sem maquiagem ou com uma imagem da maquiagem aplicada corretamente para verificar se existem diferenças indesejáveis. O protótipo do sistema proposto pode ser visto na figura 3.15 e a interface gráfica do sistema pode ser vista na figura 3.16

No artigo de Nakagawa et al. (2011), tem-se como objetivo propor um sistema que ajude o usuário a experimentar novos métodos e variações de maquiagem com os produtos utilizados no dia a dia. Criou-se então um aparato chamado de Sistema Inteligente de Maquiagem 


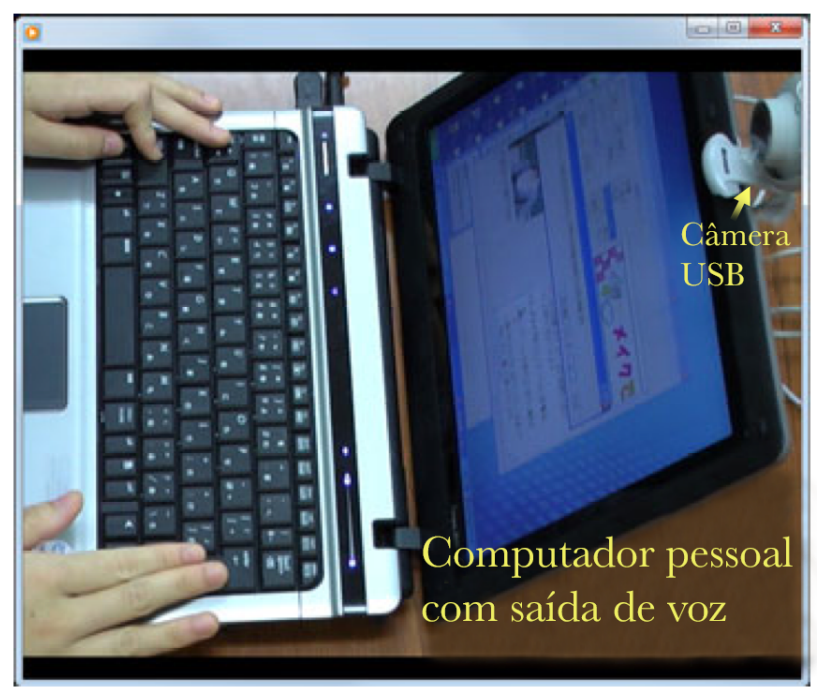

Figura 3.15: Sistema proposto em Hanafusa et al. (2010). Destaque para os equipamentos utilizados em seu funcionamento.

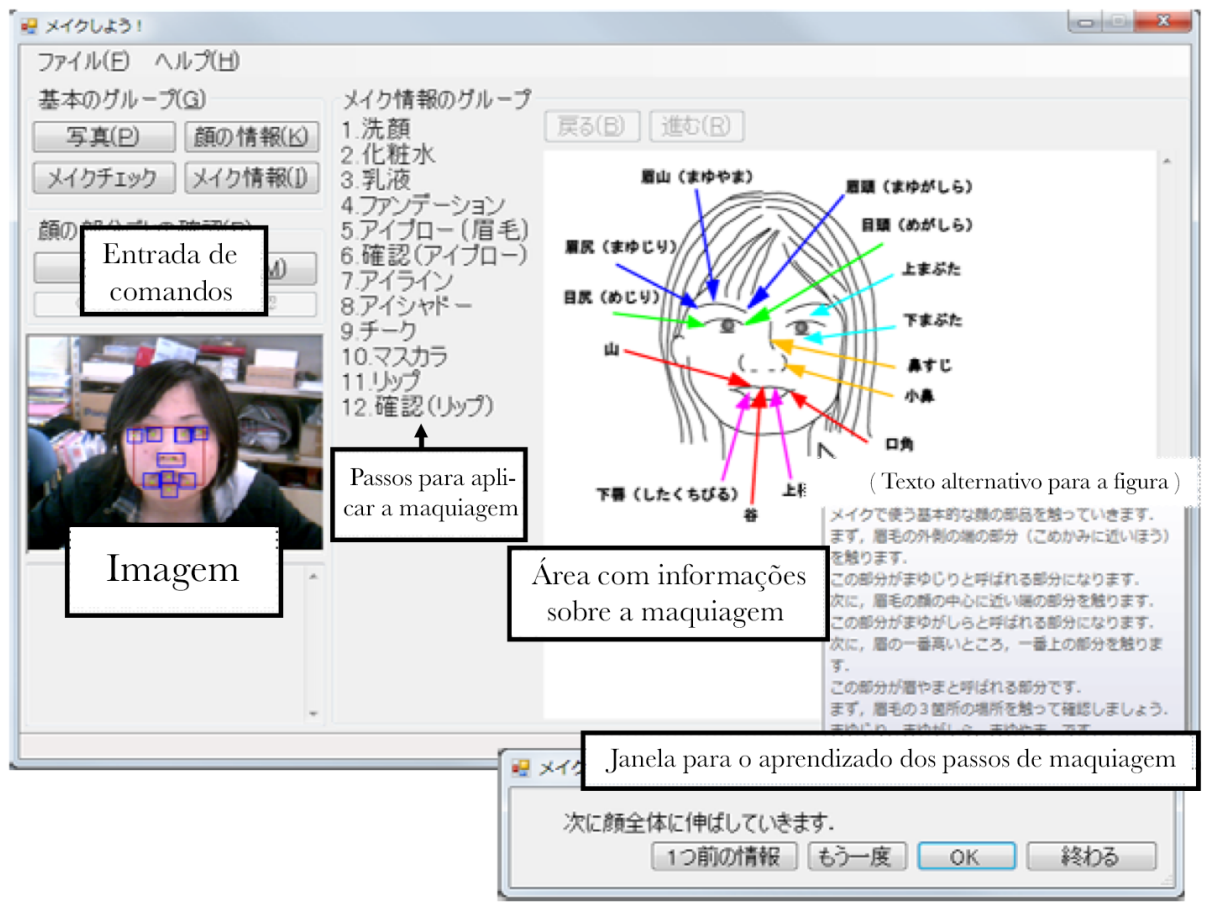

Figura 3.16: A imagem ilustra a interface gráfica do sistema proposto em Hanafusa et al. (2010).

(Smart Makeup System, SMS) para facilitar o compartilhamento entre amigos de seus históricos de maquiagens por meio de fotos ou informações sobre os produtos utilizados. O problema identificado pelos autores que motivou o trabalho seria que as mulheres têm dificuldade de variar a maquiagem.

As principais funcionalidades do SMS contemplam o registro do cosmético utilizado pelo usuário (por meio da leitura de código de barra ou RFID), conseguir gravar o histórico com pouco esforço do usuário e ser possível compartilhá-lo com os amigos para que se possa navegar por históricos semelhantes ao do usuário e assim descobrir novas combinações de maquiagens e então testá-las em si. O sistema é composto por três espelhos, um ao centro, 
um à esquerda e o da direita com um espaço no centro com um monitor e uma câmera USB. Além disso existe um leitor de RFID na cesta de produtos, um computador e uma lâmpada no topo do espelho central. O sistema pode ser visto na figura 3.17.

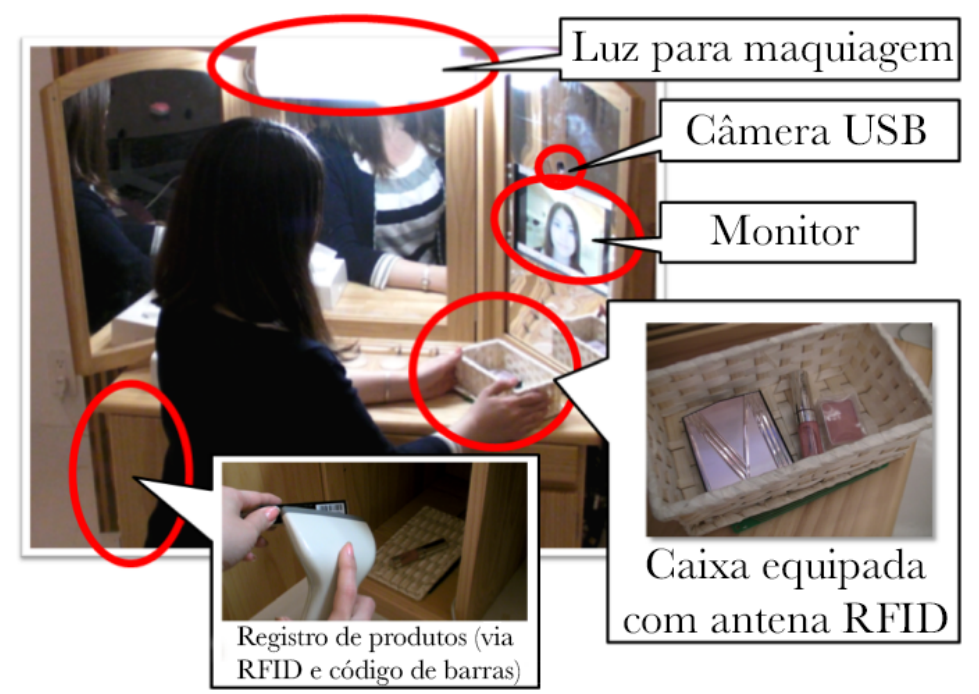

Figura 3.17: A imagem ilustra o sistema proposto destacando os equipamentos utilizados. Retirada de Nakagawa et al. (2011).

\subsubsection{Sugestão de maquiagem}

Ainda no contexto de simulação de maquiagem, mas com enfoque diferente, nesta seção serão abordados os trabalhos sobre sugestão de maquiagem.

O artigo de Dhall et al. (2009) tem como objetivo conseguir aplicar maquiagem automaticamente baseado no gênero e cor de pele da pessoa. Para alcançar seu objetivo, foi utilizado Support Vector Machine (SVM) para classificar a cor de pele do usuário em três etnias diferentes: europeu, africano e asiático. Para classificar entre gênero masculino e feminino, foi utilizada uma abordagem baseada em scalable boosting. Também foi criada uma base de dados que identifica os valores de cor de pele resultantes após a aplicação da maquiagem para alguns tons de pele dentro de cada uma das etnias. Esses valores são usados para a aplicação da maquiagem mais adequada, encontrando a cor de pele da base de dados que seja a mais próxima da cor de pele do usuário.

O artigo de Jain e Bhatti (2010) se baseia em uma solução desenvolvida para ser usada comercialmente. Seu objetivo é semelhante ao artigo anterior, já que eles querem recomendar a melhor cor de base para a cor de pele do usuário.

Nesse sistema, existem duas formas para capturar a imagem do usuário: ele pode utilizar um quiosque, por exemplo em um shopping como na figura 3.18, ou então seu celular. Em ambos, o usuário deve segurar um padrão de cor na altura do peito, sendo que esse padrão é identificado na imagem pelo software e utilizado por ele para calibrar as cores da imagem para um padrão conhecido. Com as cores dentro desse padrão, a face é detectada na imagem e apenas os pixels correspondentes à pele da face sob boa iluminação (sem brilho ou fora 
de região de sombra) são considerados na análise final. Por fim, compara-se o tom de pele extraído do usuário com uma base de dados criada com conhecimento de especialistas em maquiagem contendo as melhores opções de cor de base para cada tom de pele. Na figura 3.19 pode-se observar as etapas do sistema juntamente com algumas imagens ilustrativas de cada uma delas. Vale salientar que não existe simulação de maquiagem, apenas a recomendação.
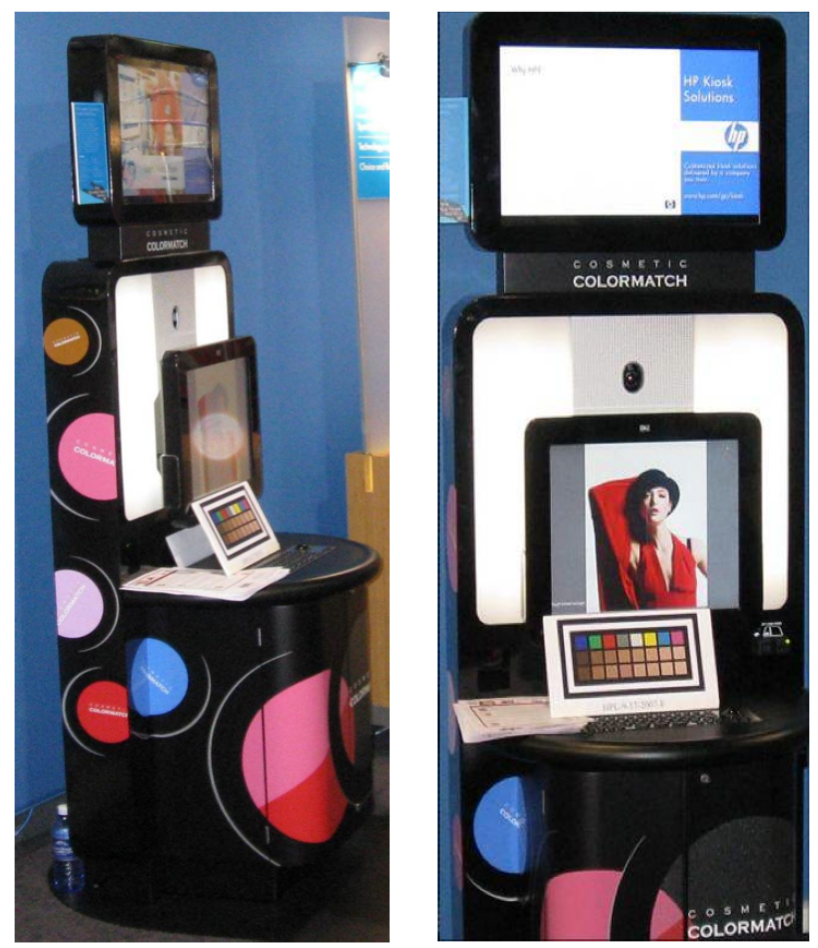

Figura 3.18: A imagem ilustra o quiosque do sistema proposto. Retirada de Jain e Bhatti (2010).

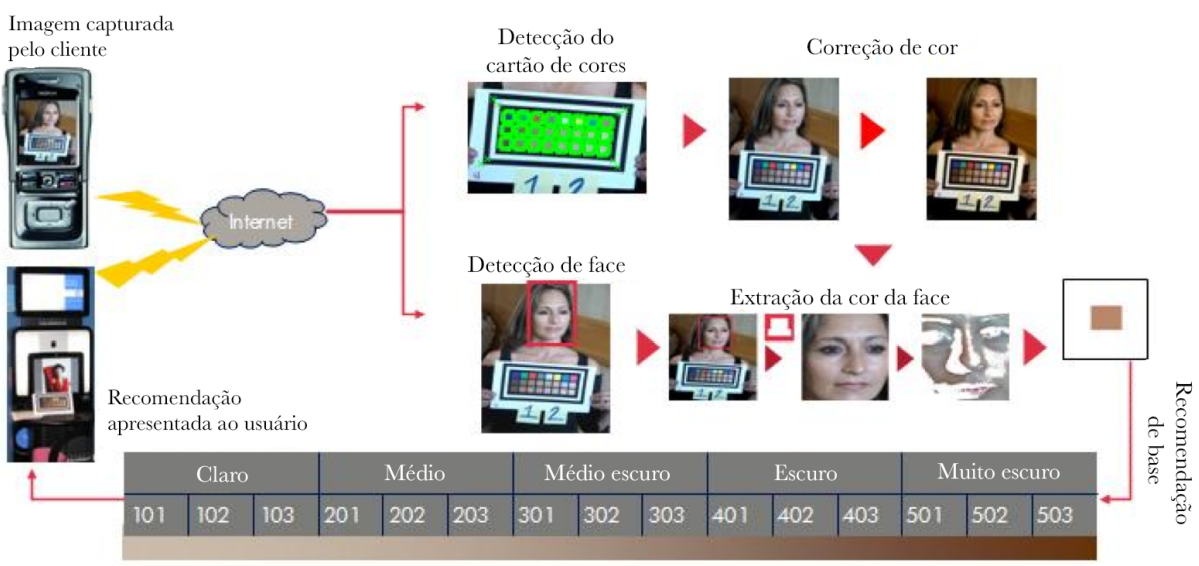

Figura 3.19: A imagem ilustra as etapas do sistema proposto. Retirada de Jain e Bhatti (2010).

O artigo de Scherbaum et al. (2011) descreve um sistema que consegue sugerir o estilo de maquiagem que um especialista escolheria para uma determinada face. A aplicação dessa maquiagem ideal é simulada em um modelo 3D criado a partir de padrões de luz aplicados na face da pessoa. 
Com relação à sugestão da maquiagem, é utilizada uma base de dados de pessoas com e sem maquiagem para que se possa sugerir as maquiagens mais adequadas para faces não presentes nessa base de dados. Essa base contém 56 exemplos de faces com e sem maquiagem, o que portanto torna conhecida, para cada um dos pares de faces, a transformação que leva da face sem para a face com maquiagem. Essa transformação pode ser relembrada revendo a parte da seção 3.1.1 que trata sobre esse artigo.

Se quisermos determinar a maquiagem para uma face que não esteja presente na base de dados, foi utilizada correlação (nearest neighbor matching) com uma função de distância modificada. Essa função leva em consideração a distância de Mahalanobis para os coeficientes do PCA que são aplicados para todas as faces do banco de dados usando a abordagem do Eigenfaces. Porém, para imitar a percepção humana, que prioriza algumas regiões da face ao analisar a maquiagem final como olhos, pele e cabelo, os coeficientes possuem pesos diferenciados para conceder maior relevância a essas regiões da face.

\subsubsection{Reconstrução facial e interação da luz com a pele}

Uma alternativa para o desenvolvimento do projeto é a reconstrução da face em 3D. Com essa abordagem, teríamos um modelo 3D de toda a face e poderíamos alterar esse modelo para simular os efeitos de maquiagem. Existem trabalhos que realizam essa reconstrução, como Scherbaum et al. (2011), Kim e Choi (2008), Bradley et al. (2010), Beeler et al. (2012) e Huang et al. (2013). Tipicamente os métodos utilizados nesse tipo de abordagem possuem alguns pontos negativos. Não é um processo simples e, portanto, demanda tempo considerável apenas para gerar o modelo da face sem nenhum tipo de maquiagem, muitas vezes são utilizados equipamentos especiais para realizar a captura da face que são caros e o laboratório não dispõem deles atualmente e, por fim, o usuário passaria por uma etapa de criação de seu modelo antes de usar o espelho, o que atrapalharia a experiência de uso do simulador, já que o desejado é que essa experiência seja semelhante a de um espelho comum. Outro problema que merece atenção seria que esse tipo de abordagem não apresenta resultados suficientemente realistas, ou seja, ao olhar a face reconstruída do usuário, é possível notar sem muito esforço que não é uma face real, não é como se o usuário estivesse se olhando no espelho.

Em geral, para reconstruir a face são utilizados modelos matemáticos que tentam simular a interação da luz com a pele. De acordo com os trabalhos a respeito desse tópico, como Baranoski e Krishnaswamy (2008), Kim et al. (2005), Donner et al. (2008), Jimenez et al. (2010) e Huang et al. (2013), pode-se perceber que apesar dos artigos mais recentes e complexos começarem a apresentar certo realismo, eles ainda não são realistas o suficiente para a nossa aplicação.

Ao interagir com o simulador de maquiagem, o usuário tem a expectativa de se ver como se estivesse olhando em um espelho. Se ele ver uma imagem da sua face que não parece real, ocorre uma quebra dessa expectativa e consequentemente uma sensação de estranhamento, 
caímos então no Uncanny Valley (Mori, 1970). Baseado no que já foi dito e nesse conceito, não faz sentido investigar o problema seguindo essas abordagens, já que os métodos atuais não são realistas o suficiente para ultrapassarmos o Uncanny Valley no contexto de nossa aplicação.

\subsubsection{Rastreamento de faces}

Para que se possa posicionar a maquiagem na face do usuário ao decorrer dos quadros do vídeo, é necessário rastrear pontos característicos da face do usuário para usá-los como referenciais do posicionamento da face. Dado que nesse projeto essa etapa será executada pelo sensor RGBD (Kinect), os trabalhos acadêmicos relacionados a rastreamento facial não se tornam foco de estudo, logo não são apresentados detalhes sobre esse tópico.

\subsection{Trabalhos não acadêmicos}

Nessa seção são abordados os projetos não acadêmicos relacionados com a proposta desse trabalho. Diferentemente dos trabalhos acadêmicos, nesse escopo, existem trabalhos com os mesmos objetivos dessa dissertação.

\subsubsection{Shiseido}

O primeiro projeto de simulação de maquiagem que se tem notícia foi encomendado pela empresa japonesa de cosméticos Shiseido. Ele é um simulador de maquiagem que funciona de forma muito semelhante ao que nos propomos com esse projeto. Ele foi usado comercialmente no Japão, mas não obteve muito sucesso entre as japonesas provavelmente devido a traços culturais que não as deixaram confortáveis ao experimentar maquiagens em ambientes sem privacidade. A primeira versão do simulador pode ser vista nesse vídeo http://www.youtube. $\mathrm{com} /$ watch? $\mathrm{v}=$ YIAtRgk2dkc.

Hoje o simulador está em sua segunda versão, como pode ser visto nesse vídeo http:// www.youtube.com/watch? $\mathrm{v}=\mathrm{sft} 5 \mathrm{ANEy} 17 \mathrm{Y}$, e é utilizado com instrumento de marketing da marca em eventos ao redor do mundo. Outros vídeos podem ser encontrados em http://www. youtube.com/watch?v=lhcGI__SEAA e http://www.youtube.com/watch?v=Uot-CpbWawU.

\subsubsection{Natura}

Em agosto de 2012, a Natura junto com a agência ID/TBWA fizeram uma ação de marketing utilizando um simulador de maquiagem desenvolvido por eles. Esse simulador ficou algumas semanas no Ici Bistrô em São Paulo como relatado pelo blog Brainstorm9 (2012).

O simulador ficava na região do banheiro do estabelecimento, mais especificamente no lugar do espelho acima das torneiras onde lavam-se as mãos. O sistema realizava a simulação 
de sombra, batom e blush sendo necessária a seleção do produto via toque na tela do simulador. Sua aplicação era feita por meio de gestos que tentavam se assemelhar à aplicação da maquiagem real como o passar dos dedos nas regiões da face a serem maquiadas. Além disso, o simulador aplica a maquiagem na face mais próxima ao espelho e também acima dele existiam seis lâmpadas de $60 \mathrm{~W}$ para controlar a iluminação no local.

Em visita ao simulador, foi possível notar que a qualidade da imagem utilizada na simulação não é boa, pois provavelmente foi utilizada a imagem da câmera do Kinect que é de baixa resolução no grande televisor que fazia o papel de espelho. Isso influenciou negativamente toda a experiência de uso do simulador. Fora isso, também foi possível perceber erros na simulação principalmente para a sombra e o batom. Esses erros consistem desde maquiagem fora de lugar, até ser possível ver uma figura geométrica que delimitava de forma inadequada a região em que a maquiagem estava sendo aplicada. Aparentemente, a simulação pareceu ser bastante simples, consistindo apenas na adição de uma camada com alguma transparência de uma cor parecida com a do produto escolhido. Ainda, a queda da taxa de quadros por segundo era perceptível nos momentos em que o sistema procurava pela face do usuário.

\subsubsection{Internet}

$\mathrm{Na}$ Internet existem sites que realizam simulação de maquiagem. Porém, todos eles simulam a maquiagem escolhida pelo usuário apenas em fotografias e também necessitam que diversos pontos da face sejam marcados manualmente para que o sistema possa localizar as regiões faciais e aplicar a maquiagem adequadamente. Um exemplo de serviço com este seria o site Taaz.com .

\subsubsection{Softwares de rastreamento facial}

Para atingir o objetivo proposto nesse trabalho precisamos rastrear pontos característicos da face de uma pessoa para que a maquiagem possa ser posicionada de forma adequada na face do usuário.

Softwares comercias de rastreamento facial são rotineiramente usados em sistemas conhecidos como facial mocap, facial motion capture, utilizados principalmente para a animação de personagens no cinema e em jogos de video game. Tais sistemas são responsáveis por registrar a posição de diversos pontos faciais enquanto o ator atua na cena. Essa informação pode ser utilizada para recriar e proporcionar realismo aos personagens virtuais.

Existem dois tipos de sistemas de mocap, com e sem marcadores. Estamos interessados nos sistemas sem marcadores e alguns exemplos de empresas que comercializam tal tipo de software são: Mova, Dynamixyz e Faceware Tech. Uma imagem do sistema da Dynamixyz pode ser observada na figura 3.20 .

Existem também outros sistemas semelhantes, mas com um propósito mais geral como o sistema da Image Metrics e o Face API da Seeing Machines. Além disso, recentemente a 


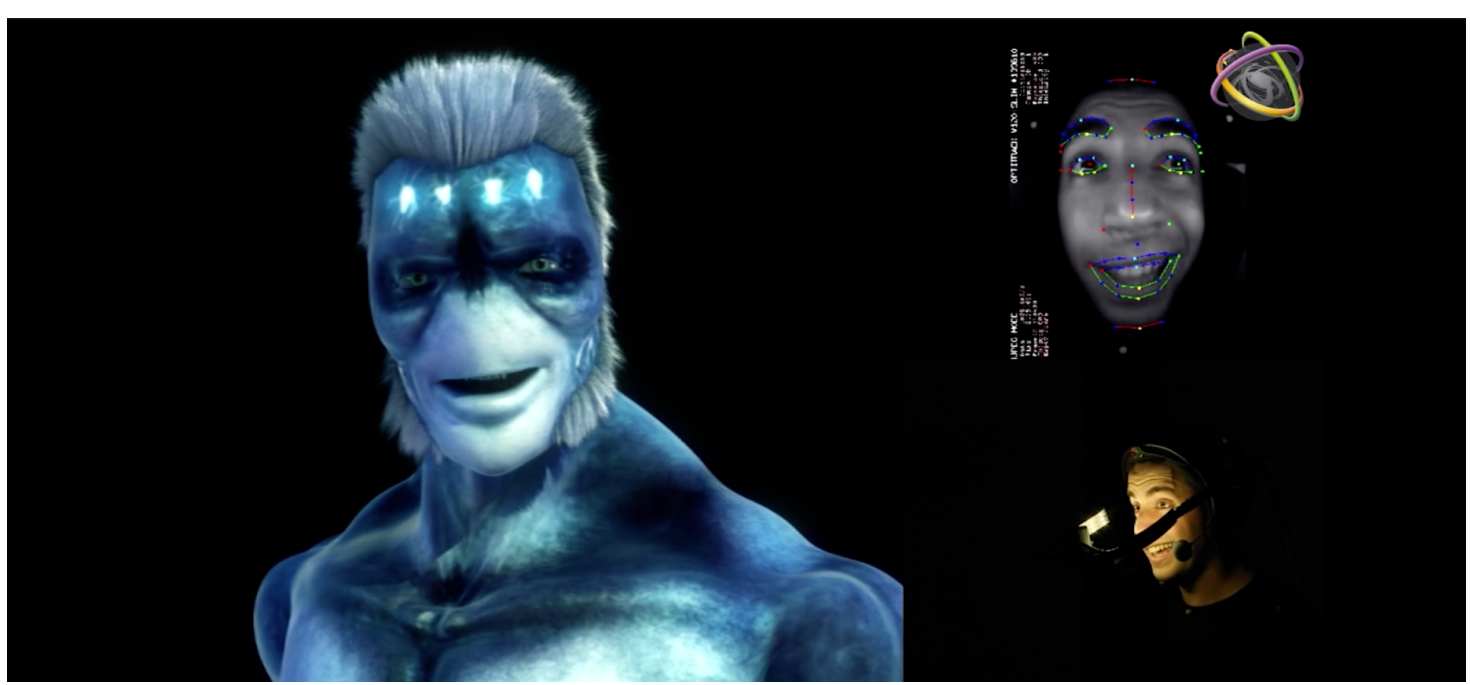

Figura 3.20: A imagem ilustra o cenário de captura da face utilizando o sistema da Dynamixyz. Imagem retirada do site da Dynamixyz.

Microsoft atualizou seu SDK para o desenvolvimento de aplicações utilizando o Kinect, sendo que agora é possível realizar rastreamento facial utilizando tal dispositivo. Vale salientar que de todas as soluções apresentadas, o Kinect não usa marcadores, pode ser obtido mais facilmente e com menor custo. Assim, foi ele o escolhido para ser usado no projeto.

\subsection{Resumo}

Levando em consideração que foram desenvolvidos dois protótipos, um focado no algoritmo para a simulação de maquiagem e outro na interação, como detalhado no capítulo 5, esta seção possui um resumo do estado da arte utilizando tabelas comparativas para os trabalhos sobre esses dois tópicos.

\subsubsection{Simulação de maquiagem}

Para o contexto do algoritmo de simulação de maquiagem, podemos analisar a tabela 3.1. Nela pode-se perceber que nenhum dos trabalhos abordados possui ao mesmo tempo as quatro características desejadas para o método de simulação de maquiagem que são: flexibilidade, baixo custo, realismo e tempo real. Na tabela, o critério de "Flexibilidade" diz respeito à possibilidade de aplicar uma maquiagem qualquer desejada pelo usuário em qualquer região da face, ou seja, a aplicação da maquiagem não está presa a um estilo ou produtos de maquiagem específicos. O critério de "Baixo custo" significa que o algoritmo para simular a maquiagem requer ou não o uso de algum equipamento especial (o artigo pode ter usado um dispositivo especial como em Kim e Choi (2008), mas ele não era estritamente necessário para o funcionamento do algoritmo). Para ser considerado "Realista", o artigo deve apresentar resultados convincentes para a simulação e quanto ao critério "Tempo real", o artigo deve descrever que seu algoritmo pode ser computado em tempo real. 


\begin{tabular}{|c|c|c|c|c|c|}
\hline Trabalho & Tipo & Flexível & Baixo custo & Realista & Tempo real \\
\hline Tong et al. (2007) & Transferência & Não & Sim & Possivelmente & Não especificado \\
\hline Guo e Sim (2009) & Transferência & Não & Sim & Possivelmente & Não especificado \\
\hline Scherbaum et al. (2011) & Transferência & Não & Sim & Possivelmente & Não especificado \\
\hline Dhall et al. (2009) & Simulação & Sim & Sim & Não & Sim \\
\hline Kim e Choi (2008) & Simulação & Sim & Sim & Não & Sim \\
\hline Huang et al. (2013) & Simulação & Sim & Não & Possivelmente & Sim \\
\hline
\end{tabular}

Tabela 3.1: Comparativo entre os métodos para simulação de maquiagem.

Com relação aos dois principais artigos que tratam sobre transferência de maquiagem, apesar do artigo de Guo e Sim (2009) ir além do trabalho de Tong et al. (2007), pois tenta extrair da face modelo o que seria a maquiagem e não apenas aprender a diferença entre a face modelo sem e com maquiagem, os dois artigos tratam sobre transferência de maquiagem e assim dependem de um exemplo da maquiagem já aplicada para realizar sua simulação. Dessa forma, eles não introduziram um modelo genérico que permitisse simular os efeitos da maquiagem no rosto de uma pessoa. Ambos também necessitam que a pose da face alvo seja parecida com a da imagem modelo e ficam restritos a aplicar o estilo de maquiagem da imagem modelo, não sendo possível simular a aplicação de diferentes maquiagens de forma independente. Essas características relacionadas à transferência de maquiagem também estão presentes no trabalho de Scherbaum et al. (2011), já que a simulação é baseada no método de Tong et al. (2007).

Quanto aos outros artigos, os trabalhos de Dhall et al. (2009), Kim e Choi (2008), se limitam a modelar a simulação dos efeitos da maquiagem na pele com uma média ponderada no espaço de cor HSV ou RGB. Essa abordagem, em geral, não trás resultados realistas. Já o trabalho de Huang et al. (2013), apesar de ser computacionalmente eficiente quando implementado em GPU, necessita conhecer propriedades ópticas da pele em que a simulação ocorrerá para seu funcionamento. Isso requer o uso de equipamentos especiais para cada usuário, o que limita a aplicação do método.

\subsubsection{Interação humano computador}

Para o contexto da interação do simulador de maquiagem, podemos analisar as tabelas 3.2 e 3.3. Na primeira tabela temos o comparativo com características da interação que estão relacionadas com a simulação de maquiagem e na segunda tabela temos algumas outras características importantes a serem consideradas.

Na tabela 3.2 temos a coluna "Simula maquiagem", nela indicamos se a interface proposta possui ou não a simulação de maquiagem. Para "Aplicação", diferenciamos os trabalhos que permitem aplicar uma maquiagem virtual qualquer livremente pela face dos que não permitem isso, nessa característica tivemos um trabalho que não tornou claro em seu texto como que a maquiagem era aplicada, então ele foi marcado como N.E. (Não Especificado). "Apresentação" significa a forma com que a imagem do usuário é apresentada para ele, ela 
pode ser por meio de um modelo 3D ou a própria imagem do usuário captada utilizando uma câmera. Quanto à coluna "Marcadores", esta especifica se o artigo utilizou algum tipo de marcador para rastrear a face ou algum outro objeto de interesse. Por fim, a coluna "Pronto para uso" esclarece se é possível usar a interface proposta imediatamente ou se é necessário algum processo de calibração ou criação de modelos antes de começar o uso do sistema.

Na tabela 3.3 temos a coluna "Alusão ao espelho", nela indicamos se a interface proposta faz uso ou não da metáfora do espelho para a interação. Para o critério "Social", indicamos os trabalhos apresentam recursos sociais como compartilhamento de fotos, sugestão e avaliação de maquiagens utilizadas por outros usuários. "Sugestão de produtos", significa que o modelo de interação proposto continha a sugestão de maquiagem para o usuário. Quanto à coluna "Custo"/, esta especifica o custo do projeto de acordo com os equipamentos utilizados, sendo que foi classificado como baixo custo os projetos que utilizaram apenas um computador e uma câmera simples (até dois mil reais), médio os que utilizaram outros sensores de custo não elevado, além do computador e câmera (até três mil reais), e alto para os que utilizaram equipamentos de custo elevado (maior que três mil reais). Por fim, a coluna Deficientes esclarece se o projeto possui alguma abordagem que auxilie portadores de deficiência.

\begin{tabular}{|c|c|c|c|c|c|}
\hline Trabalho & Simula maquiagem & Aplicação & Apresentação & Marcadores & Pronto para uso \\
\hline Kim e Choi $(2008)$ & Sim & Sim & Modelo 3D & Não & Não \\
\hline Iwabuchi et al. $(2009)$ & Não & - & Imagem & Sim & Sim \\
\hline Rahman et al. $(2010)$ & Sim & N.E. & Modelo 3D & Sim & Não \\
\hline Hanafusa et al. $(2010)$ & Não & - & Imagem & - & Sim \\
\hline Nakagawa et al. $(2011)$ & Não & - & Imagem & - & Sim \\
\hline
\end{tabular}

Tabela 3.2: Primeiro comparativo entre os trabalhos sobre interação no contexto de simulação de maquiagem. N.E. significa não especificado no artigo.

\begin{tabular}{|c|c|c|c|c|c|}
\hline Trabalho & Alusão ao espelho & Social & Sugestão de produtos & Custo & Deficientes \\
\hline Kim e Choi $(2008)$ & Não & Não & Não & Alto & Não \\
\hline Iwabuchi et al. $(2009)$ & Sim & Sim & Não & Médio & Não \\
\hline Rahman et al. $(2010)$ & Sim & Não & Sim & Médio & Não \\
\hline Hanafusa et al. $(2010)$ & Não & Não & Não & Baixo & Sim \\
\hline Nakagawa et al. $(2011)$ & Não & Sim & Sim & Médio & Não \\
\hline
\end{tabular}

Tabela 3.3: Segundo comparativo entre os trabalhos sobre interação no contexto de simulação de maquiagem.

O modelo de interação proposto neste trabalho contempla uma interface que faz alusão a um espelho para aplicar independentemente os produtos de maquiagem desejados em qualquer região da face tocada no espelho. Por estar maquiando a imagem do reflexo do espelho, o sistema deve realizar a simulação em um vídeo da imagem do usuário e deve manter o correto posicionamento da maquiagem conforme o usuário movimenta a face em frente ao espelho sem o uso de marcadores. Ao analisar a tabela, logo pode-se perceber que existe apenas um trabalho que faz alusão ao espelho e também simula maquiagem, 
Rahman et al. (2010). Nesse trabalho o reflexo do espelho é um modelo 3D do usuário que mimetiza seus movimentos e a maquiagem é simulada nesse modelo. Além disso, existe a necessidade de marcadores para o adequado funcionamento do sistema. Ou seja, o usuário precisa passar por algumas etapas preparatórias antes de iniciar o uso do sistema como criar seu modelo 3D, que não será tão realista quanto a imagem da câmera, e posicionar marcadores.

O outro trabalho que realiza simulação de maquiagem é o artigo de Kim e Choi (2008) que se propõe a criar um sistema interativo para aplicar maquiagem em um modelo 3D com feedback háptico e visão estéreo e portanto não faz alusão ao espelho. O dispositivo háptico utilizado serve para a aplicar a maquiagem no modelo 3D do usuário e além dele outros equipamentos são utilizados encarecendo os custos como escâneres 3D e monitor 3D.

Entre os outros artigos, o trabalho de Iwabuchi et al. (2009) apesar de fazer alusão ao espelho, não realiza a simulação de maquiagem. O trabalho apresenta uma espécie de espelho com funcionalidades a mais que um espelho comum e utiliza marcadores para os objetos utilizados. O trabalho de Nakagawa et al. (2011) tem um enfoque mais social e de recomendação de produtos. Esse artigo não usa a metáfora do espelho, já que faz uso de espelhos reais para que o usuário se maqueie de forma real e use o monitor apenas para se fotografar, compartilhar suas imagens e ver indicações de produtos. Por fim, o artigo de Hanafusa et al. (2010) ensina um deficiente visual a aplicar a maquiagem e depois confere se ela foi aplicada adequadamente. Apesar de ser um trabalho bastante interessante, ele não se encaixa tão bem nos critérios, já que tem um enfoque diferente do tema desse trabalho. 


\section{Capítulo 4}

\section{Sistema Proposto}

Neste trabalho, o termo maquiagem será utilizado para representar os produtos de maquiagem e o verbo maquiar representará a aplicação desses produtos. A representação computacional de cada produto de maquiagem será chamada de maquilet e conterá as propriedades responsáveis pelo efeito que esse produto causa na pele.

Para modelar o problema de simulação de maquiagem, seja $I$ a imagem de entrada sem maquiagem contendo a face $F, R$ a imagem resultante após a simulação de maquiagem, $M$ o conjunto de maquiagens a serem aplicadas e $m$ cada uma das maquiagens pertencentes a $M$. Cada $m$ corresponde à representação computacional da maquiagem real utilizada para a simulação, um maquilet. Além disso, seja $m_{\alpha}$ a intensidade padrão de cada maquilet a ser aplicado e $m_{\text {asc }}$ a imagem correspondente à máscara que define o local de aplicação de $m$ e suas variações de intensidade. Tanto $I$ quanto $R$ podem ser descritos adicionando $R G B$ para designar que estão no espaço de cor $\operatorname{RGB}\left(I_{R G B}, R_{R G B}\right)$ ou $L a^{*} b^{*}$ para designar que estão no espaço de cor La*b* $\left(I_{L a^{*} b^{*}}, R_{L a^{*} b^{*}}\right)$.

Assim, podemos definir a simulação de maquiagem como o processo que compõem a imagem $R$ com a face $F$ maquiada com $M$ a partir de $I, I \stackrel{M}{\rightarrow} R$.

\subsection{Contextualização}

As pessoas que utilizam maquiagem precisam experimentar tais cosméticos para decidirem quais utilizar em determinadas situações. Esse processo é realizado de forma manual, aplicando produtos reais na face e observando os resultados até que se encontre uma combinação de produtos satisfatória. O objetivo é criar um simulador que permita ao usuário experimentar tais produtos de uma maneira mais fácil e conveniente, podendo observar os resultados de forma rápida (sem a necessidade de preparação, além da aplicação e remoção da maquiagem ocorrerem instantaneamente) e barata (não é necessário comprar o produto ou gastar produtos já existentes).

Os usuários desse sistema são pessoas que utilizam maquiagem, sejam elas as que recebem a aplicação virtual dos produtos ou as pessoas que trabalham com maquiagem, como, por 
exemplo, vendedores desse tipo de produto ou maquiadores. Isso engloba desde pessoas jovens até idosos, com conhecimento variável sobre maquiagens e podem ter familiaridade, ou não, com dispositivos eletrônicos ou de computação. O objetivo do usuário que utiliza maquiagem é estético, ou seja, tem a intenção de aparentar ser mais atraente, elegante ou bonito.

O principal uso do simulador por vendedores e maquiadores seria auxiliando seus clientes a utilizarem o sistema para ilustrar o resultado dos produtos vendidos por eles ou do estilo de maquiagem proposto pelo maquiador antes da aplicação dos produtos. Para o cenário do vendedor, hoje a aplicação dos cosméticos é feita manualmente em frente a um espelho, para que os clientes provem os produtos. Para o caso do maquiador, hoje existe uma explicação verbal sobre o estilo de maquiagem desejado pelo cliente ou sugerido pelo maquiador, ou então a ilustração desse estilo em fotografias de pessoas já maquiadas com ele. À medida que os produtos são aplicados, o cliente pode conferir os resultados nos espelhos do salão de beleza.

Sem a ajuda desses profissionais, o cenário típico do uso desses produtos de maquiagem ocorre em frente a um espelho que é útil tanto para auxiliar o posicionamento e a aplicação da maquiagem quanto para avaliar o resultado.

\subsection{Arquitetura}

A figura 4.1 apresenta a arquitetura geral do sistema proposto. Nela nota-se que o sensor RGBD utilizado (ilustrado pelo Kinect) fornece dois tipos de dados (cinza), o vídeo da câmera RGB que conterá a imagem da face do usuário, $I_{R G B}$, e a localização de pontos faciais da face do usuário que são utilizados na triangularização (verde). Em azul, temos os modelos a serem usados na simulação, o modelo de face é criado a partir dos dados da triangularização. Já as maquiagens a serem simuladas, $M$, são modeladas pelos maquilets correspondentes a essas maquiagens. A partir da imagem da face do usuário juntamente com o modelo de face e os maquilets, o módulo Simulação (verde) realiza a simulação de maquiagem na imagem da face do usuário que é exibida pela interface (laranja) possibilitando a interação do usuário com o sistema.

O módulo Simulação será tratado na seção 4.4 e o restante do sistema, responsável pela interação, na seção 4.3. No capítulo 5 serão apresentados mais detalhes do funcionamento de todos os módulos.

\subsection{Interação}

Dado que um dos objetos mais utilizados ao experimentar produtos de maquiagem é o espelho, inicialmente, o modelo de interação para o simulador de maquiagem foi baseado na metáfora do espelho. Além dela, as pessoas costumam utilizar os dedos ou outros ins- 


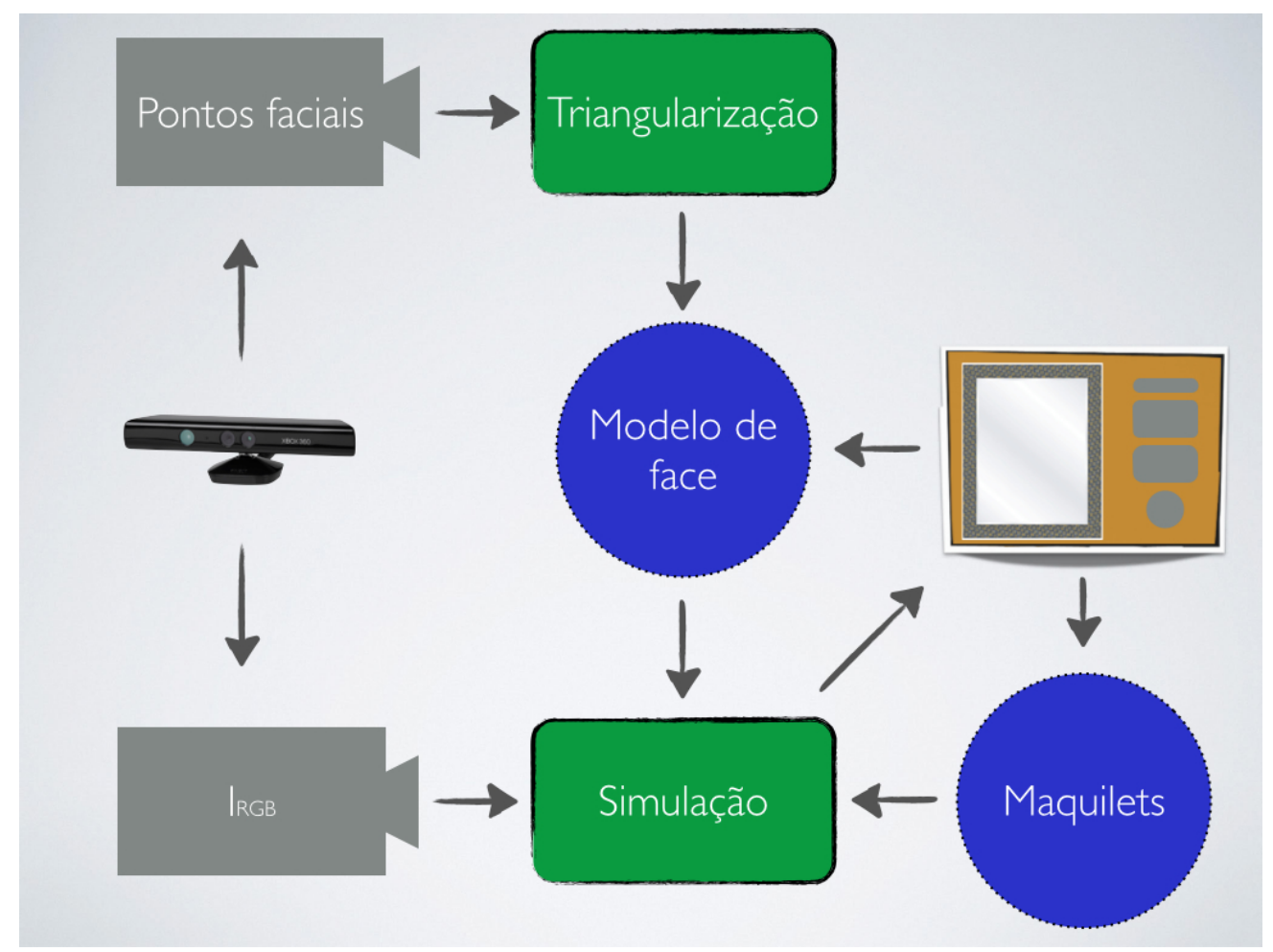

Figura 4.1: Arquitetura geral.

trumentos de maquiagem, como pincéis de maquiagem, para aplicar a maquiagem na face sendo que cada produto de maquiagem é aplicado na pele de forma independente, na região e quantidade desejada pelo usuário. Assim, também foi considerado o uso de gestos para a aplicação da maquiagem no simulador.

Entretanto, para simplificar a complexidade computacional da interação, decidiu-se por utilizar o toque na tela para aplicar a maquiagem. Desta forma, a metáfora do espelho é quebrada, já que para aplicar a maquiagem é necessário tocar o espelho e não a face, porém ainda é possível manter a liberdade de aplicação da maquiagem na face.

Sendo assim, a interação para o simulador de maquiagem foi pensada de tal forma que ela fosse semelhante à interação que uma pessoa tem ao se maquiar utilizando um espelho. Assim, o intuito é que o usuário seja capaz de se maquiar livremente, escolhendo os tipos de maquiagens, suas cores e intensidades para combiná-las e aplicá-las em qualquer lugar de sua face. Além da liberdade de aplicação, o aparato a ser usado deve fazer a alusão ao espelho e utilizar os equipamentos disponíveis no laboratório. Desta forma, a interface a ser desenvolvida para essa dissertação é constituída por:

- um computador com monitor sensível a toque;

- um sensor RGBD (Kinect).

Acima do monitor, posiciona-se o sensor RBGD, responsável por prover as imagens e outros dados para a simulação. O computador com monitor sensível a toque fará o papel de espelho e também exibirá a interface para a escolha da maquiagem e suas características. 
Para isso, a interface foi dividida em duas regiões, a região de espelho e a região de controles como pode ser observado na figura 4.2. Utilizando o toque na tela, pode-se escolher o produto e outras características para a aplicação da maquiagem que é realizada tocando o monitor na região do rosto desejada para sua aplicação. Caso o usuário permaneça com seu dedo em um mesmo local da face ou toque essa região múltiplas vezes, a maquiagem será intensificada proporcionalmente ao tempo ou ao número de vezes em que o local foi tocado. Para facilitar a aplicação, a região dos controles permite que o usuário possa congelar a imagem do espelho para aplicar os cosméticos. Desta forma, não existe a necessidade de manter a face imóvel enquanto a maquiagem é aplicada. Além disso, também existe a possibilidade de salvar a imagem da simulação de maquiagem, alterar entre modos de exibição (por exemplo comparar antes e depois da simulação) e definir o tipo de traçado a ser simulado por meio da escolha do produto de maquiagem, seu modo de aplicação (aplicar, suavizar, remover), instrumento, quantidade e pressão com que o produto de maquiagem será aplicado na simulação.

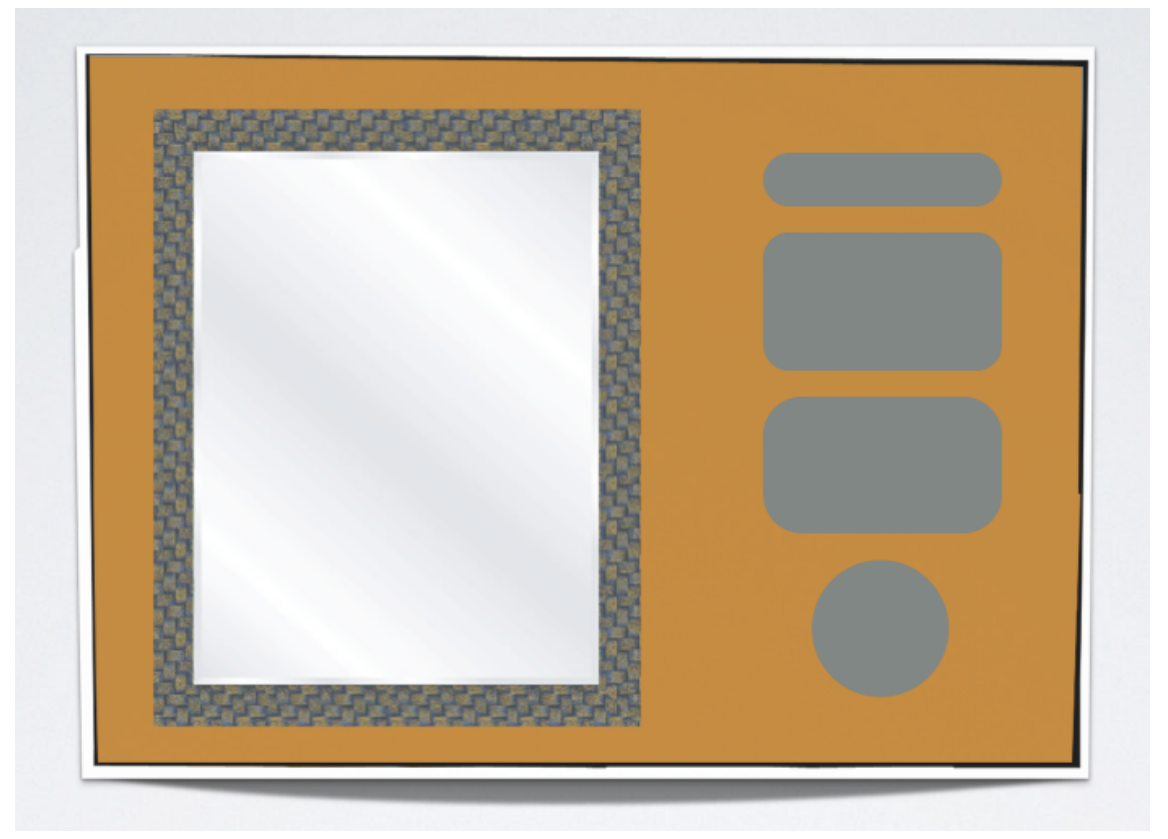

Figura 4.2: À esquerda a região do espelho e à direita a região dos controles.

\subsection{Simulação de maquiagem}

O método proposto para a simulação de maquiagem é capaz de simular o resultado da aplicação de maquiagem na pele da face em uma imagem do rosto do usuário, simulando a alteração das propriedades óticas e de textura da pele causadas pela maquiagem, o que modifica a forma com que a face é percebida.

Como ideia geral, o processo de simulação funciona decompondo a imagem da face em diversas camadas que são tratadas independentemente para simular o efeito desejado da maquiagem real. Cada camada, ou grupo de camadas, separa cada característica a ser simulada e é responsável por tratar essa questão específica. 
Usando essa abordagem, pode-se isolar cada questão, como textura da pele, cor da pele, especularidade, pelos faciais e iluminação não uniforme, tratando-as de forma independente sem que uma interfira na outra. Além disso, o uso dessa abordagem facilita futuras melhorias e expansões do método, já que basta criar novas camadas, e também permite um melhor controle do equilíbrio entre qualidade da simulação e custo computacional do método, permitindo utilizar ou não utilizar determinadas camadas de acordo com a capacidade de processamento do dispositivo.

Para esse projeto, a simulação de maquiagem se concentrará em alterar a textura da pele e mudar sua cor. Assim, o módulo de simulação foi dividido em dois submódulos, Textura e Cor. O primeiro é responsável por tornar o tom de pele mais uniforme e suavizar ou realçar os detalhes da pele e o segundo pela introdução da cor da maquiagem. Dadas as características adotadas para cada tipo de maquiagem a ser simulada nessa dissertação definido na seção 2.6, não será necessário realçar detalhes faciais, apenas suavizá-los, assim, não será apresentado neste trabalho o tratamento correspondente ao realce de textura.

O primeiro módulo do processo de simulação, chamado de Textura, é responsável pela suavização dos detalhes faciais e a homogeneização do tom de pele, características da aplicação de base. A partir de $I_{R G B}$ tal imagem é dividida em cinco camadas distintas, cada uma representando uma faixa diferente de frequência, sendo que o número de camadas foi obtido de forma empírica. A imagem da camada com os detalhes faciais mais sutis, maior frequência, $C_{f A}$, não deve ser alterada já que esses detalhes caracterizam a face do indivíduo e também são preservados pela maquiagem real. O mesmo acontece para a imagem que representa a faixa de baixa frequência, $C_{f B}$, ou seja, ela também não é alterada. Assim, restam três outras faixas de frequências em que a simulação atua. Todas as suavizações seguem o referencial de intensidade estabelecido por $m_{a s c}$, porém existe uma diferenciação entre a intensidade da suavização aplicada para cada camada. A maior suavização ocorre para a camada de frequência intermediária $3, C_{f 3}$, principal responsável pela homogeneização do tom de pele. A camada de frequência intermediária $2, C_{f 2}$, recebe uma suavização um pouco menor e a camada de frequência intermediária $1, C_{f 1}$, uma suavização menor do que a anterior. Com isso, consegue-se mimetizar o efeito da maquiagem suavizando os detalhes e tons de pele sem que isso resulte em uma aparência artificial. O diagrama de blocos desse módulo pode ser observado na figura 4.3.

Para dividir $I_{R G B}$ em cinco faixas de frequência, é utilizado o filtro gaussiano que atua como um filtro passa baixa. Ao aplicar o filtro gaussiano em $I_{R G B}$, tem-se uma nova imagem $G 1$. Ao subtrair $G 1$ de $I_{R G B}$, teremos a imagem com a primeira faixa de frequência, $C_{f A}$, que conterá a faixa das altas frequências do espectro dessa imagem. Continuando o processo, aplicamos novamente o filtro gaussiano na imagem $G 1$ criando $G 2$. Ao subtrair $G 2$ de $G 1$, temos uma imagem correspondente a uma outra faixa de frequências intermediárias dessa imagem, $C_{f 1}$. Repetindo o procedimento, obtém-se $C_{f 2}, C_{f 3}$ e $C_{f B}$ como ilustrado na figura 4.4 .

Já o segundo módulo, chamado de Cor, é responsável pela simulação da cor da maquia- 


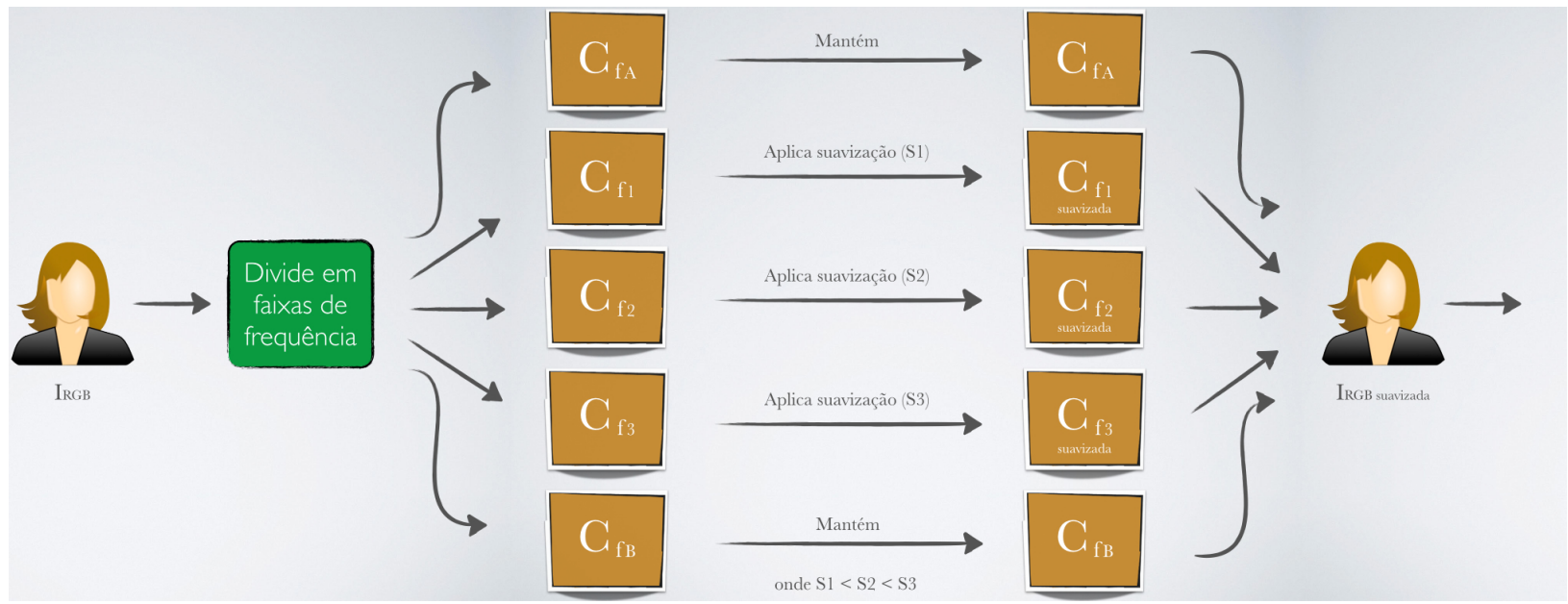

Figura 4.3: Fluxo da simulação de maquiagem - Textura.

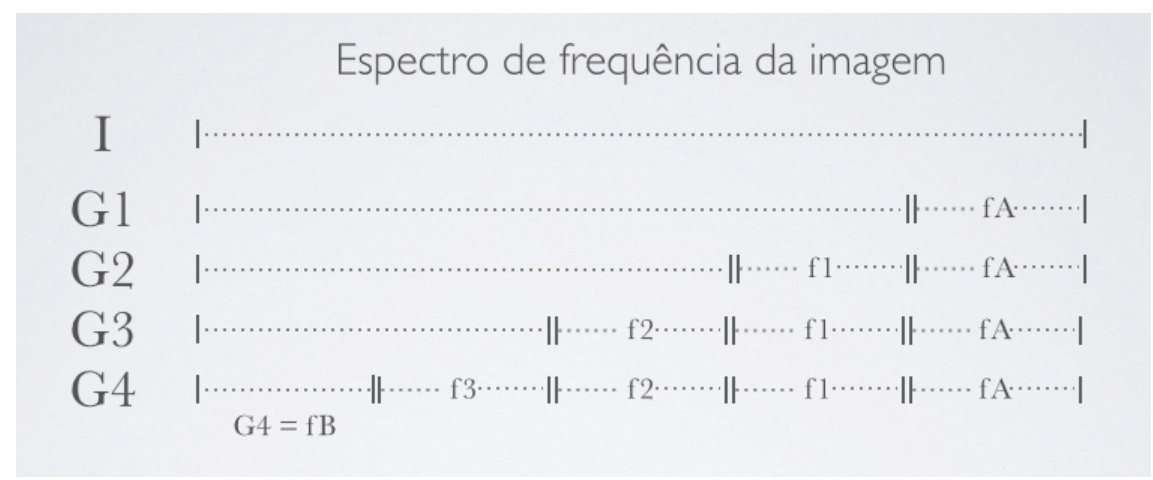

Figura 4.4: Divisão da imagem da face em cinco faixas de frequência a serem tratadas independentemente.

gem. Para isso, $I$ é transformada para o espaço de cor La*b* $I_{L a^{*} b^{*}}$. Neste espaço, cada um dos canais torna-se uma camada e é tratada de forma independente. O canal L, $C_{L}$, permanece como o original, já que o objetivo é alterar apenas as cores da imagem preservando sua iluminação. Para o canal a* $C_{a^{*}}$, é calculada uma média ponderada para cada pixel com o mesmo canal de uma imagem com a cor do maquilet correspondente. De forma análoga, o mesmo procedimento é realizado para o canal b*, $C_{b^{*}}$. Por fim, pode-se converter a imagem novamente para o espaço de cor RGB, $I_{R G B}$, caso seja esse o espaço utilizado na interface. O diagrama de blocos desse módulo pode ser observado na figura 4.5.

A média ponderada em questão é calculada de acordo com a equação 4.1 onde $r_{p}$ é o valor resultante para cada pixel da imagem que representa a aplicação de $m, I_{p}$ o valor da cor inicial para cada pixel da imagem de entrada $I$ e $m_{c}$ o valor de cor do maquilet que está sendo aplicado.

$$
r_{p}=\left(1-\alpha_{p}\right) * I_{p}+\alpha_{p} * m_{c}
$$

O valor de $\alpha_{p}$ não é constante para todos os pixels, pois deve acomodar o efeito da variação da intensidade da maquiagem aplicada no local, possibilitando intensificar a aplicação do produto em determinadas regiões do rosto em que a maquiagem for aplicada mais de uma 


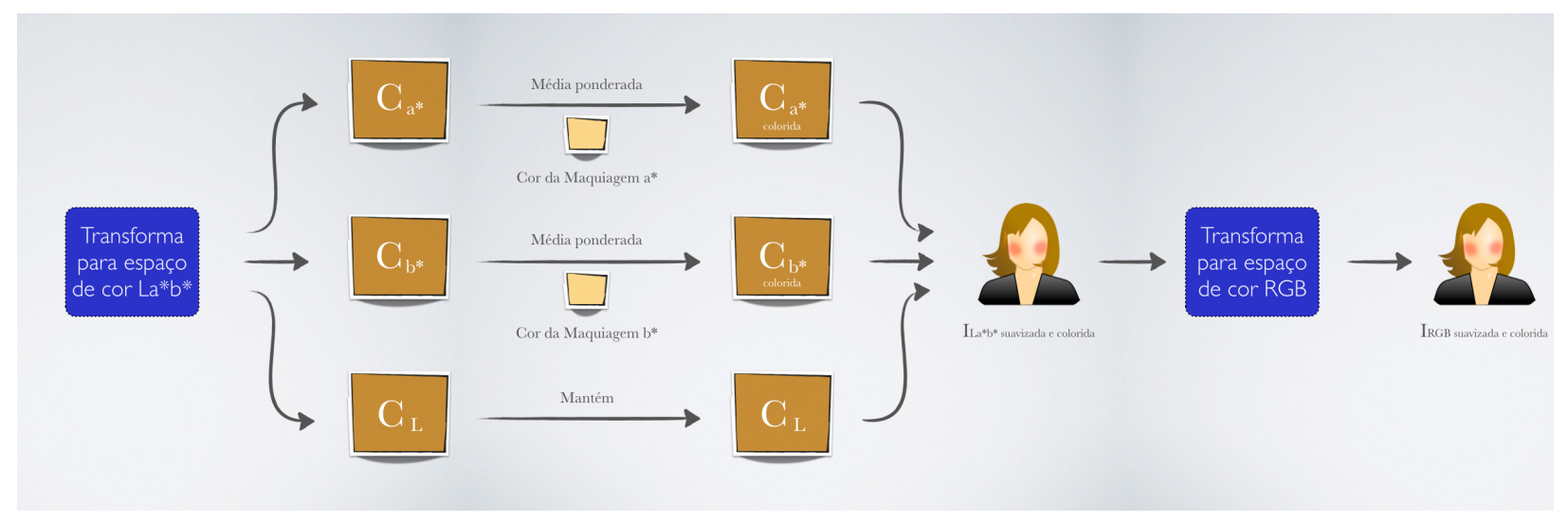

Figura 4.5: Fluxo da simulação de maquiagem - Cor.

vez ou então suavizar outras regiões criando degradês. O valor de $\alpha_{p}$ é calculado seguindo a equação 4.2

$$
\alpha_{p}=m_{\alpha} *\left(m_{a s c_{p}} / v m p\right)
$$

sendo $m_{a s c_{p}}$ o valor da intensidade do pixel da máscara do maquilet que é criada de acordo com o tempo e número de vezes que o usuário toca a tela do monitor sensível ao toque. Como os valores possíveis para cada pixel de $m_{a s c}$ são representados por um byte e o valor de $m_{\alpha}$ está compreendido entre 0 e 1, o valor do pixel da máscara foi dividido pela constante $v m p$ (valor máximo do pixel) que vale 255 para que o valor de $\alpha_{p}$ também esteja entre 0 e 1.

Com relação à cor de $m$, ela pode ser escolhida livremente pelo usuário para que ele crie a maquiagem que deseja ou então ele pode escolher valores pré-determinados que simulam maquiagens reais.

Com esses dois módulos, o algoritmo criado é capaz de simular a aplicação de base, sombra e batom. A simulação para o maquilet de base utiliza todo o algoritmo, Textura e Cor, já os maquilets de sombra e batom necessitam apenas da etapa Cor, pois seu comportamento na pele afeta predominantemente as cores como definido na seção 2.6. 


\section{Capítulo 5}

\section{Prototipação}

Para que fosse possível obter maior flexibilidade na escolha das técnicas utilizadas e consequentemente possibilitar a percepção de todos os detalhes da aplicação da maquiagem na pele, o ideal seria utilizar computadores de altíssimo desempenho, um sensor RGBD com grande resolução de imagem e qualidade óptica e também implementações específicas para o propósito do projeto para que se pudesse explorar todo o poder computacional e toda a qualidade de imagem disponível.

Entretanto, os recursos de tempo e de hardware não são ilimitados. Assim, utilizou-se como sensor RGBD o Microsoft Kinect e como monitor sensível a toque um dos computadores do laboratório que possui tal funcionalidade.

Para contornar as limitações de recursos, foram criados dois protótipos: um focado no algoritmo para a simulação de maquiagem, Simulação de Maquiagem, e outro focado na interação, Interação. Portanto, a Interação utilizará um procedimento bastante simples para simular a maquiagem com o objetivo de poupar processamento e a Simulação de Maquiagem ficará restrita apenas ao método para simulação da maquiagem, também poupando processamento por não conter outros procedimentos utilizados para a interação. Nos dois casos, os protótipos foram implementados utilizando a linguagem de programação $\mathrm{C}++$, bem como a biblioteca OpenCV (Bradski, 2000) que contém diversas funções básicas de processamento de imagens e visão computacional.

Apesar de independentes, os dois protótipos são facilmente combináveis já que o sistema foi pensando como um todo e apenas separado durante a prototipação para explorar melhor os recursos disponíveis e assim demonstrar a viabilidade do projeto. O elo de ligação entre os dois protótipos são os modelos (face e maquilets), representados na figura 5.1 pela $m_{\text {asc }}$, necessitando apenas da evolução do poder computacional do hardware para que se possa unir os dois utilizando o ponto forte de cada um deles. 


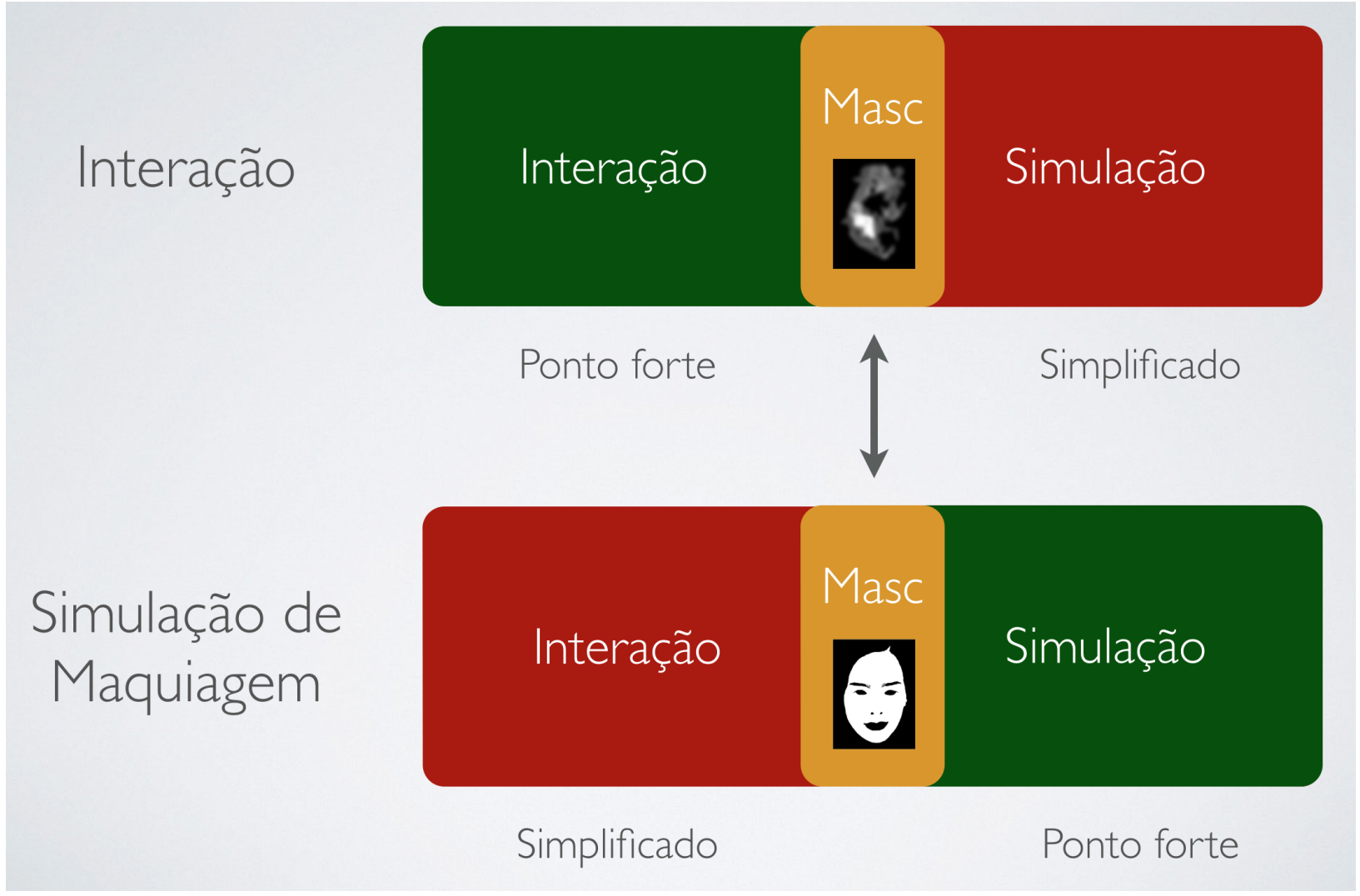

Figura 5.1: Pontos fortes e fracos dos protótipos da Interação e da Simulação de Maquiagem, bem como seu elo de ligação para junção dos dois protótipos em um só, quando a capacidade computacional do hardware permitir.

\subsection{Interação}

Para a prototipação do projeto, dada a separação da interação do algoritmo de simulação de maquiagem, foi necessário simplificar o módulo Simulação apresentado na figura 4.1 para a Interação. A simplificação consistiu em tornar o método de simulação de maquiagem computacionalmente mais econômico o que também reduziu o realismo da simulação, mas garantiu que o vídeo usado como imagem do espelho fosse fluido e permitisse a utilização apropriada da interface.

Para possibilitar a interação, foi desenvolvido um software específico para essa parte do projeto que deve ser capaz de:

- gerar um vídeo em tempo real para a imagem a ser usada como espelho exibindo os efeitos da maquiagem;

- simular a maquiagem de forma simplificada para economizar processamento;

- encontrar os mesmos pontos faciais em cada quadro do vídeo da imagem do rosto do usuário de forma automatizada e sem o uso de marcadores;

- gerar a triangularização baseado nos pontos faciais encontradas para a face; 
- aplicar cada tipo de maquiagem independentemente dos demais permitindo sua composição interativamente.

Além disso, tem-se as seguintes limitações:

- simulação de sombra, batom e base;

- condições controladas de iluminação para que ela seja uniforme;

- usuário não usará óculos ou algum outro acessório que possa cobrir toda ou parte de sua face;

- usuário não possuirá pelos faciais cobrindo características relevantes da face;

- Kinect possui uma limitação de funcionamento em que o usuário deve ficar a pelo menos $80 \mathrm{~cm}$ do dispositivo para que ele funcione adequadamente.

Para criar o software da Interação foi utilizada a versão 1.8 do SDK da Microsoft para o Kinect (Microsoft). O sistema utiliza $82 \mathrm{~ms}$ para cada quadro do vídeo a ser computado o que resulta em 12 quadros por segundo para o vídeo da interface. Esses resultados foram obtidos por meio de testes realizados em um notebook com processador Core i7 2,6 GHz utilizando a imagem do próprio Kinect que possui 640x480 pixels. Para a Interação, não se fez uso de processamento paralelo para diminuir o tempo de computação do sistema.

\subsubsection{Triangularização e Modelo de face}

Como pode ser observado em 4.1 o Kinect é o sensor RGBD que fornece a imagem e os dados de rastreamento da face (pontos faciais) que são obtidos utilizando o SDK do Kinect. Com os pontos faciais e mais algumas funções do mesmo SDK, é possível obter uma triangularização inicial da face.

A triangulação obtida usando o SDK do Kinect fornece 206 triângulos espalhados por toda a face como pode ser observado nas figuras 5.2a e 5.2b. Como o objetivo com a triangularização é obter uma maneira para manter o posicionamento da maquiagem aplicada na face do usuário durante a movimentação de seu rosto, quanto maior for o número de triângulos gerados pela triangularização, mais preciso será o mapeamento da maquiagem na face do usuário. Nesse protótipo, o mapeamento foi realizado atribuindo para cada triângulo cada maquilet que foi aplicado nessa posição e que deve ser simulado nessa região da face ocupada pelo triângulo.

Para aumentar a precisão, os 206 triângulos foram subdivididos uma vez, sendo que, para cada subdivisão, a região era repartida em 6 novos triângulos totalizando 1236 triângulos ao final do procedimento, que podem ser observados na figura $5.2 \mathrm{c}$ e $5.2 \mathrm{~d}$. A subdivisão foi realizada da seguinte forma, dado um triângulo $T$, com vértices $A, B$ e $C$, pontos médios $X$ 


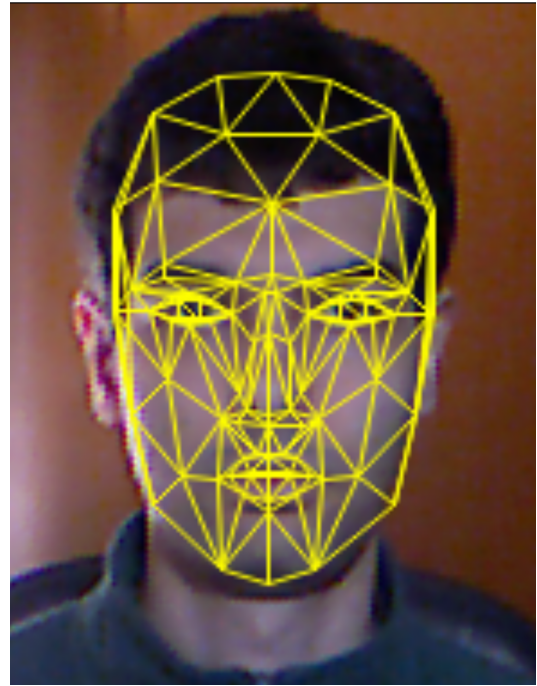

(a)

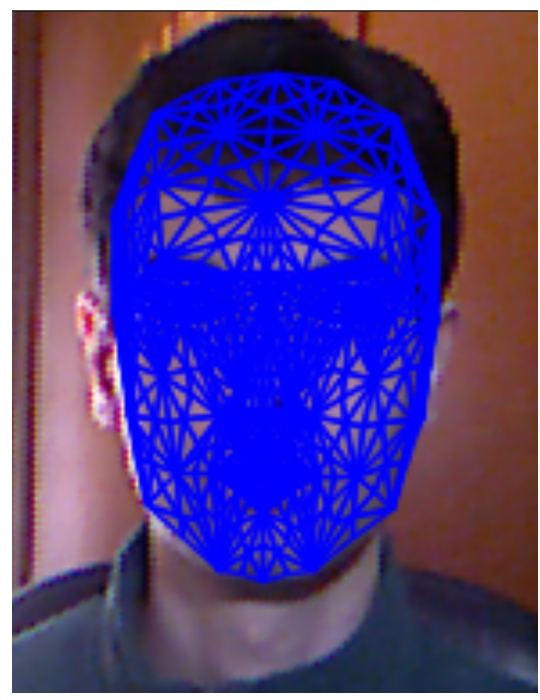

(c)

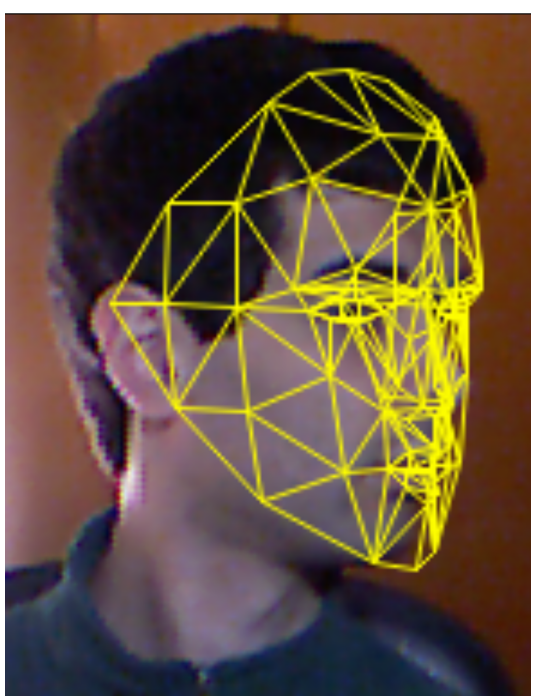

(b)

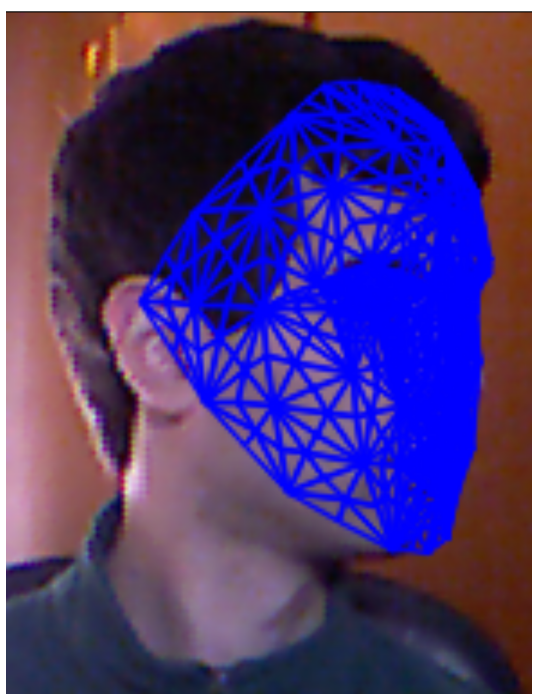

(d)

Figura 5.2: (a) triangularização obtida apenas com as funções do SDK do Kinect, vista frontal; (b) triangularizaçâao obtida apenas com as funçôes do SDK do Kinect, vista lateral; (c) triangularizaçẫo final, vista frontal; (d) triangularização final, vista lateral.

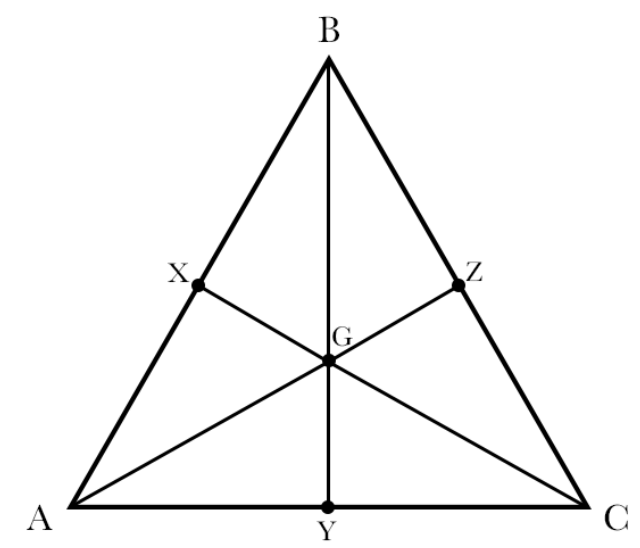

Figura 5.3: Um exemplo de subdivisão de um triângulo $A B C$. 
(aresta $\overline{A B}$ ), $Y$ (aresta $\overline{A C}$ ) e $Z$ (aresta $\overline{B C}$ ) e com baricentro $G$ os triângulos formados são $A G X, G X B, B G Z, Z G C, C G Y$ e $Y G A$. A figura 5.3 ilustra um exemplo de subdivisão.

A partir das informações sobre os pontos faciais, sua triangularização e locais de aplicação da maquiagem é construído o Modelo de face usado pela simulação de maquiagem.

\subsubsection{Simulação de maquiagem}

No módulo Simulação, é realizada a simulação da aplicação de maquiagem de forma simplificada utilizando os dados do Modelo de face e dos Maquilets a cada quadro do vídeo provido pelo Kinect.

Para a simulação da maquiagem deve-se criar para cada maquilet a ser simulado sua $m_{a s c}$, a máscara responsável por definir o local de aplicação de $m$ e suas variações de intensidade (figura 5.4a). A máscara possui as mesmas dimensões da imagem RGB do Kinect, 640x480 pixels, e define o local e a intensidade da maquiagem de acordo com o valor do pixel nesse local. Pixel com valor zero representa ausência de maquiagem e pixel com valor maior do que zero representa o oposto, sendo que o valor do pixel retrata a intensidade de $m$ nessa posição da imagem. Então, para cada triângulo que possui um maquilet associado, a $m_{\text {asc }}$ correspondente é atualizada para que seja maquiada a região delimitada pelo triângulo com a intensidade descrita pelo maquilet.

Caso o usuário permaneça com o dedo em um mesmo local da face ou toque mais de uma vez em um mesmo triângulo com o mesmo maquilet, a cor correspondente ao $m$ dessa região será intensificada gradualmente, de acordo com o número de vezes em que a maquiagem for aplicada nesse local. Para o caso de maquilets diferentes em um mesmo triângulo, as cores serão misturadas, já que a aplicação da maquiagem é realizada em sequência uma para cada maquilet.

Para evitar possíveis imprecisões com relação a qual pixel corresponde a qual triângulo nas regiões de borda entre eles, foi aplicada a operação morfológica de dilatação em $m_{\text {asc }}$. Além disso, para evitar regiões de transição brusca entre as áreas que recebem maquiagem (os triângulos) e as que não recebem, foi aplicada uma suavização gaussiana em $m_{\text {asc }}$. Um exemplo do resultado desse procedimento pode ser visto na figura 5.4b.

A aplicação da maquiagem foi modelada como uma média ponderada, no espaço de cor RGB, entre o valor do pixel da imagem da face (apenas para os pixels delimitados por $m_{a s c}$ ) e o valor de cor da maquiagem desejada. Por fim, a imagem resultante desse processo é exibida pela interface. Um exemplo do resultado pode ser observado em 5.4c.

\subsubsection{Interface e maquilets}

A interface do protótipo desenvolvido foi baseada em um monitor widescreen e portanto tem proporção de 16:9. Das 16 partes para a largura, 10 foram utilizadas para a região da imagem da face do usuário em alusão ao espelho na parte esquerda do monitor, região do 


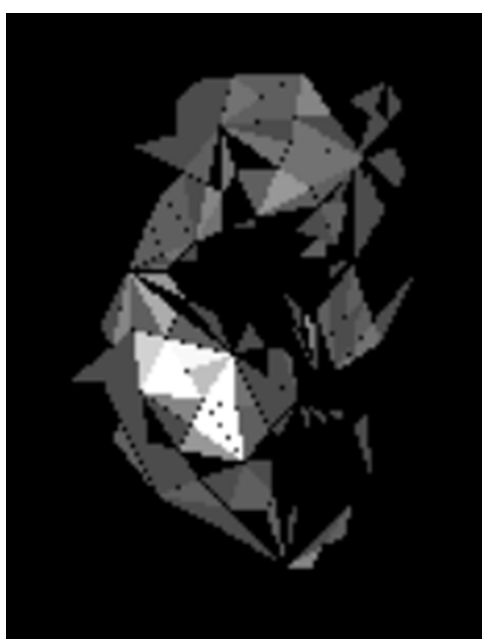

(a)

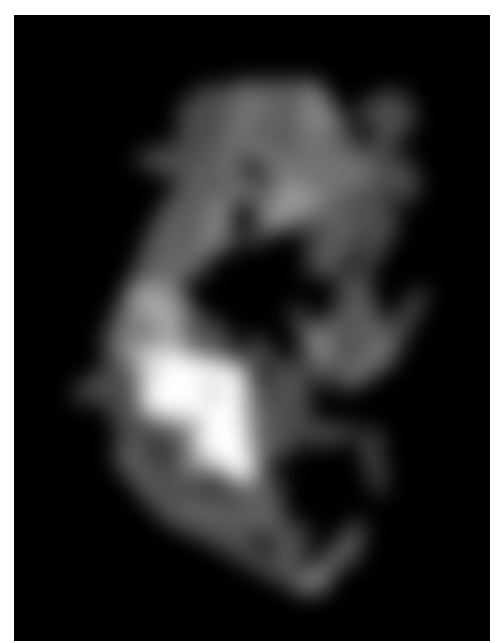

(b)

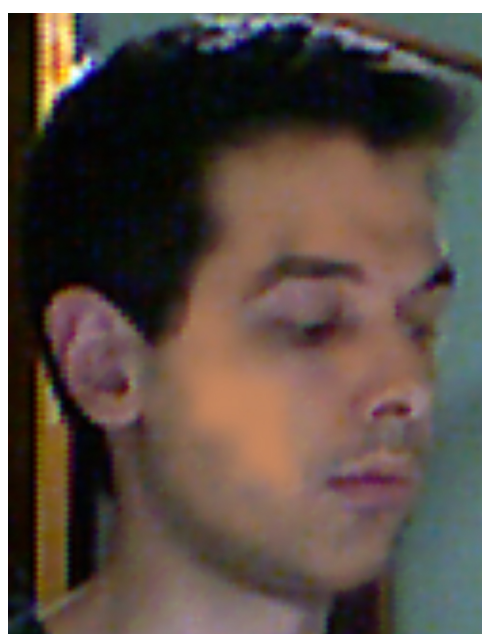

(c)

Figura 5.4: (a) Exemplo de máscara para o protótipo da interação criada a partir do toque do usuário na imagem da face; (b) Mesma máscara de (a) após operação de dilatação e suavização; (c) Resultado da aplicação de maquiagem para o protótipo da interação considerando a $m_{\text {asc }}$ apresentada em (b).

espelho, e as 6 partes restantes foram alocadas para as opções necessárias para a escolha das maquiagens desejadas e suas características, região de controles. Devido à pequena resolução da imagem RGB do Kinect, foi necessário aumentá-la em 5 vezes para que a face cobrisse toda a região dedicada a ela.

A interface apresenta as opções para todo tipo de controle necessário para simular a maneira com que a maquiagem escolhida é aplicada ou removida da pele. Para a prototipação, os esforços foram concentrados nas funcionalidades básicas, como a escolha da maquiagem e sua aplicação. A partir das escolhas relacionadas aos produtos de maquiagem que o usuário faz na interface, são criados os maquilets correspondentes a cada um desses produtos. Eles contém informações do tipo de produto, cor e intensidade da maquiagem que eles representam.

Pode-se ver a disposição dos equipamentos para a interação na figura 5.5 e também a região de espelho e de controles da interface.

\subsection{Simulação de maquiagem}

Considerando esse módulo de forma independente do resto do sistema, algumas adaptações foram necessárias frente ao que foi apresentado no capítulo 4 . Na imagem da arquitetura geral, 4.1, o módulo Simulação recebia um vídeo e fazia uso do Modelo de Face e de Maquilets. Agora, no lugar do vídeo temos uma imagem da face do usuário, o Modelo de Face não é utilizado já que o posicionamento da maquiagem é fixo e associado à $m_{a s c}$, e continuamos a utilizar os maquilets.

Com relação à máscara $m_{a s c}$, ela é específica para cada imagem em que se simulará a 


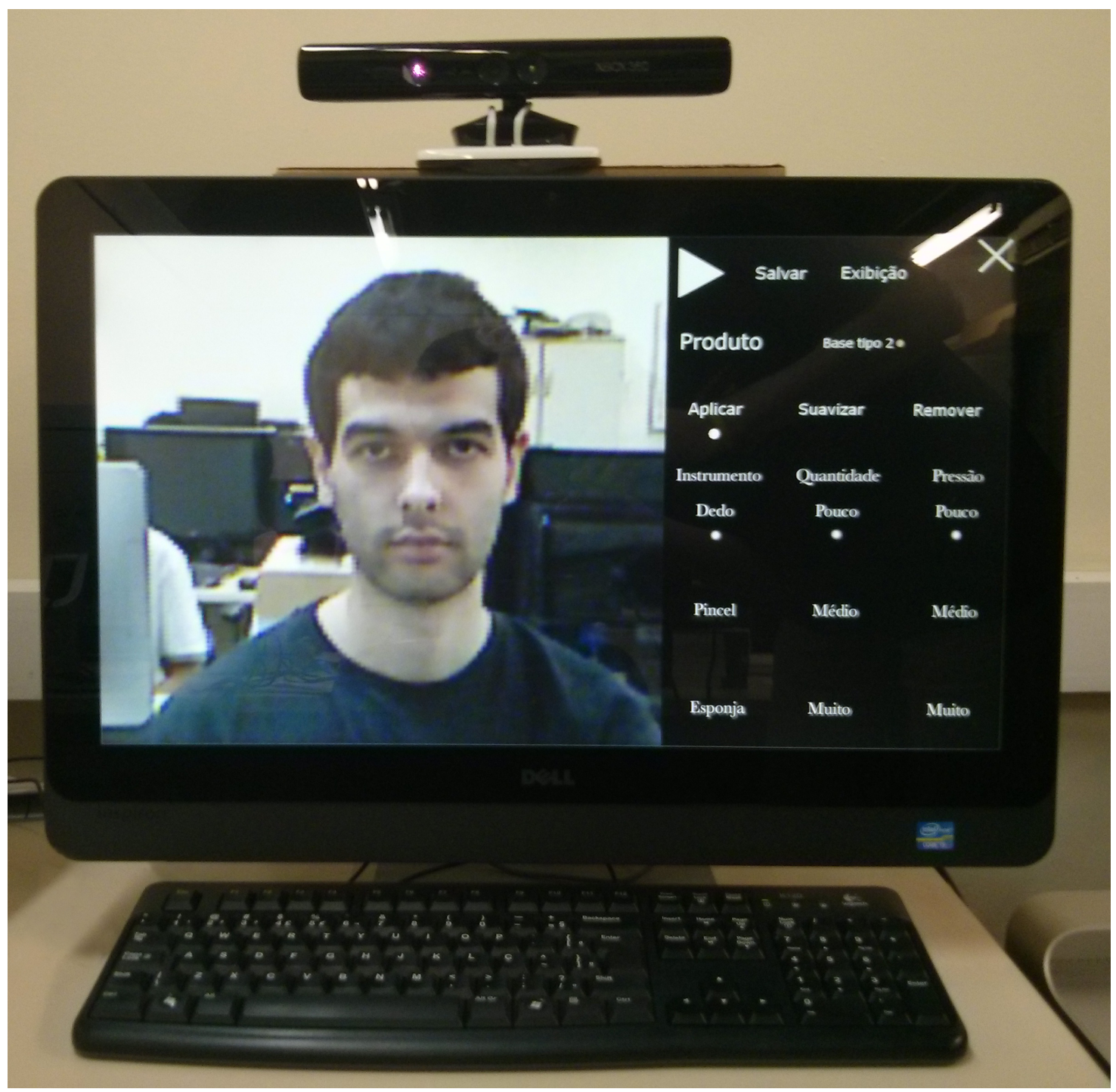

Figura 5.5: Disposição dos equipamentos do protótipo da interação exibindo também a região de espelho e a região de controles da interface. O teclado não é necessário para a utilização do sistema, é usado apenas durante o uso comum do computador.

maquiagem, já que ela depende do posicionamento e morfologia da face. A máscara pode ser criada manualmente por meio da interface do protótipo desenvolvido para essa parte do sistema, permitindo que o usuário aplique a maquiagem nas regiões da face que ele desejar. Além desta forma, a máscara também pode ser criada em um programa de edição de imagens e depois utilizada no software desenvolvido. Isto seria útil para criar modelos padrões de maquiagem para que o usuário não tenha o trabalho de definir a região de aplicação de $m$ realizando apenas retoques dessa máscara dentro do protótipo. A figura 5.6 apresenta alguns exemplos de máscaras utilizadas para o algoritmo.

Para que o algoritmo de simulação de maquiagem seja bem sucedido, ele deve ser capaz de simular o resultado da aplicação de maquiagem na pele da face em uma imagem do rosto do usuário. Isso simulará a alteração das propriedades óticas e de textura da pele causadas pela maquiagem. As limitações existentes são as mesmas da interação, 5.1, exceto pela limitação referente ao uso do Kinect, já que ele não foi utilizado para o protótipo da simulação de 


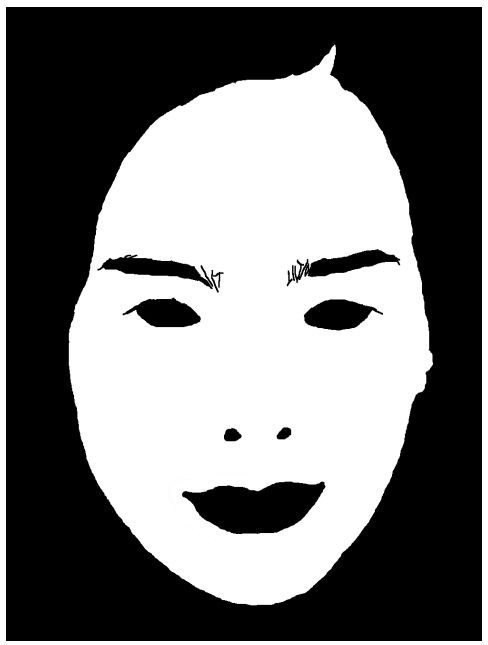

(a)

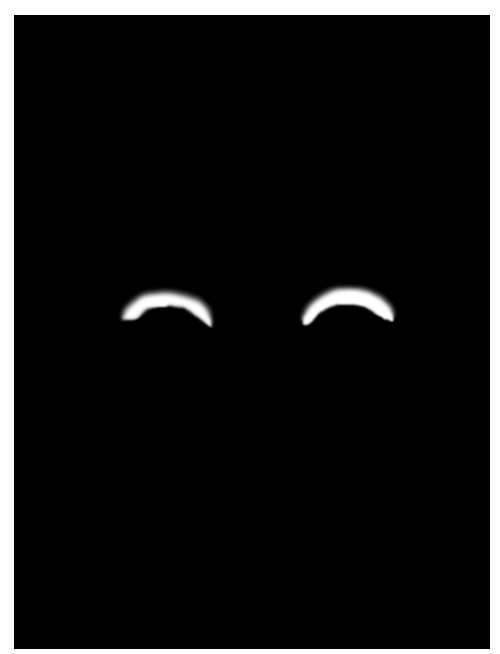

(b)

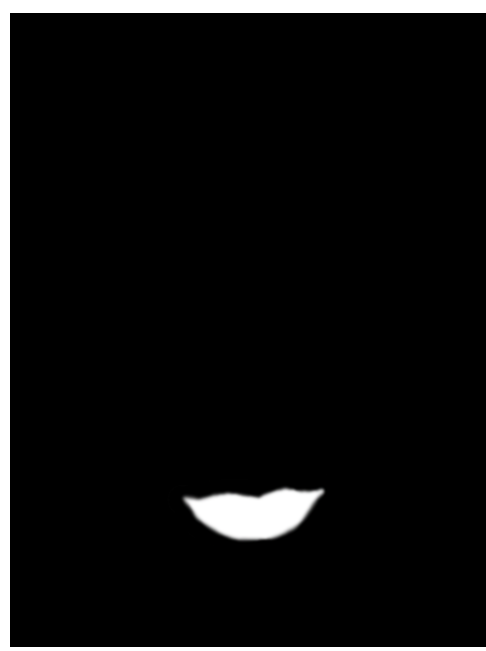

(c)

Figura 5.6: Exemplos de máscaras, $m_{a s c}$, para a aplicação de cada produto de maquiagem no protótipo da simulação de maquiagem. (a) exemplo de máscara para a aplicação de base; (b) exemplo de máscara para a aplicação de sombra; (c) exemplo de máscara para a aplicação de batom.

maquiagem.

\subsubsection{Simulação de maquiagem - Textura}

Como explicado no capítulo anterior, o módulo de Textura é responsável pela suavização dos detalhes faciais e a homogeneização do tom de pele. Para solucionar essa etapa da simulação, a imagem original foi dividida em algumas faixas de frequências que foram suavizadas.

Para as suavizações, tanto as responsáveis por dividir a imagem da face em faixas de frequências quanto as responsáveis pelo efeito da maquiagem, foi utilizado, no lugar do filtro gaussiano, o box filter. Essa substituição se deu, pois o resultado dos dois filtros são semelhantes (box, 2013), porém o tempo de computação da suavização com o filtro utilizado é menor. Isso contribuiu para que fosse possível realizar a simulação mais rapidamente sem compromisso da qualidade do resultado da simulação.

Neste módulo da simulação de maquiagem, separamos a imagem inicial em 5 camadas. Cada camada é representada por uma imagem de uma faixa diferente de frequência da imagem inicial. Devido a essa diferença de faixas de frequência, temos as camadas $C_{f A}, C_{f 1}$, $C_{f 2}$ e $C_{f 3}$ contendo detalhes faciais dos mais sutis aos menos sutis e uma camada final, $C_{f B}$, que também pode ser chamada de residual, já que ela contém todo o restante da informação. Dessa forma, estamos separando detalhes faciais do resto da imagem da face para que seja possível trabalhar neles sem alterar outras caraterísticas da imagem. Para voltar a formar a imagem completa, deve-se somar cada uma das camadas.

A figura 5.7 apresenta o resultado do procedimento de divisão da imagem em faixas de frequência. Em $5.7 \mathrm{~h}$ e $5.7 \mathrm{~g}$ tem-se as duas camadas que não são alteradas, $C_{f B}$, baixa 
frequência, e $C_{f A}$, alta frequência, respectivamente. As outras três camadas, $5.7 \mathrm{a}, 5.7 \mathrm{c}$ e $5.7 \mathrm{e}$ são suavizadas na simulação para atingir os objetivos citados acima para essa etapa.

A camada residual, $C_{f B}$, representa o que resta após serem removidas quatro camadas de detalhes faciais da imagem. Assim, essa camada possui características globais da face da pessoa como a maior parte de sua cor e os traços básicos da face. Essa camada é deixada intacta já que os detalhes faciais a serem modificados não estão presentes e também não se obtém ganhos significativos de homogeneização da pele se ela fosse alterada.

A camada $C_{f 3}$ contém os detalhes faciais menos sutis. Nessa camada, detalhes como os poros faciais normalmente não são claramente visíveis, porém pode-se observar melhor as diferenças de tons de pele que são importantes para a percepção de uma pele mais homogênea. Assim, o tratamento dessa camada é o principal responsável pela homogeneização do tom de pele, para isso ela recebe a maior suavização das três camadas tratadas, já que estamos trabalhando com os detalhes mais grosseiros da face.

A camada $C_{f 2}$ contém os detalhes faciais de intensidade intermediária. Nela ainda é possível observar algumas diferenças mais sutis de tons de pele e começam a aparecer detalhes faciais menores. Nesta camada suavizamos com intensidade menor do que na camada anterior, já que as diferenças de tom de pele são mais sutis e alguns detalhes da textura da pele já estão presentes.

A camada $C_{f 1}$ contém detalhes faciais mais finos do que a anterior. A suavização a ser utilizada aqui deve ser sutil para não descaracterizarmos a face.

A camada $C_{f A}$ apresenta os detalhes faciais mais sutis. Nela pode-se observar claramente pelos faciais, fios de cabelo, alguns contornos de regiões da face entre outras pequenas perturbações da pele. Esta camada é mantida intacta pois ela apresenta os detalhes faciais mais importantes para a caracterização da pele e consequentemente do indivíduo. Assim, se os detalhes forem modificados a pele perde seu aspecto natural e começa a ser percebida como manipulada artificialmente.

Os detalhes faciais que aparecem em cada uma dessas camadas dependem de cada indivíduo. Algumas pessoas possuem poros faciais que estarão mais visíveis na camada $C_{f 2}$ outras na $C_{f 1}$, o que também vale para rugas e outros detalhes faciais. Para a simulação de maquiagem, o objetivo não é remover toda e qualquer ruga ou poro da face como é comum em fotografias de revistas. No contexto desse trabalho, estamos interessados em mimetizar o efeito da maquiagem, portanto, se aplicarmos uma base em uma face com, por exemplo, rugas muito intensas não se deve esperar que elas desapareçam, mas sim que sejam suavizadas. Dependendo de quão severa são as características faciais, elas estarão presentes em uma ou mais camadas e o efeito da maquiagem será aplicado se restringindo ao que a maquiagem real faria. $\mathrm{O}$ fato de decompormos em camadas com detalhes de intensidades diferentes e suavizá-las com intensidades diferentes é o que contribui para se aproximar do comportamento real da maquiagem.

A figura 5.7 também exibe os resultados parciais da simulação de maquiagem levando em conta apenas o primeiro módulo da simulação, ou seja, ainda sem a adição de cores. Em 


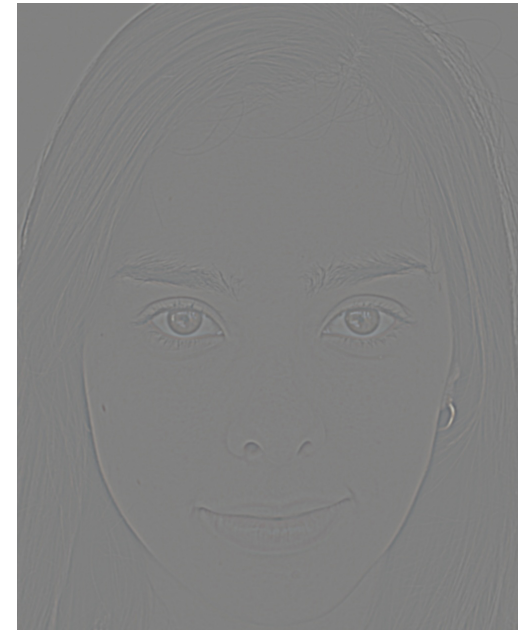

(a)

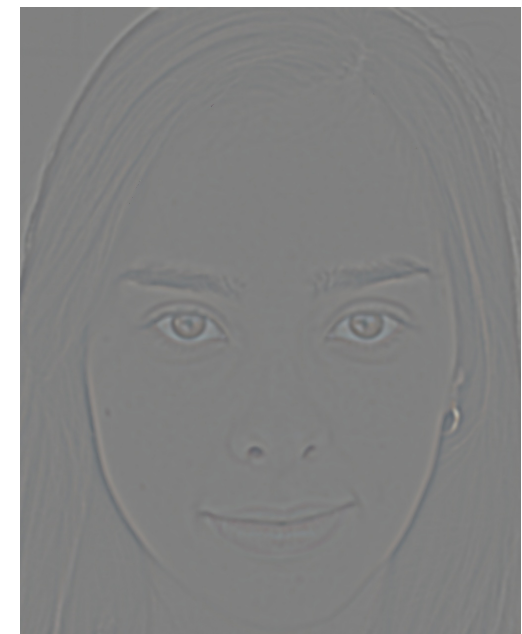

(d)

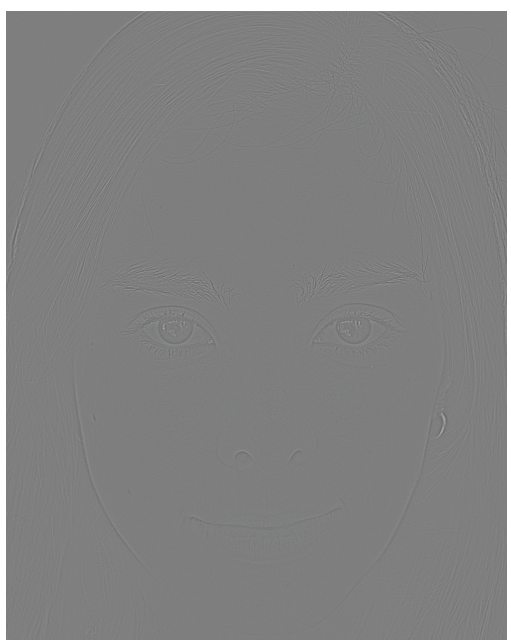

(g)

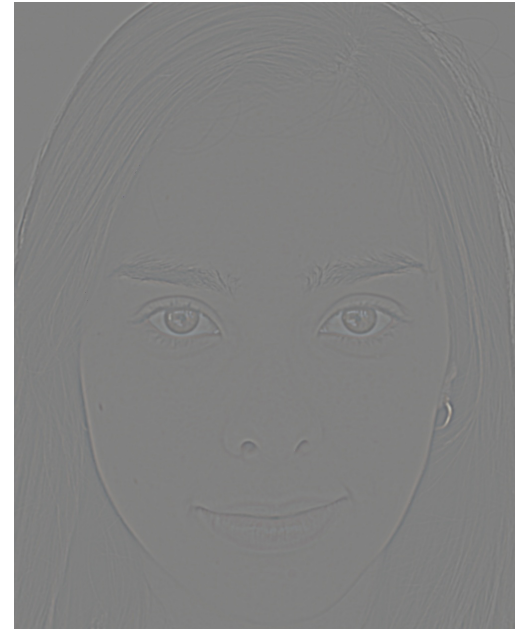

(b)

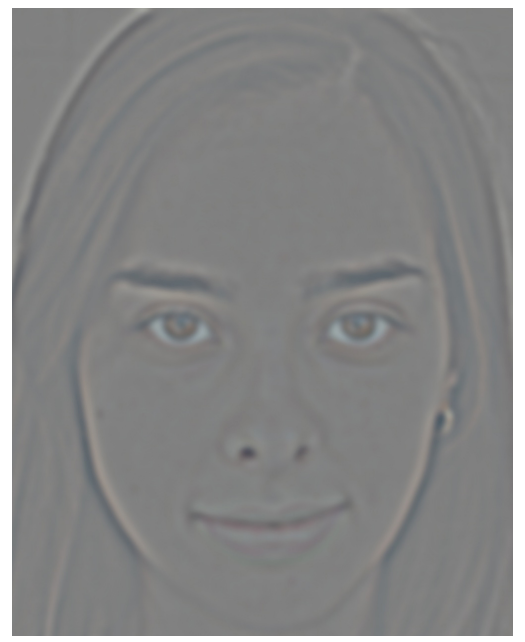

(e)

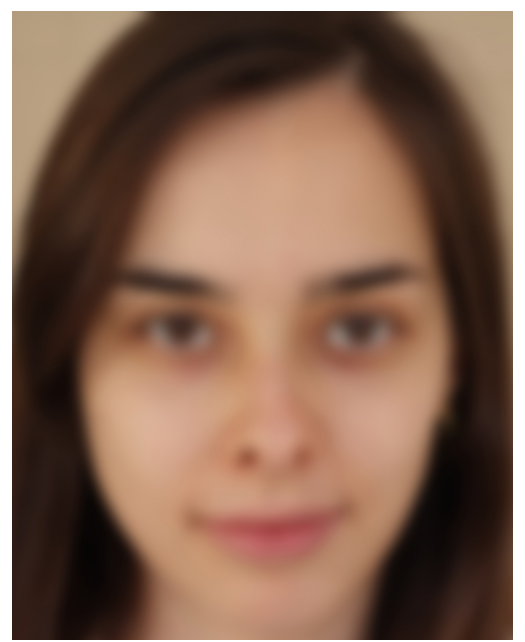

(h)

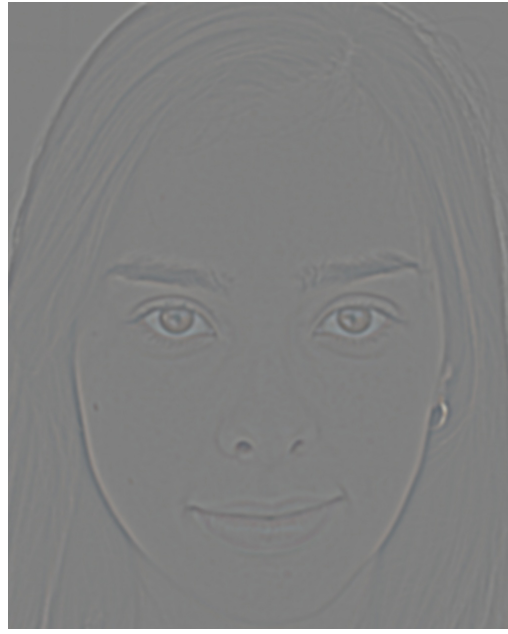

(c)

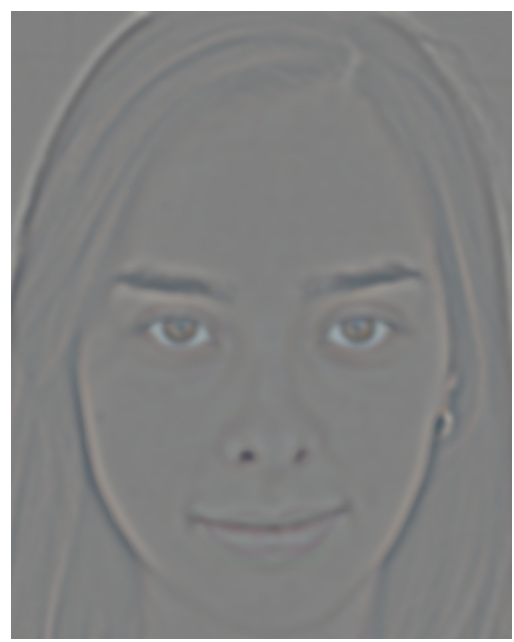

(f)

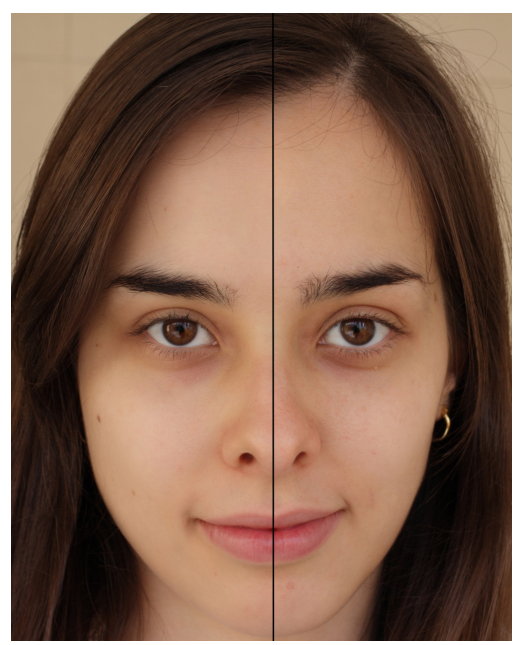

(i)

Figura 5.7: (a) camada de frequência intermediária $1, C_{f 1}$; (b) camada de frequência intermediária 1, $C_{f 1}$, após suavização; (c) camada de frequência intermediária $2, C_{f 2}$; (d) camada de frequência intermediária 2, $C_{f 2}$, após suavização; (e) camada de frequência intermediária $3, C_{f 3}$; (f) camada de frequência intermediária 3, $C_{f 3}$, após suavização; $(g)$ camada de alta frequência, $C_{f A}$; $(h)$ camada residual, $C_{f B}$; (i) esquerda: resultado da simulação levando em conta apenas o módulo Textura, direita: imagem original. 
5.7i tem-se o resultado do módulo Textura à esquerda, e à direita a imagem original, $I$. Em $5.7 \mathrm{~b}, 5.7 \mathrm{~d}$ e $5.7 \mathrm{f}$ as camadas $C_{f 1}, C_{f 2}$ e $C_{f 3}$ após suavização.

Como pode ser observado, as imagens das faixas de frequência sofrem suavizações que abrandam detalhes faciais e ajudam a tornar mais uniforme as diferenças de tons de pele. Observando a comparação entre a imagem inicial e a final da face, nota-se que a pele está mais uniforme. Observando regiões específicas, pode-se perceber que o tom de pele está mais homogêneo principalmente na região da testa, queixo e a na região do nariz e abaixo dos olhos. Apesar dessas suavizações, ainda é possível observar pequenos detalhes faciais que caracterizam a pele e consequentemente a face da pessoa.

\subsubsection{Simulação de maquiagem - Cor}

O módulo Cor da simulação de maquiagem trabalha a mudança de cor que ocorre na pele. Para simularmos essa alteração, foram testados diferentes espaços de cor. A ideia para mimetizarmos o efeito de cor era alterar os canais responsáveis pela cor em cada um dos espaços de cor testados com a média ponderada definida na equação 4.1.

A figura 5.8 apresenta o resultado desse procedimento para RGB, HSL e La*b*, os espaços de cor testados. Nela é possível perceber que os espaços de cor RGB e HSL tiveram resultados semelhantes enquanto que o La*b* mostrou melhores resultados. Para o La*b*, pode-se notar que ele foi capaz de separar melhor a informação de cor da iluminação, o que resultou em um melhor tratamento para as regiões sombreadas, como próximo ao cabelo e olhos em detalhe na figura. Em RGB ou HSL, essas regiões se tornaram mais claras, inclusive sendo possível perceber o fim da região em que o algoritmo foi aplicado na transição da pele para o cabelo. Com isso, a face obteve um aspecto mais caricaturado, já que a iluminação natural não foi respeitada, perdendo então o realismo da simulação. Assim, o espaço de cor La*b* foi utilizado para esse segundo módulo da simulação.

Cada uma das camadas criadas nesse módulo pode ser vista na coluna da esquerda da figura 5.9, em que 5.9e é a camada $C_{L}$, 5.9a é a camada $C_{a^{*}}$ e $5.9 \mathrm{c}$ é a camada $C_{b^{*}}$. $\mathrm{Na}$ coluna da esquerda, podemos notar a mesma camada após o procedimento da média ponderada, sendo $5.9 \mathrm{~b}$ o resultado para a camada $C_{a^{*}}$ e $5.9 \mathrm{~d}$ o resultado para a camada $C_{b^{*}}$. Neste exemplo, a média ponderada foi realizada igualmente para toda a imagem, ou seja, sem respeitar $m_{a s c}$. É possível perceber também que os canais correspondentes às cores não possuem a área sombreada na região da testa próxima ao cabelo, enquanto que isso se faz presente no canal $L$ demonstrando a melhor separação entre iluminação e cor o que nos levou a melhores resultados ao utilizar esse espaço de cor.

\subsubsection{Desempenho}

Para a primeira abordagem de paralelismo, tentou-se aproveitar o poder computacional da GPU. Para tal, foram utilizados os algoritmos que já estão implementados no OpenCV (Bradski, 2000) utilizando OpenCL (Khronos ). O principal problema dessa abordagem é que 


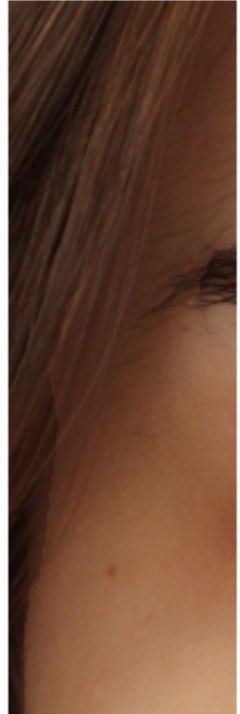

(a)

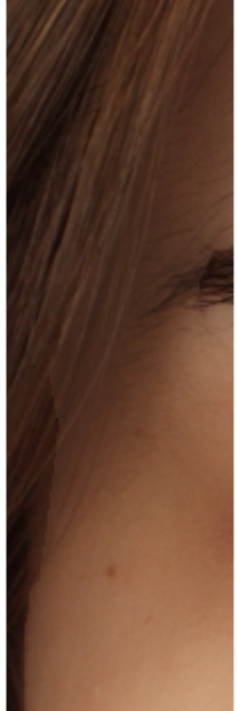

(b)

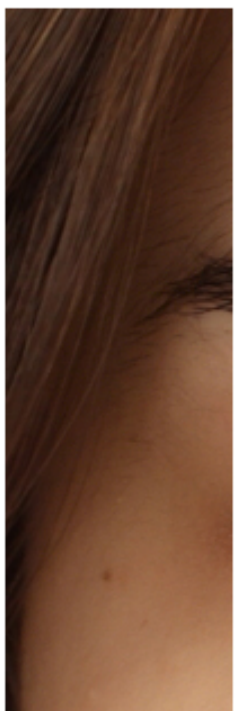

(c)

Figura 5.8: Resultado da simulação utilizando os espaços de cor HSL, RGB e La* ${ }^{*}$. Para facilitar a visualização das diferenças entre os resultados dos três espaços de cor, foram recortados da imagem do resultado de cada uma delas a região entre o olho direito e o cabelo. (a) resultado para a simulação utilizando o espaço de cor HSL; (b) resultado para a simulação utilizando o espaço de cor RGB e (c) resultado para a simulação utilizando o espaço de cor La*b*.

o algoritmo proposto nesse trabalho necessita de funções que ainda não estão implementadas utilizando OpenCL dentro da biblioteca em uso. Assim, para concluir todo o processo de simulação, era necessário processar parte do algoritmo em GPU e parte em CPU, o que acarreta em um gasto de tempo extra para a conversão entre as estruturas de dados usados pelo OpenCV e para a transferência dos dados entre a memória RAM e a memória da GPU. Esse custo extra foi significativo e fez com que o ganho obtido com o processamento em GPU fosse perdido. Uma saída para esse problema seria implementar as rotinas faltantes, mas por razões de tempo optou-se por utilizar paralelismo na CPU.

Para paralelizar usando CPU, foi utilizado o OpenMP (Board, 2008). Os testes de desempenho para essa forma de paralelismo foram conduzidos em um notebook com processador Core i7 2,6GHz com 4 núcleos. O tempo de execução médio de todo o algoritmo para a simulação de maquiagem para uma imagem de 1018x990 pixels pode ser observado na Tabela 5.1 .

\begin{tabular}{|c|c|c|}
\hline & Tempo (ms) & FPS \\
\hline Sem paralelização & 140 & 7 \\
Com paralelização & 83 & 12 \\
\hline
\end{tabular}

Tabela 5.1: Desempenho do algoritmo de simulação de maquiagem com e sem paralelização em CPU para uma imagem de $1018 x 990$ pixels.

Pode-se perceber que ocorreu um ganho significativo de desempenho com o paralelismo. O maior ganho se deu na etapa responsável pela divisão da imagem em faixas de frequências. 
Essa primeira etapa do módulo Textura precisava de $60 \mathrm{~ms}$ para realizar seu processamento antes da paralelização e depois $22 \mathrm{~ms}$. Entretanto, nem todas as etapas do código foram beneficiadas já que algumas funções do OpenCV, como cvtColor e bitwise_and não obtiveram ganhos ao tentar usá-las de forma paralela. Provavelmente o OpenCV não permite que essas funções atuem de forma paralela ou a biblioteca já as implementou utilizando todo o potencial da CPU e portanto não são obtidos ganhos ao tentar paralelizá-las.

Vale ressaltar que para o contexto do módulo de Simulação de Maquiagem, estamos realizando a simulação em uma imagem do usuário e não em um vídeo. Logo, não temos a necessidade de realizar o procedimento de decomposição da imagem em faixas de frequências mais de uma vez, o que nos permite descontar do tempo total de execução o custo relativo a essa etapa que, como já foi dito, é de 22ms. Assim, temos 61ms (16FPS) para realizar a aplicação da maquiagem na imagem do usuário com 1018x990 pixels, que é um tamanho suficiente para exibir a imagem em um monitor Full HD descontando o espaço utilizado pelos cabeçalhos das janelas do software. 


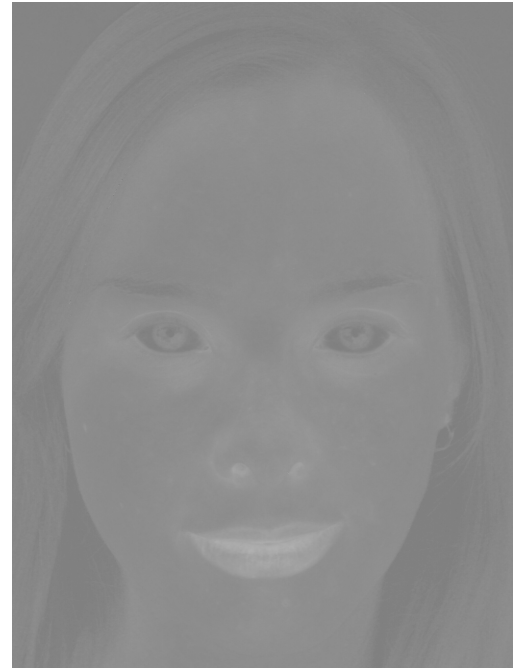

(a)

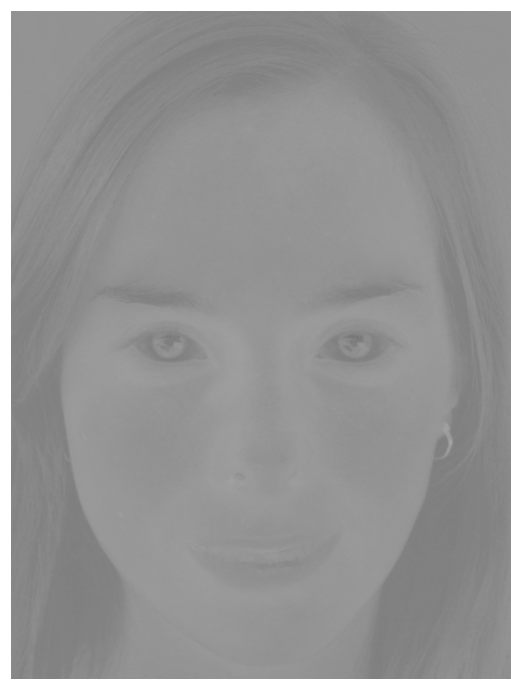

(c)

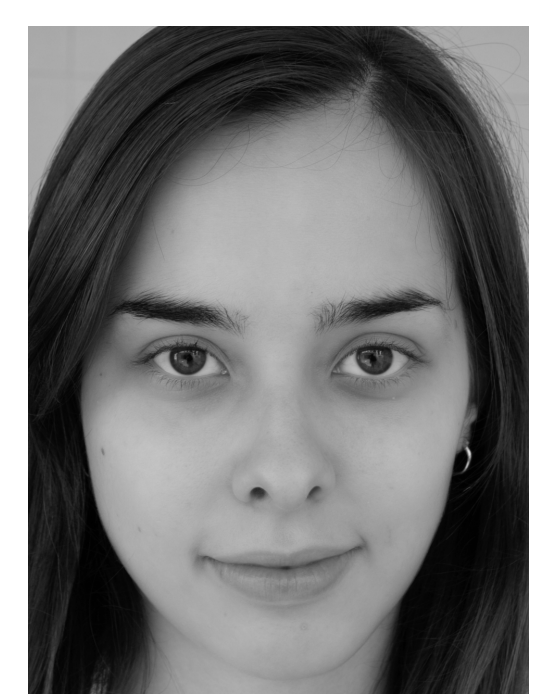

(e)

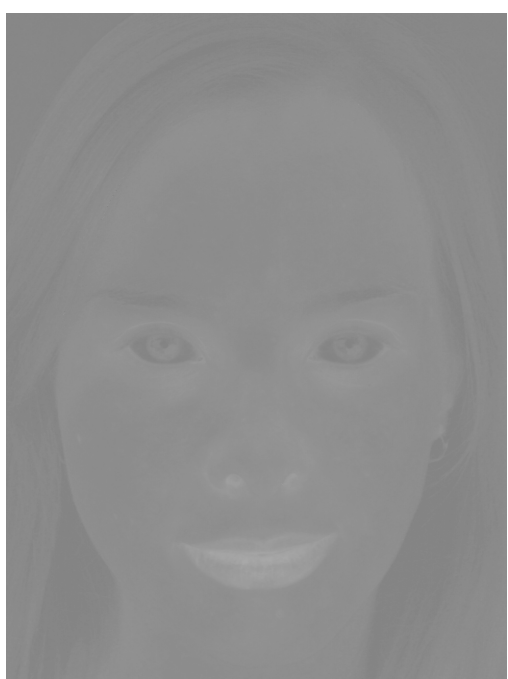

(b)

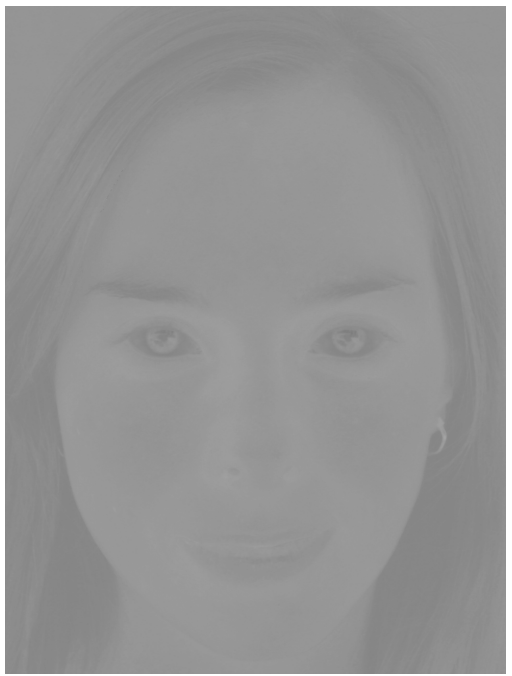

(d)

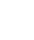




\section{Capítulo 6}

\section{Resultados}

Este capítulo discute e apresenta os resultados obtidos com a prototipação dos métodos propostos.

\subsection{Interação}

Nas figuras 6.1, 6.2 e no vídeo em https://www.youtube.com/watch?v=c-Y6xUXsfQM pode-se observar o protótipo da interação. Na região dos controles, a primeira linha contém funcionalidades gerais do sistema como pausar a imagem do espelho, salvar a imagem do espelho, escolher modo de exibição e fechar o sistema. Abaixo, se encontra a primeira escolha que o usuário fará no simulador, o produto de maquiagem a ser aplicado. Como isso ocorre com frequência durante a interação, sua região é grande e pode ser tocada facilmente. Para realizar a escolha da maquiagem, basta tocar no produto desejado na nova região que é exibida no meio do monitor e dispõe das opções existentes de base, batom e sombra. Após ter escolhido a maquiagem, na próxima linha o usuário poderá escolher se deseja aplicar, suavizar ou remover o produto. Dependendo de sua opção, os controles adequados aparecerão abaixo para definir a maneira com que o cosmético é aplicado na face. Para a aplicação, é possível escolher entre o instrumento utilizado para aplicar a maquiagem (pincel, esponja e dedo), a quantidade de maquiagem a ser utilizada (pouca, média, muita) e a pressão com que o instrumento seria pressionado contra a pele da face (baixa, média, alta). Para a suavização, é possível escolher o instrumento a ser usado na aplicação (porém apenas entre dedo e pincel) e a pressão, enquanto que para a remoção não existem opções a serem escolhidas. A escolha do tipo de maquiagem também pode alterar as opções disponíveis, caso algum batom seja escolhido, o usuário poderá apenas aplicar ou remover (não terá a opção de suavizar) o produto e definir apenas a pressão para a sua aplicação, já que o instrumento a ser utilizado para a aplicação desse produto é o próprio batom e a quantidade de material não é variável. Para base e sombra todas as opções estão disponíveis.

Para aplicar a maquiagem, após escolher o produto e as características para sua aplicação, basta tocar com o dedo na região da face desejada. Então, o usuário poderá aplicar os 
produtos de maquiagem que ele escolheu em qualquer lugar da face, inclusive combinando esses produtos ou então realçando um mesmo produto, caso ele passe o dedo mais de uma vez na mesma região. Para que a face fosse grande o suficiente para permitir a interação por meio do toque para a aplicação da maquiagem, foi necessário aumentar em cinco vezes a imagem obtida pela câmera RGB do Kinect. Devido a esse fator e à qualidade da câmera e lente do dispositivo, a imagem utilizada como espelho não possui boa aparência, mas possibilita a interação com o hardware disponível no momento.

Na figura 6.3, pode-se observar o resultado da aplicação de maquiagem utilizando o protótipo da interação. A taxa de quadros por segundo obtida para 1236 triângulos em um notebook com processador Core i7 2,6 GHz foi de 12 quadros por segundo.

Além do realismo da simulação de maquiagem para a interação não ser bom, o que era esperado já que se trata de uma simplificação e utiliza uma imagem de baixa resolução, podese notar formatos geométricos e também é possível perceber certa imprecisão ao aplicar a maquiagem na face ao utilizar o protótipo. Ambos, apesar de serem efeitos indesejados, são consequência do número de triângulos utilizados. Da forma com que a simulação foi proposta, quanto maior o número de triângulos na face, melhor será a precisão da maquiagem e menos triangular será sua simulação. Ao utilizar um hardware de melhor desempenho, pode-se utilizar mais triângulos simultaneamente mantendo ou melhorando a taxa de quadros por segundo.

Quanto ao desempenho do rastreamento de face do Kinect, ele demonstrou algumas falhas em sua precisão, mas em termos gerais teve um funcionamento adequado para mostrar a viabilidade da solução.

\subsection{Simulação de maquiagem}

Neste tópico trataremos dos resultados proporcionados apenas pelo algoritmo para simulação de maquiagem.

Na figura 6.4, temos o resultado para a simulação de base. Em 6.4a temos a imagem original, em 6.4 b é possível verificar o resultado apenas para o módulo Textura, responsável pela suavização de detalhes faciais e homogeneização do tom de pele e em $6.4 c$ pode-se ver o comparativo entre o antes e depois do módulo Textura, sendo a região da esquerda o resultado da simulação e a da direita a imagem original. Como pode ser observado, os detalhes faciais e as diferenças de tom de pele foram suavizados tornando a pele mais uniforme, porém ainda é possível observar pequenos detalhes faciais que caracterizam a pele e consequentemente a face da pessoa. Em 6.4d, nota-se que a adição da cor da base ajuda a tornar a cor da pele mais homogênea se aproximando do efeito real da base. A cor da base utilizada nesse exemplo é RGB(209,153,120).

A figura 6.5 exibe um comparativo entre simulações onde apenas os parâmetros do módulo Textura foram modificados, ou seja, tem-se alterações na suavização de cada uma das 
faixas de frequência. A primeira imagem suavizada 6.5b, a mesma utilizada nas outras figuras deste trabalho, possui a menor suavização das três. A imagem seguinte $6.5 \mathrm{c}$, possui uma suavização um pouco mais forte e a terceira $6.5 \mathrm{~d}$ apresenta suavização ainda mais intensa, perdendo o aspecto natural da face. Pode-se notar que regiões sutis como os cílios também foram suavizados, o que não é o ideal. Ao considerar regiões de pelos faciais na simulação, além destas acabarem sendo suavizadas, sua presença também atrapalhará a suavização da pele, pois a operação matemática envolvida na suavização levará em conta áreas com intensidade diferente da intensidade da pele. O desejado seria segmentar os pelos faciais criando uma nova camada para a simulação. Assim, poderíamos tratar a pele de forma independente dos pelos faciais e também, por exemplo, simular maquiagens específicas como o rímel.

Na figura 6.6, temos o resultado da simulação para batom, sombra e base. Além dos efeitos já citados sobre a base, é possível observar a adição de cor referente à sombra na região da pálpebra e do batom nos lábios. As cores da base, batom e sombra utilizados foram, respectivamente: $\operatorname{RGB}(209,153,120)$, $\operatorname{RGB}(177,3,4)$ e $\operatorname{RGB}(73,73,73)$.

Apesar de não definidas desta forma para esse trabalho, sombras ou batons que também possuam uma componente que altere a textura da pele, como suavizar ou realçar os detalhes faciais, também podem ser criadas utilizando a mesma arquitetura do método proposto.

Na figura 6.7, podemos comparar os resultados para a base obtidos com a aplicação real da maquiagem e sua simulação. A cor da base utilizada para a simulação foi RGB(144,112,89). Para obter esse tom de cor, que deve ser o mais próximo possível da maquiagem real para a comparação dos resultados, inicialmente verificou-se o valor de cor de alguns pixels do resultado da pele maquiada com maquiagem real, para então obter um valor inicial de cor para a simulação. Mais alguns justes de cor foram feitos até chegar no tom de cor final.

Na figura, é possível observar que o resultado da simulação utilizando o método proposto se aproxima da maquiagem real. Podemos observar também o resultado para o método sendo executado além de suas limitações, neste caso, iluminação não uniforme. Na região próxima ao nariz e logo abaixo dos lábios, em que a iluminação não estava uniforme, pode-se perceber que a região de sombra foi suavizada o que não ocorre na maquiagem real. 


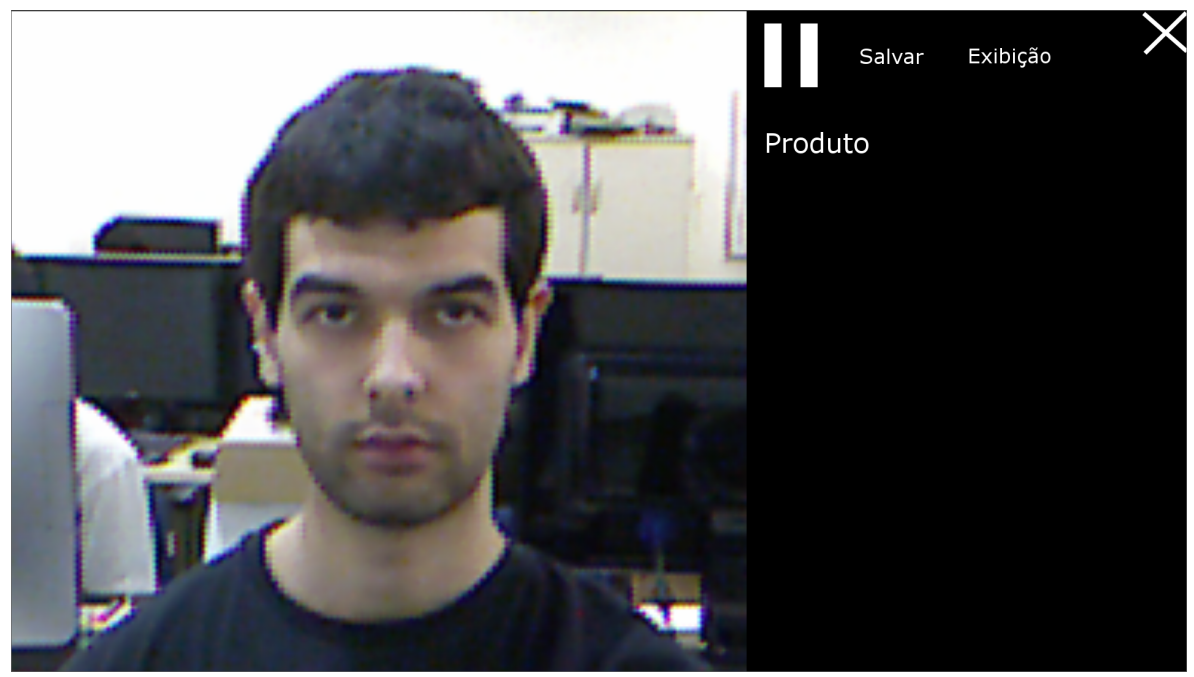

(a)

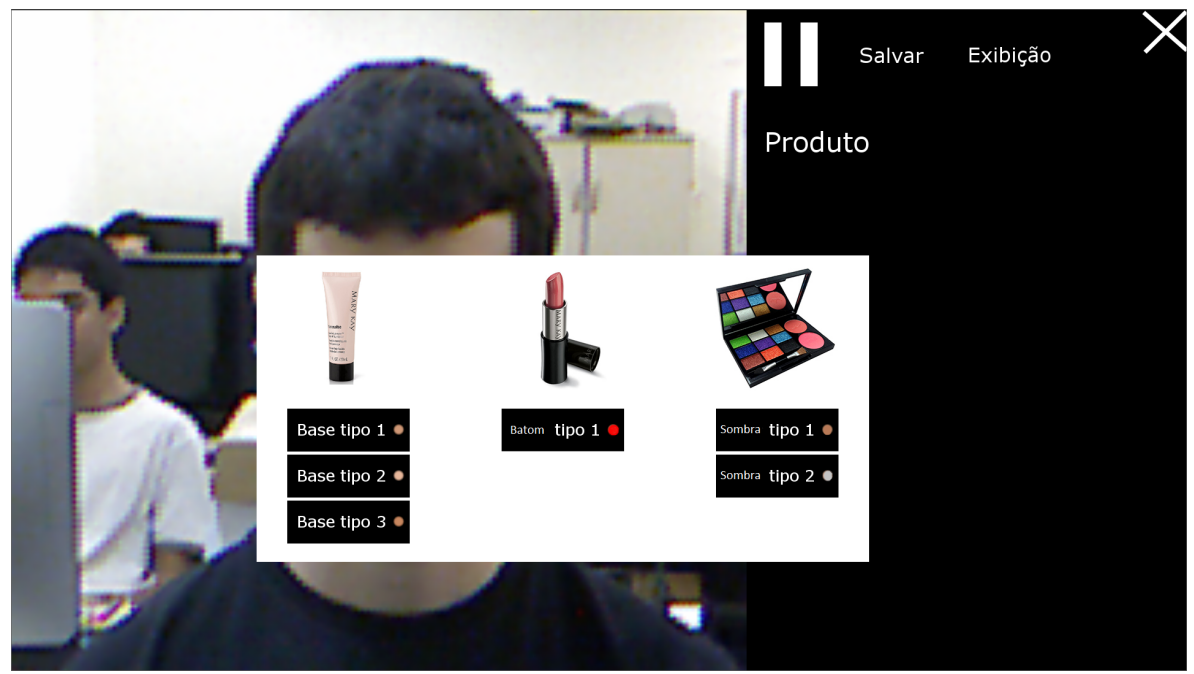

(b)

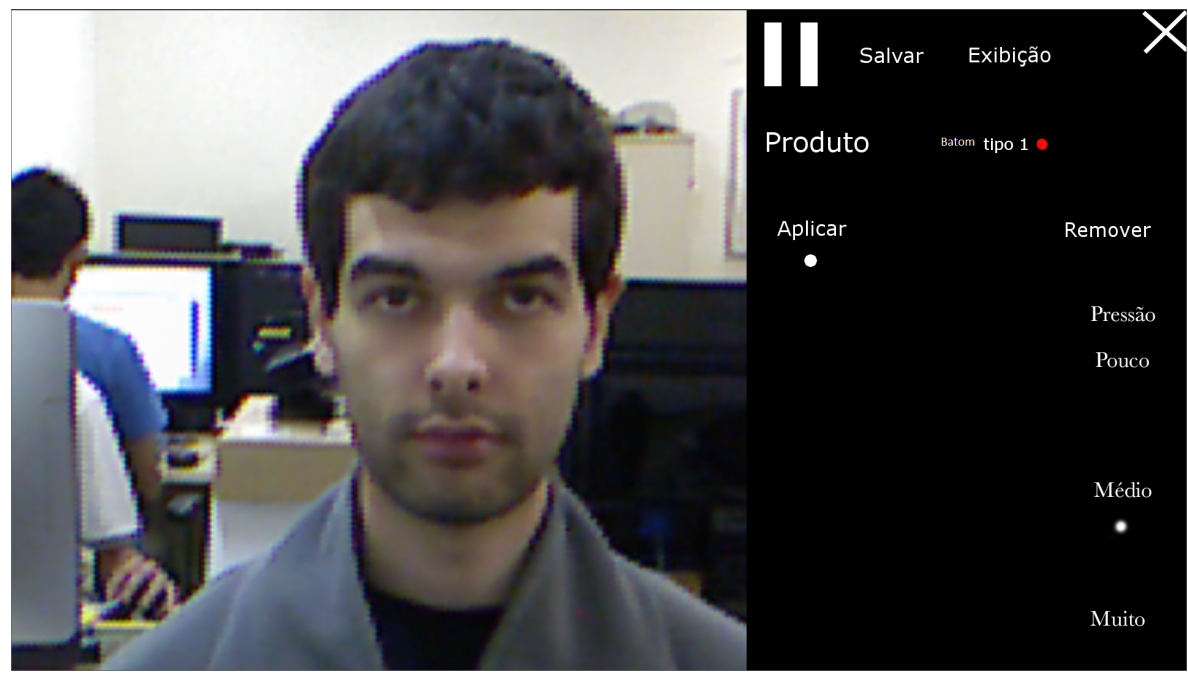

(c)

Figura 6.1: (a) Representa o estado inicial da interface quando o simulador é iniciado; (b) Exibe a interface quando o usuário toca na tela para escolher o produto de maquiagem a ser aplicado; (c) Exibe a interface e as opções disponíveis para a aplicação de batom. 


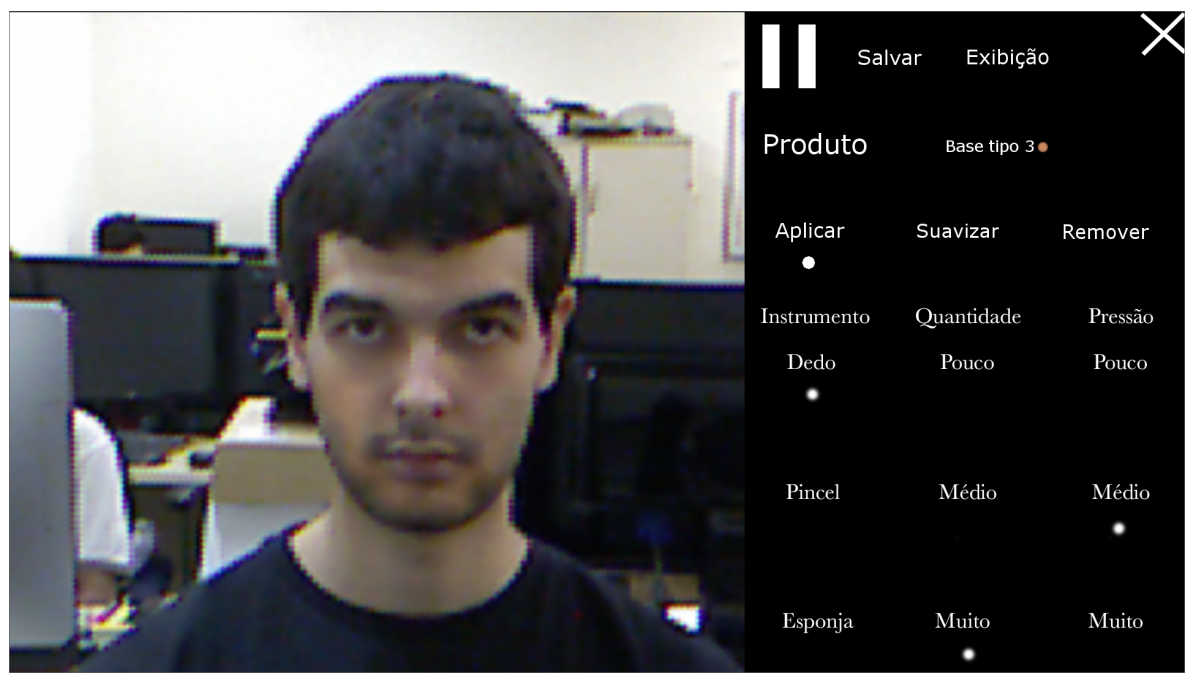

(a)

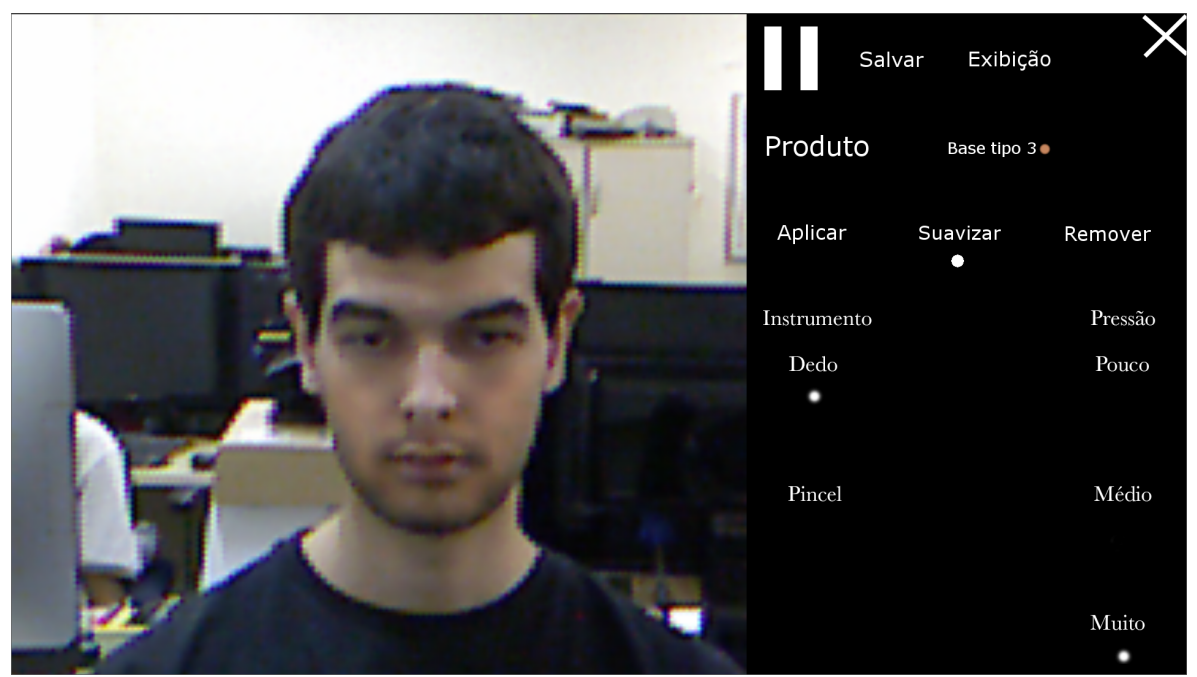

(b)

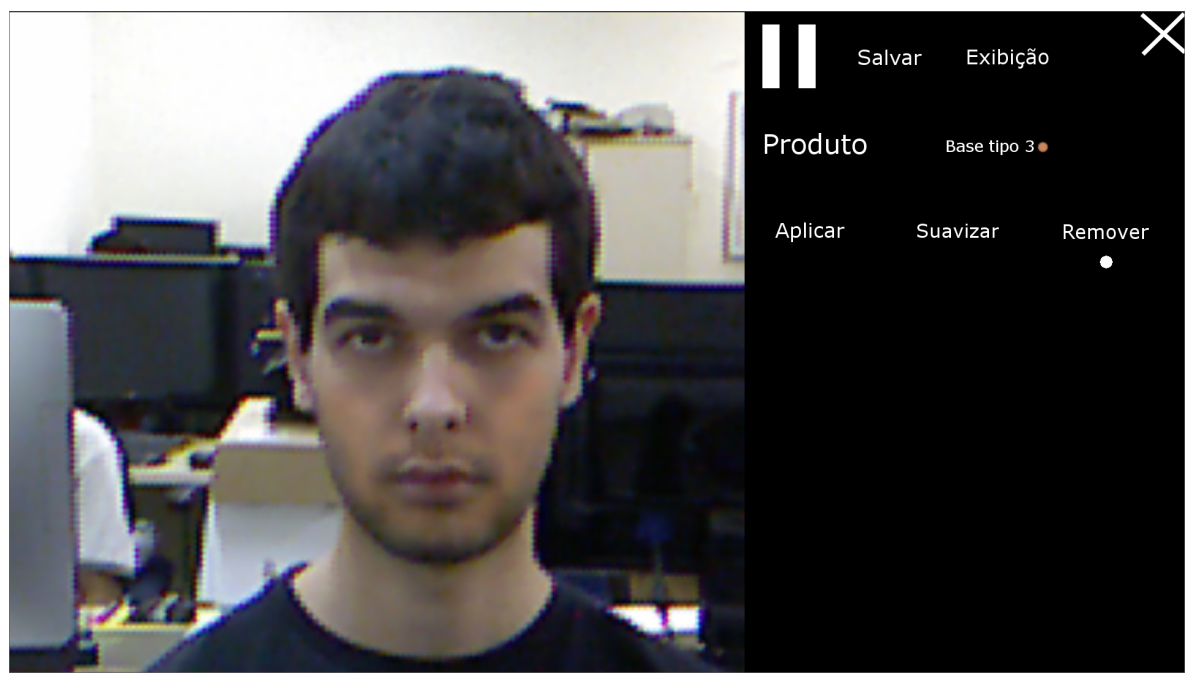

(c)

Figura 6.2: (a) Exibe a interface e as opçôes disponíveis para a aplicação de batom ou sombra; (b) Exibe a interface e as opçôes disponiveis para a suavização de batom ou sombra; (c) Exibe a interface e as opçôes disponíveis para a remoção de batom ou sombra. 


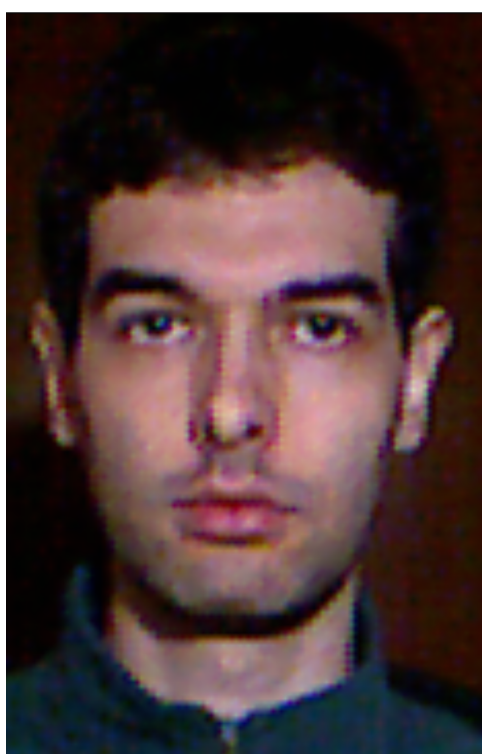

(a)

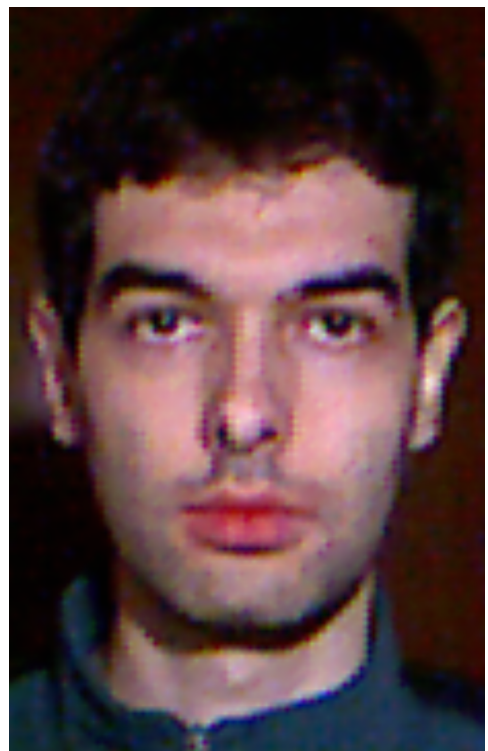

(d)

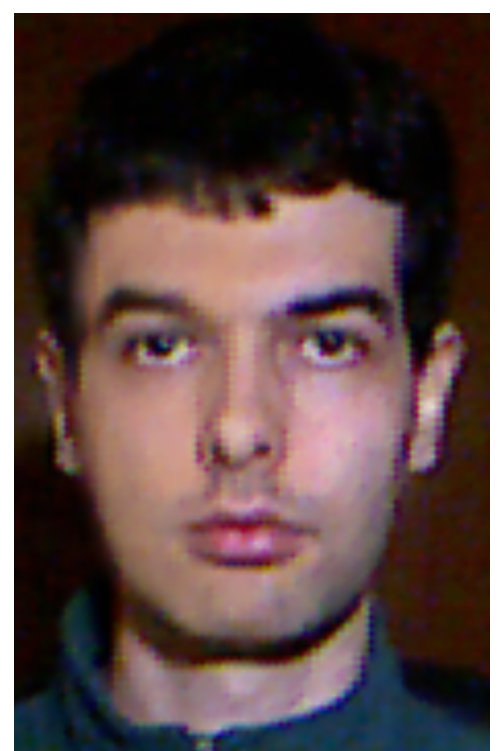

(b)

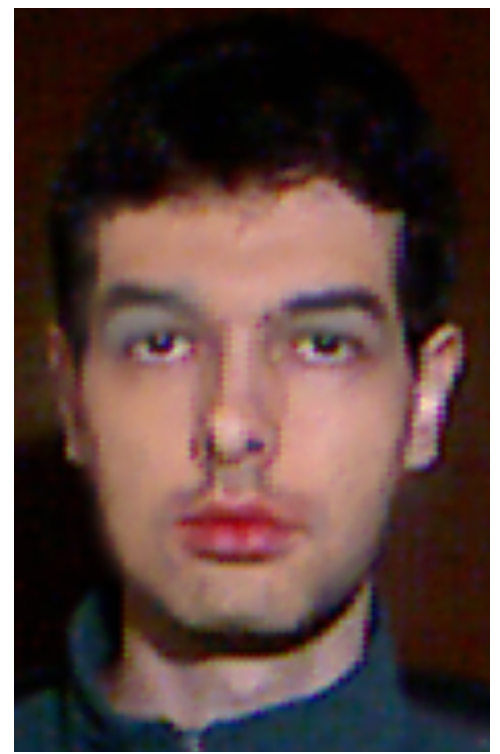

(e)

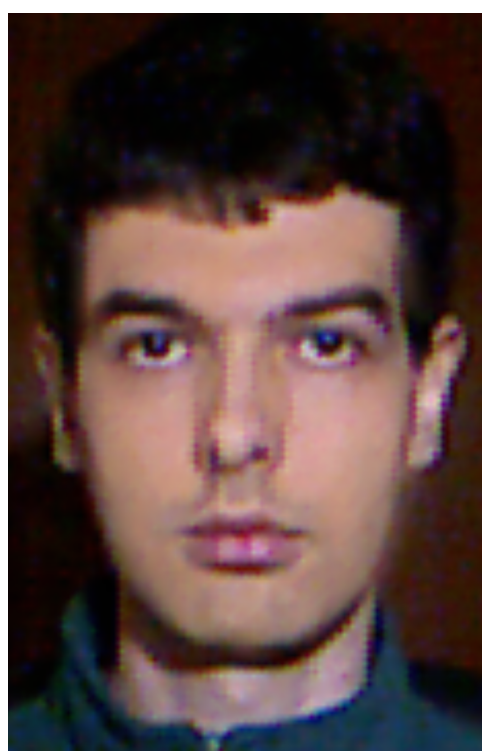

(c)

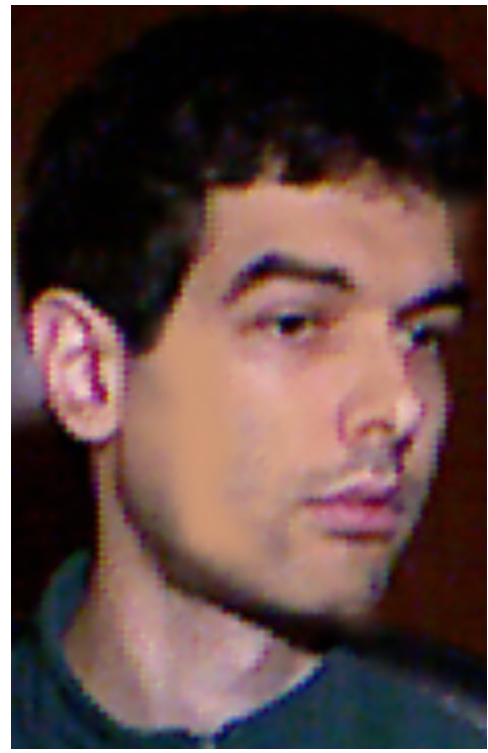

(f)

Figura 6.3: (a) Imagem da face sem maquiagem; (b) Resultado para a base aplicada apenas na metade da face do lado esquerdo da imagem; (c) Resultado para a aplicação de base em toda face; (d) Resultado para a aplicação de batom; (e) Resultado para a aplicação de base, batom e sombra; (f) Resultado para aplicação de base na metade visivel da face, porém aplicando o produto algumas vezes em uma mesma região da face tornando a maquiagem mais intensa nesse local. 


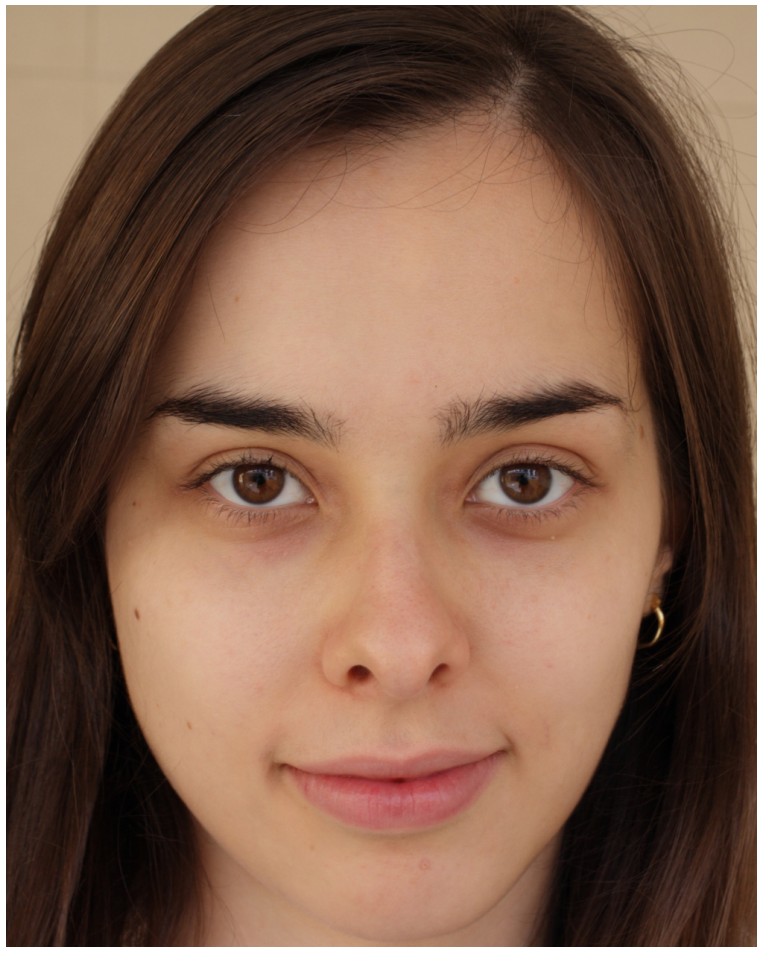

(a)

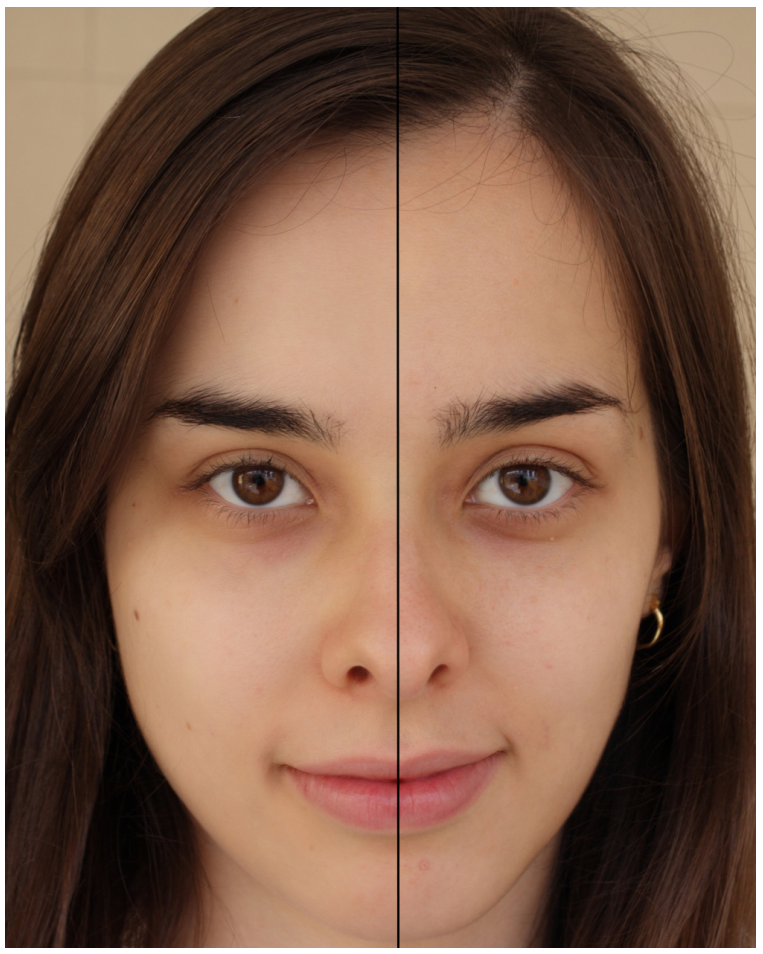

(c)

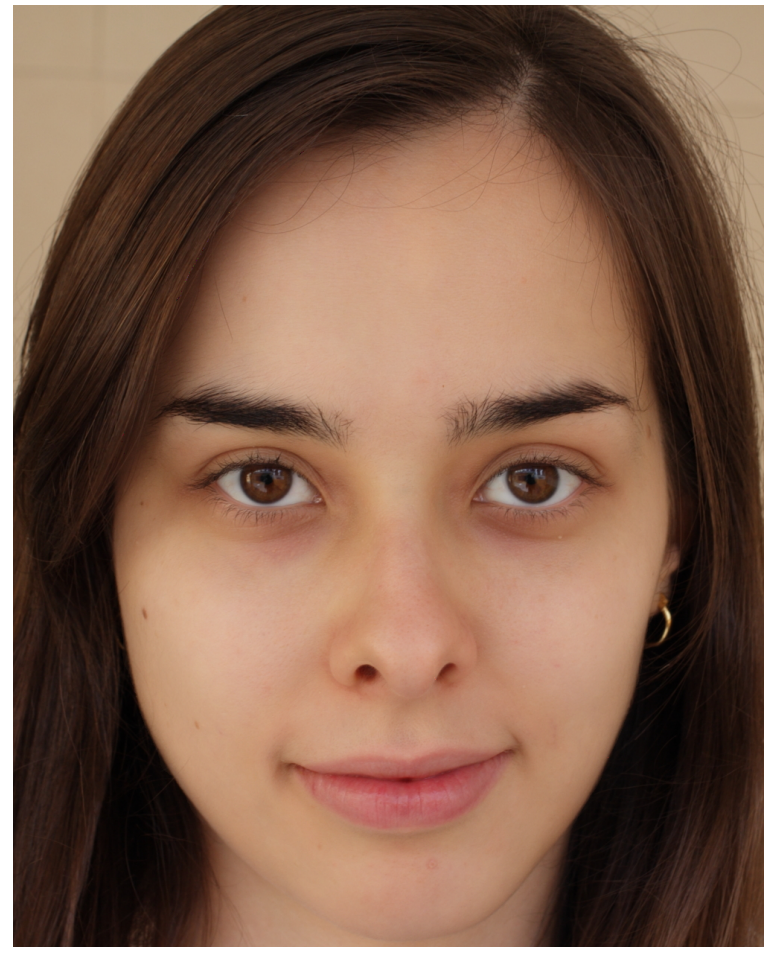

(b)

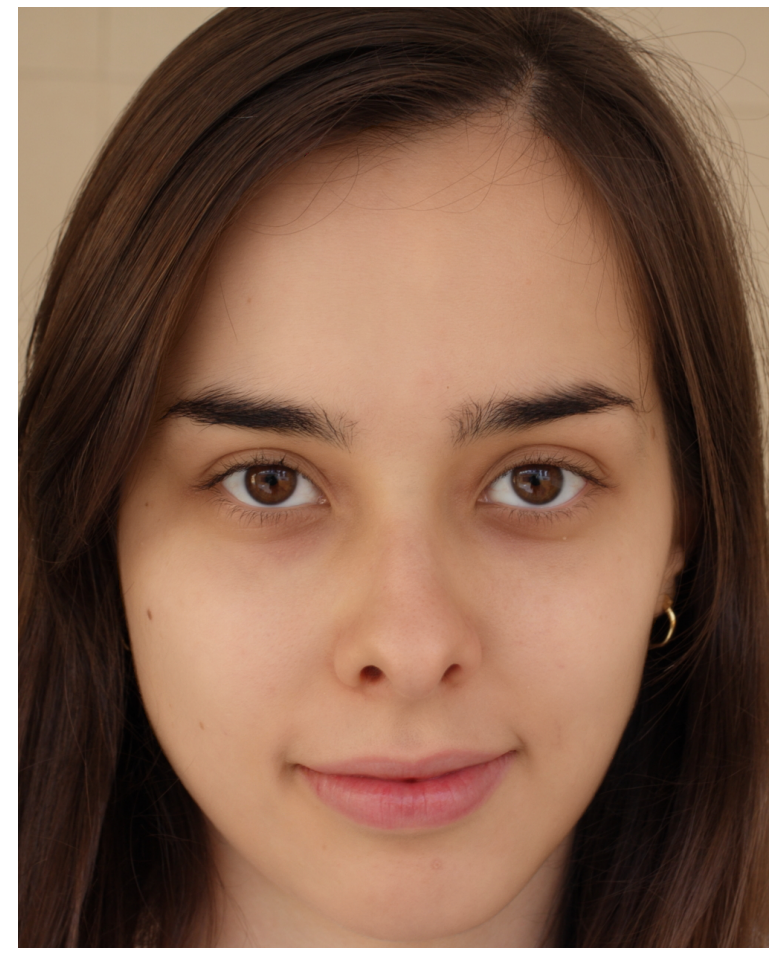

(d)

Figura 6.4: (a) Imagem original, I; (b) Resultado apenas para o módulo Textura do algoritmo de simulação; (c) Comparativo entre I e o resultado em (b), lado direito: imagem original, lado esquerdo: resultado do módulo Textura; (d) Resultado do módulo Textura e Cor. 


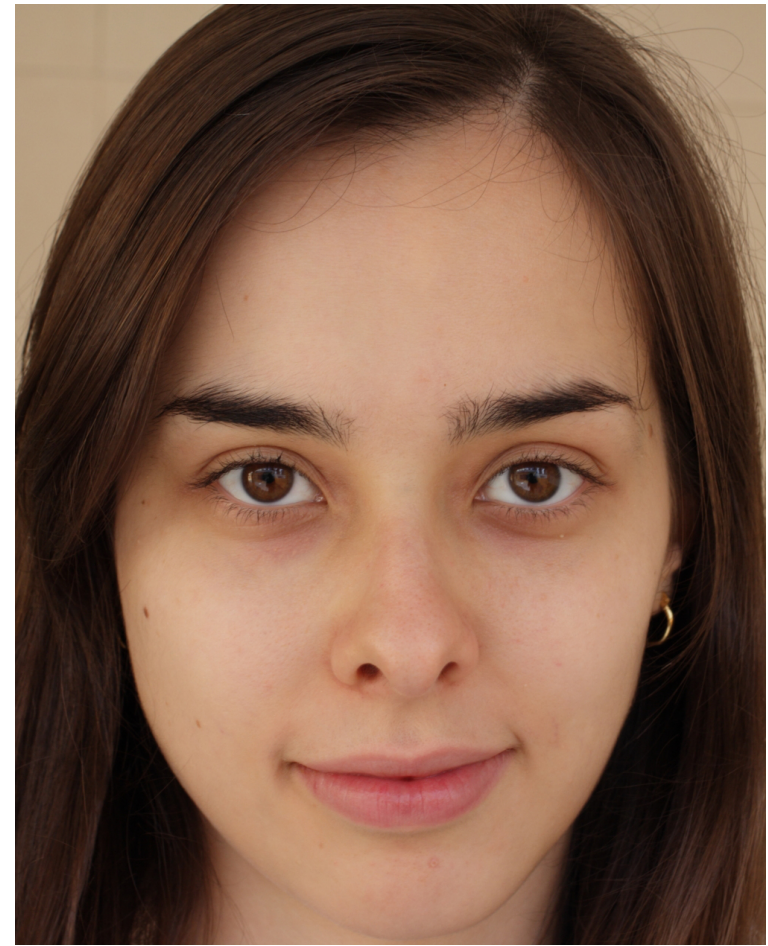

(a)

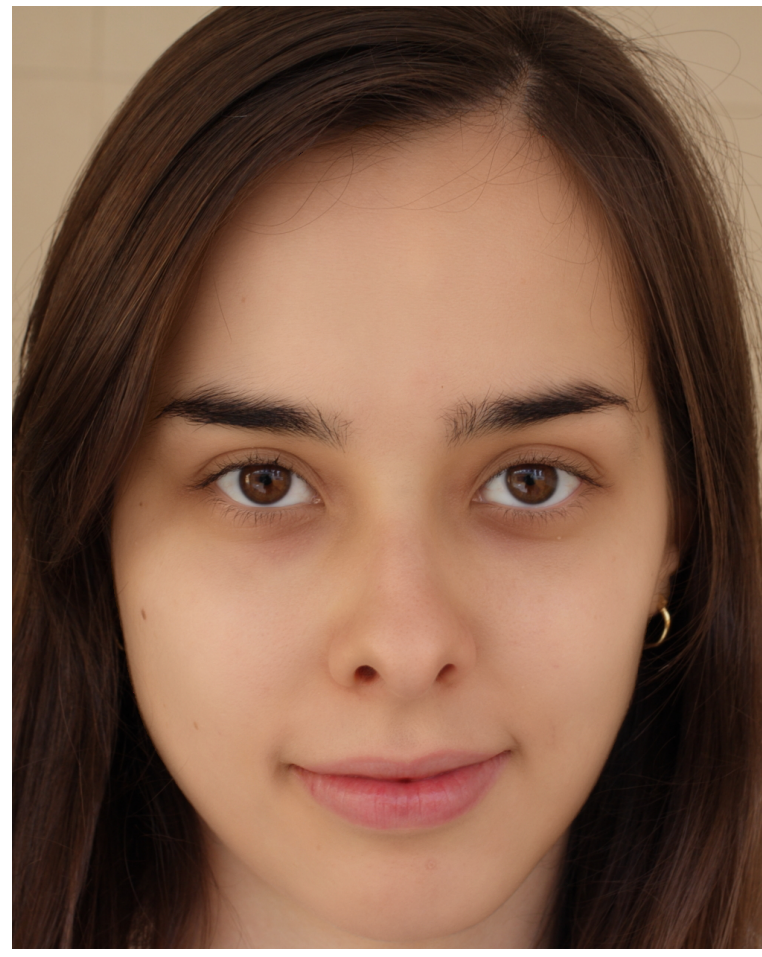

(c)

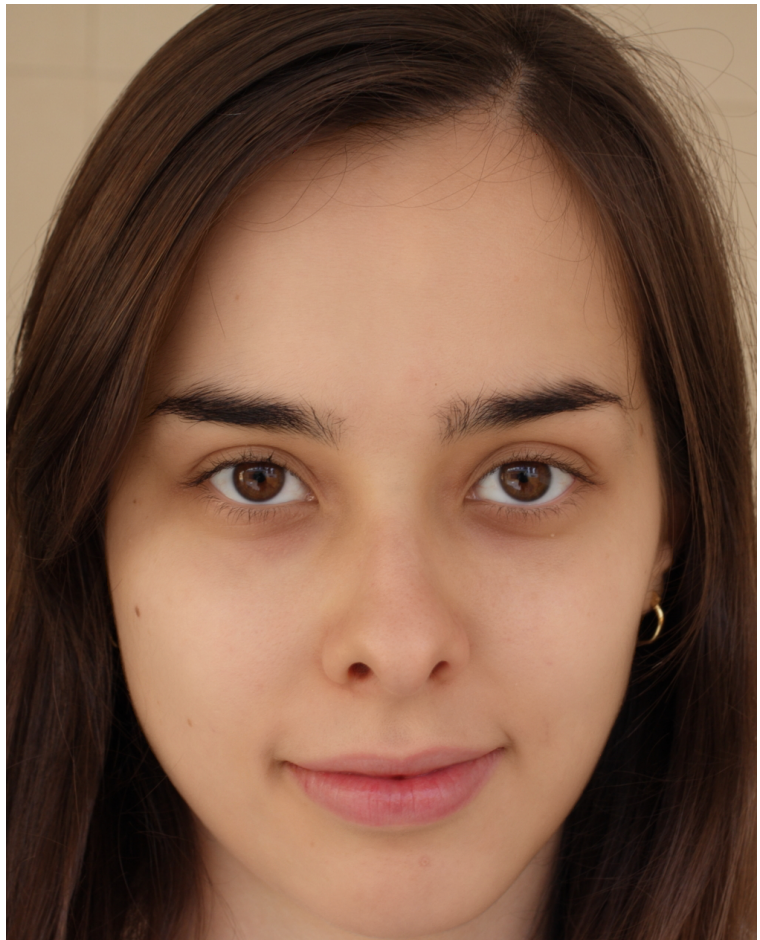

(b)

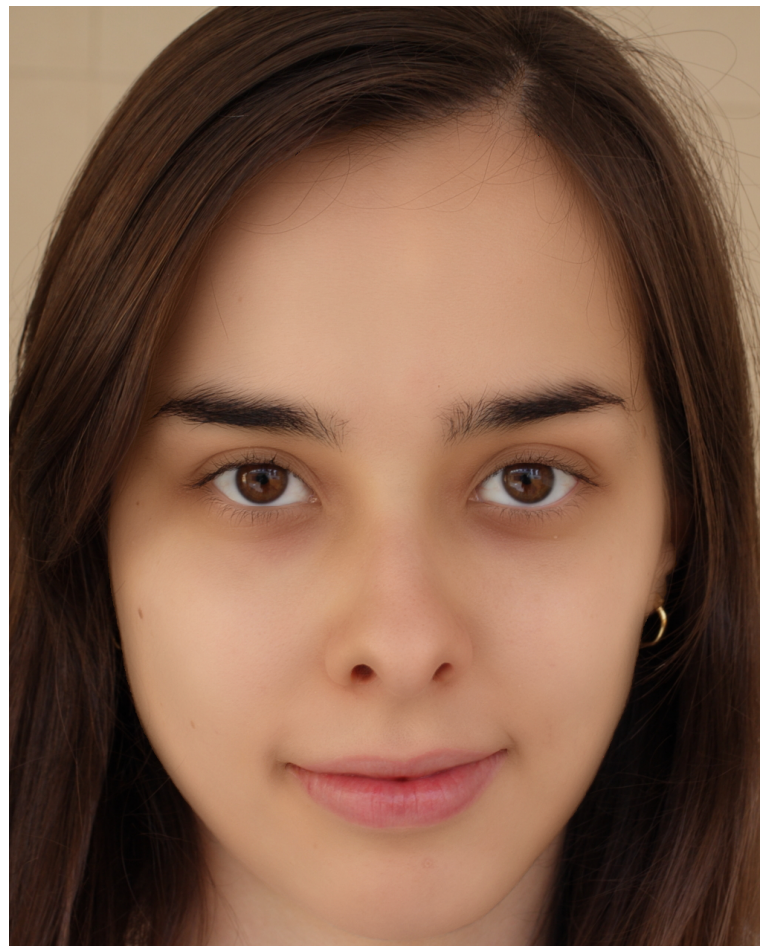

(d)

Figura 6.5: Resultado da simulação para intensidades diferentes de suavização. Parâmetros se referem ao tamanho do kernel utilizado na suavização. (a) Imagem original; (b) Suavização utilizada nas outras imagens deste trabalho. Parâmetros: 5-9-17 para $C_{f 1}, C_{f 2}$ e $C_{f 3}$ respectivamente; (c) Suavização um pouco mais intensa. Parâmetros: 5-13-25 para $C_{f 1}, C_{f 2}$ e $C_{f 3}$ respectivamente; (d) Suavização ainda mais intensa, começando a perder seu aspecto natural. Parâmetros: 7-17-37 para $C_{f 1}, C_{f 2}$ e $C_{f 3}$ respectivamente. 


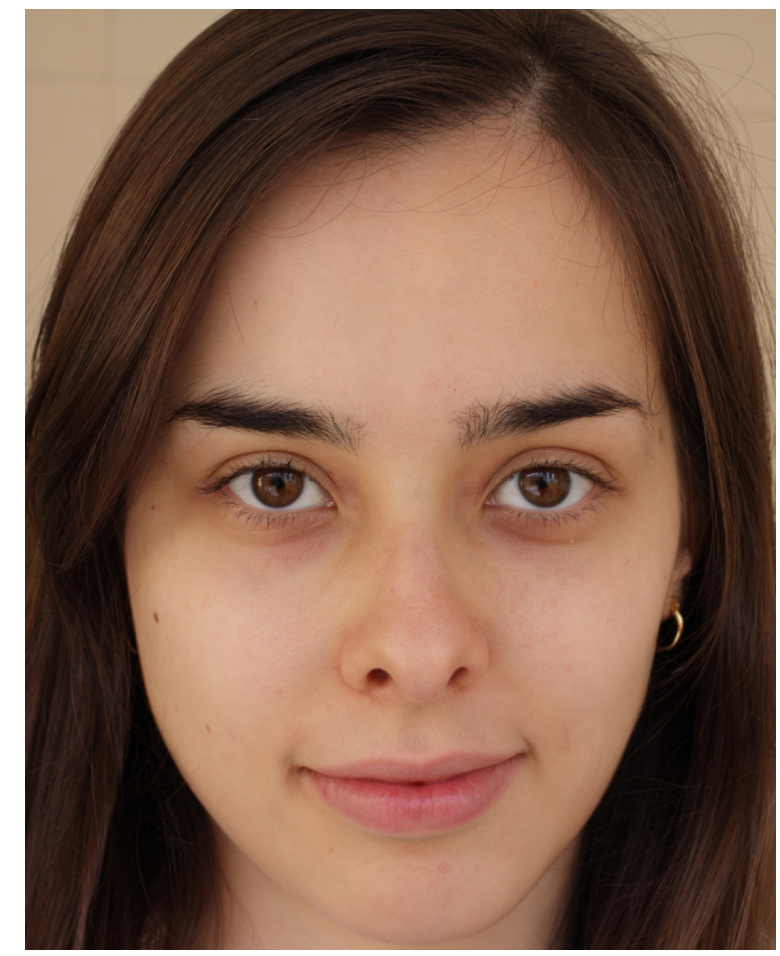

(a)

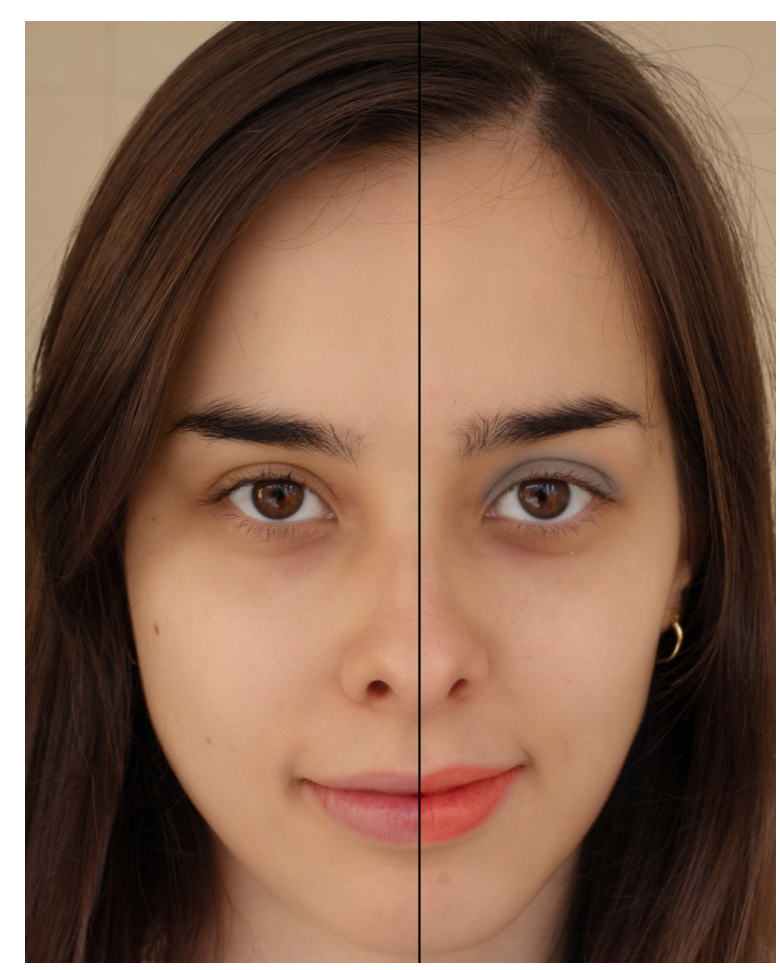

(c)

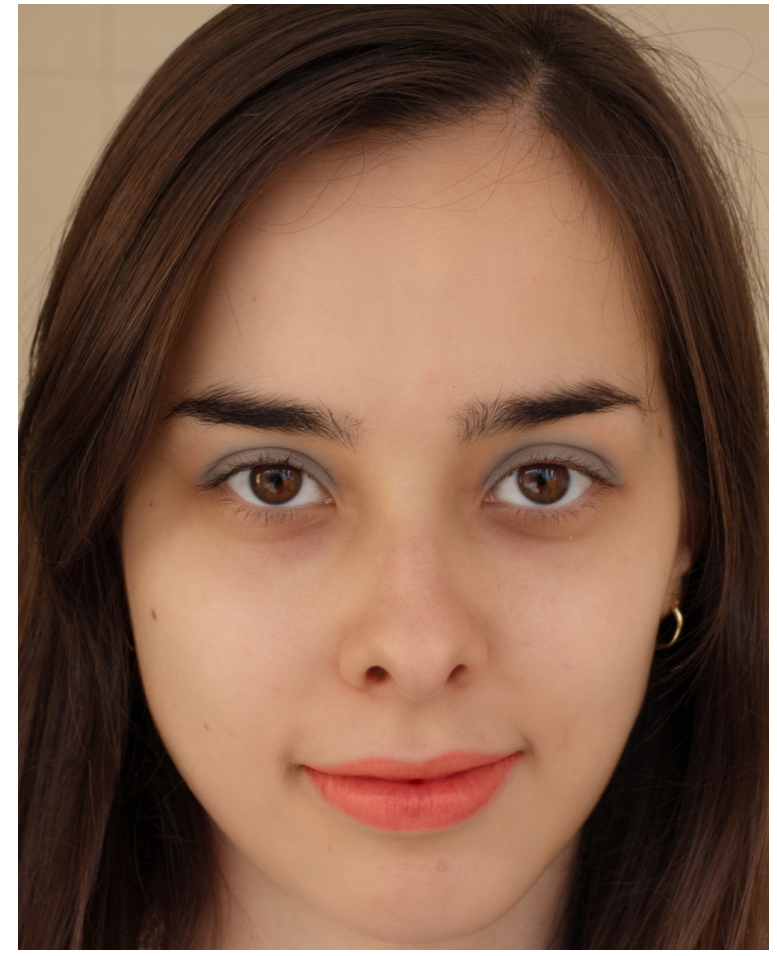

(b)

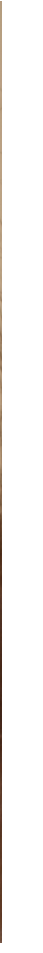

Figura 6.6: Resultado da simulação para batom, sombra e base. (a) Imagem original; (b) Resultado da simulação; (c) Comparativo, lado esquerdo: original, lado direito: maquiada. 


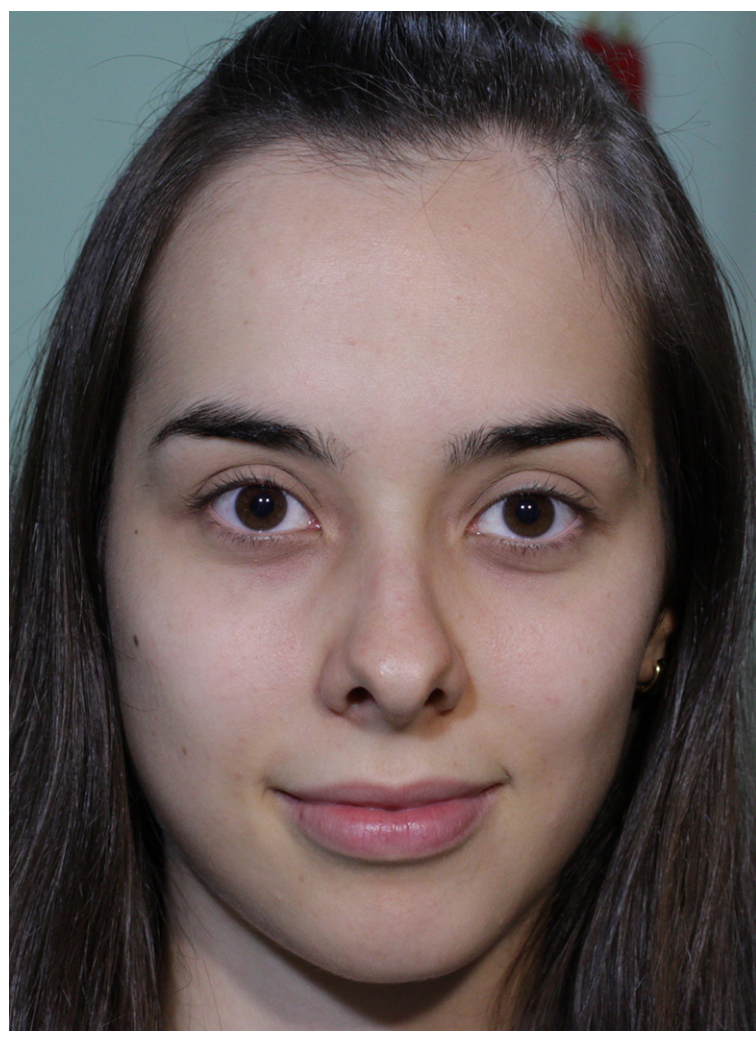

(a)

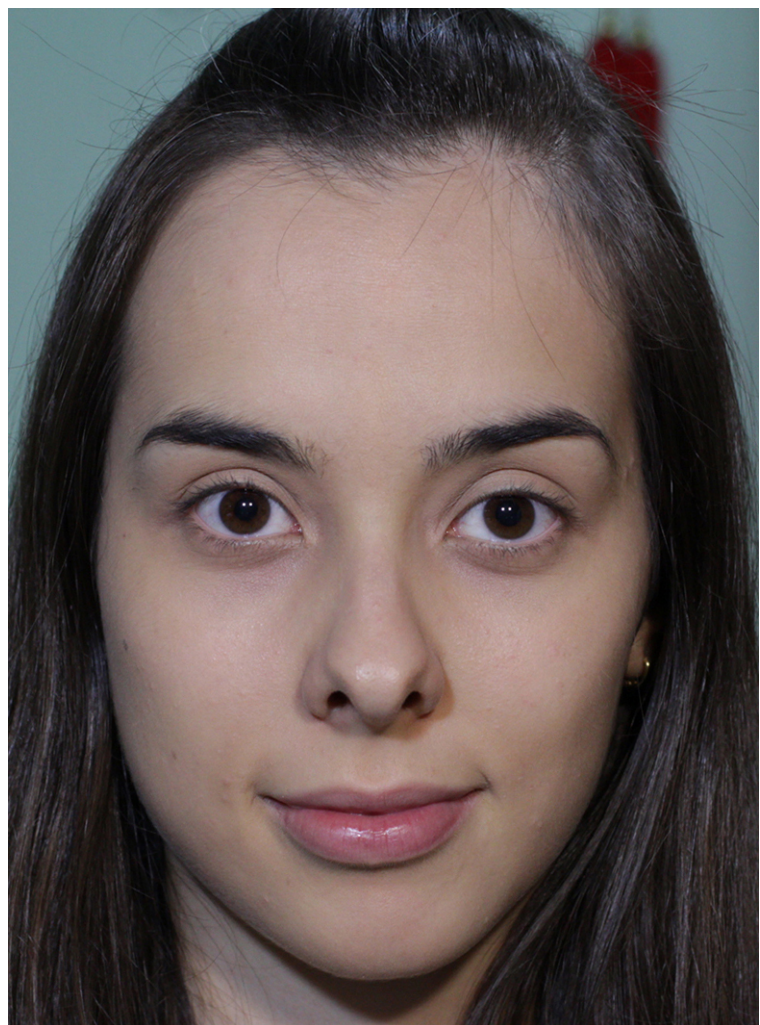

(c)

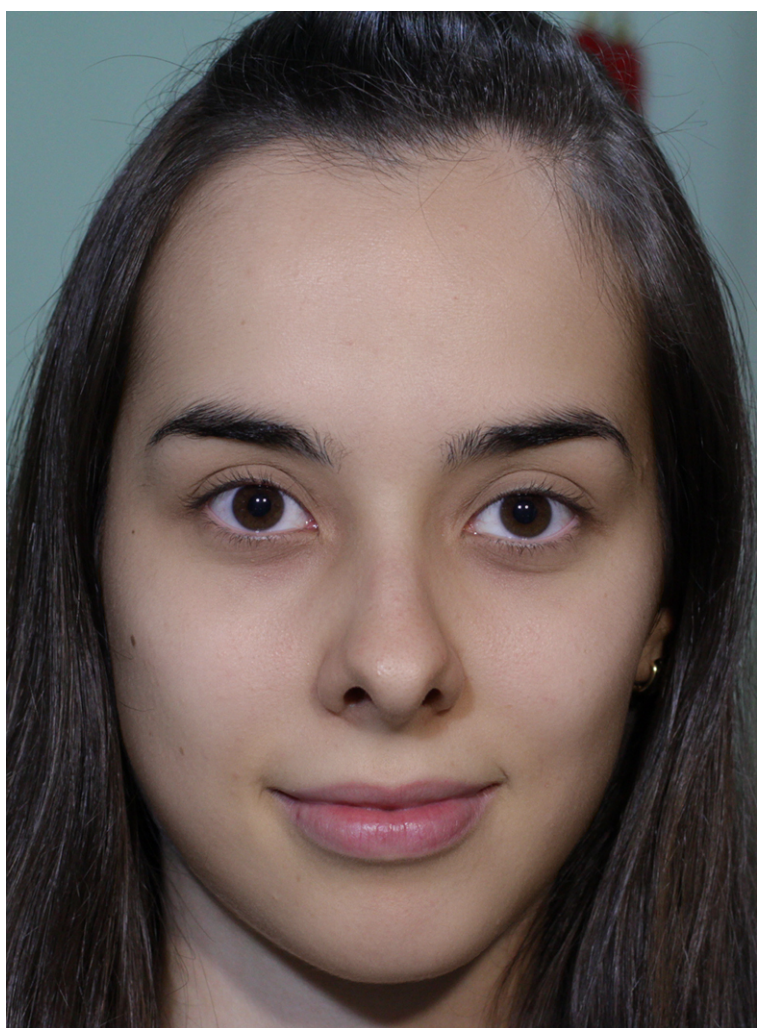

(b)

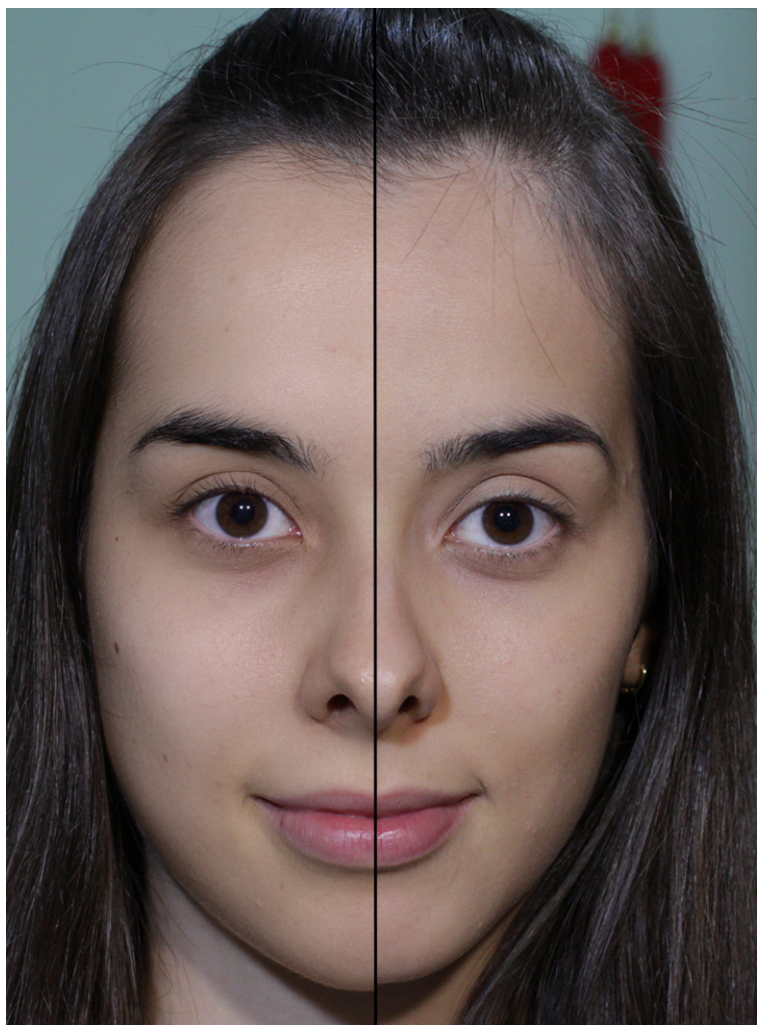

(d)

Figura 6.7: Comparativo entre o resultado da simulação e maquiagem real. (a) Imagem sem maquiagem; (b) Resultado da simulação de maquiagem; (c) Maquiagem real; (d) Comparativo, lado esquerdo: simulada, lado direto: real 


\section{Capítulo 7}

\section{Conclusão}

Esse trabalho apresenta um espelho virtual interativo para simulação de maquiagem que permite a escolha e aplicação desses produtos na imagem do usuário. Tal simulador tem como intuito possibilitar que o usuário experimente um produto de maquiagem de forma mais fácil e conveniente do que utilizando os cosméticos reais, podendo observar os resultados de forma mais rápida (sem a necessidade de preparação, além da aplicação e remoção da maquiagem ocorrerem instantaneamente) e barata (não é necessário comprar o produto ou gastar produtos já existentes). Durante o desenvolvimento do projeto, duas grandes questões foram abordadas, a Interação e a Simulação de Maquiagem, estas serão discutidos independentemente nos próximos parágrafos.

A interação com o sistema ocorre por meio do toque no monitor que faz o papel de espelho, permitindo a escolha da maquiagem desejada e também sua aplicação na imagem do espelho. A interface permite que o usuário possa aplicar a maquiagem da forma que ele quiser em sua face criando efeitos diversos, por exemplo, intensificando determinadas regiões ou passando mais de um produto de maquiagem na mesma região. Além disso, uma vez que a maquiagem foi aplicada, o sistema é capaz de manter o posicionamento da maquiagem durante a movimentação da face do usuário sem que isso interfira na fluidez da imagem do espelho e sem a necessidade de marcadores.

O protótipo desenvolvido segue as características citadas no parágrafo anterior e portanto está de acordo com o objetivo inicial do trabalho. Embora tenha sido possível contornar as limitações de hardware para mostrar a viabilidade da interação proposta, alguns sinais dessas limitações são perceptíveis. A imagem da face obtida com o Kinect possui baixa resolução o que degrada a qualidade da imagem observada pelo usuário. Além disso, a capacidade de processamento do computador utilizado também limitou o número de triângulos a serem usados para o posicionamento da maquiagem. Com o avanço natural dos dispositivos utilizados, ganha-se melhor qualidade de imagem e poder de processamento, o que resulta na melhoria da qualidade de imagem do espelho e também possibilita o uso de algoritmos computacionalmente mais caros melhorando o rastreamento da face, sua triangularização e consequentemente o posicionamento da maquiagem aplicada na face do usuário. Entretanto, 
diferentemente de outros trabalhos, a interface proposta não tem a necessidade de etapas preparatórias, como a criação de um modelo 3D da face do usuário ou uso de marcadores, e, portanto, se encontra pronta para o uso imediato do usuário.

Além da evolução do hardware já citada, também existem outras melhorias que podem ser realizadas em trabalhos futuros do simulador. No lugar da aplicação da maquiagem utilizando o toque no monitor, poderiam ser utilizados gestos na face, o que seria mais próximo da forma com que uma pessoa se maqueia na vida real. Outra melhoria consiste na simulação do resultado da maquiagem sob iluminação não uniforme e também diferentes tipos de iluminação como luz do sol, nublado, luz provinda de uma lâmpada incandescente ou fluorescente. Além disso, o algoritmo de rastreamento dos pontos faciais poderia ser substituído por outro método que não precisasse utilizar o Kinect, apenas uma câmera comum, o que ajudaria a diminuir o custo do projeto e abriria a possibilidade dele ser utilizado em dispositivos móveis. Por fim, podemos citar também o uso de homografia para alinhar a direção do olhar do usuário com a imagem do espelho.

Além da Interação, esta dissertação apresenta um método para simular a aplicação de base, batom e sombra em uma imagem da face de uma pessoa sem maquiagem. Para realizar a simulação utiliza-se a ideia de decompor cada propriedade a ser simulada em uma ou mais camadas que podem ser tratadas independentemente. Para a simulação de base, além da simulação de cor, realizada no espaço de cor La*b*, foi feita uma homogeneização do tom de pele e uma suavização dos detalhes faciais por meio de suavizações em algumas camadas de faixas de frequência da imagem da face. Para batom e sombra, a simulação restringiu-se à introdução de cor nas regiões maquiadas.

Diferentemente dos trabalhos de transferência de maquiagem, nossa simulação permite a livre aplicação de tipos diferentes de maquiagem em qualquer área do rosto de forma independente, sem a necessidade de um modelo pré-existente e sem uma pose específica para o rosto (flexibilidade). Com relação aos trabalhos de simulação, nosso método vai além do que foi proposto por esses trabalhos, tornando o resultado mais realista e sem a necessidade de equipamentos especiais (custo). Além disso, o algoritmo proposto também pode ser computado em tempo real o que confere a presença das quatro características desejadas para o algoritmo simultaneamente atingindo o objetivo do algoritmo.

Apesar dos bons resultados, ainda existe espaço para trabalhos futuros. Ao utilizar a abordagem de camadas, novas camadas podem ser incorporadas no método proposto para abordar aspectos ainda não trabalhados como o tratamento de regiões especulares, a remoção dos pelos faciais antes da simulação da maquiagem na pele, iluminação não uniforme, tipos diferentes de fontes de luz e outros tipos de maquiagens. Também podemos citar a implementação do algoritmo em GPU para o tornar ainda mais rápido, a adição no módulo de Textura do realce da textura da pele e não somente a suavização e também um método para treinar um maquilet para que ele simule uma maquiagem real.

Como resultado deste trabalho, um artigo completo foi publicado no Simpósio de Realidade Virtual e Aumentada (SVR) 2014 (Campos e Morimoto, 2014b) e outro artigo curto 
foi publicado no Simpósio Brasileiro Sobre Fatores Humanos em Sistemas Computacionais (IHC) 2014 (Campos e Morimoto, 2014a). 


\section{Referências Bibliográficas}

box (2013) Box blur, dec 2013. URL http://en.wikipedia.org/w/index.php?title=Box_ blur\&oldid $=517348792$. Page Version ID: 517348792. Citado na pág. 52

Baranoski e Krishnaswamy (2008) Gladimir V. G. Baranoski e Aravind Krishnaswamy. Light interaction with human skin: from believable images to predictable models. Em ACM SIGGRAPH ASIA 2008 courses, SIGGRAPH Asia '08, páginas 27:1-27:80, New York, NY, USA. ACM. doi: 10.1145/1508044.1508071. URL http://doi.acm.org/10.1145/ 1508044.1508071. Citado na pág. 30

Barrow e Tenenbaum (1978) H. G. Barrow e J. M. Tenenbaum. RECOVERING INTRINSIC SCENE CHARACTERISTICS FROM IMAGES. Em International Conference on Computer Vision Systems. Citado na pág. 11

Beeler et al. (2012) Thabo Beeler, Bernd Bickel, Gioacchino Noris, Paul Beardsley, Steve Marschner, Robert W. Sumner e Markus Gross. Coupled 3d reconstruction of sparse facial hair and skin. ACM Trans. Graph., 31(4):117:1-117:10. ISSN 0730-0301. doi: 10.1145/2185520.2185613. URL http://doi.acm.org/10.1145/2185520.2185613. Citado na pág. 30

Board (2008) OpenMP Architecture Review Board. Openmp application program interface, May 2008. URL http://openmp.org/wp/. Citado na pág. 56

Bookstein (1989) F.L. Bookstein. Principal warps: Thin-plate splines and the decomposition of deformations. Pattern Analysis and Machine Intelligence, IEEE Transactions on, 11(6):567-585. Citado na pág. 11, 16

Bradley et al. (2010) Derek Bradley, Wolfgang Heidrich, Tiberiu Popa e Alla Sheffer. High resolution passive facial performance capture. Em ACM SIGGRAPH 2010 papers, SIGGRAPH '10, páginas 41:1-41:10, New York, NY, USA. ACM. ISBN 978-1-4503-0210-4. doi: 10.1145/1833349.1778778. URL http://doi.acm.org/10.1145/1833349.1778778. Citado na pág. 30

Bradski (2000) G. Bradski. Dr. Dobb's Journal of Software Tools. Citado na pág. 45, 55

Brainstorm9 (2012) Carlos Merigo Brainstorm9. Natura: Espelho de maquiagem virtual, 2012. URL http://www.brainstorm9.com.br/30910/advertising/ natura-espelho-de-maquiagem-virtual/. Citado na pág. 31

Campos e Morimoto (2014a) Filipe M. S. de Campos e Carlos H. Morimoto. Interactive virtual mirror for makeup simulation. Em Proceedings of the 13th Brazilian Symposium on Human Factors in Computer Systems, IHC'14. Citado na pág. 71 
Campos e Morimoto (2014b) Filipe M. S. de Campos e Carlos H. Morimoto. Virtual makeup: foundation, eye shadow and lipstick simulation. Em Proceedings of the 16th Symposium on Virtual and Augmented Reality, SVR'14. Citado na pág. 70

Chuang et al. (2001) Y.Y. Chuang, B. Curless, D.H. Salesin e R. Szeliski. A bayesian approach to digital matting. Em Computer Vision and Pattern Recognition, 2001. CVPR 2001. Proceedings of the 2001 IEEE Computer Society Conference on, volume 2, páginas II-264. IEEE. Citado na pág. 10

Cootes et al. (1995) T. F. Cootes, C. J. Taylor, D. H. Cooper e J. Graham. Active shape models\&mdash; their training and application. Comput. Vis. Image Underst., 61(1):38-59. ISSN 1077-3142. doi: 10.1006/cviu.1995.1004. URL http://dx.doi.org/10.1006/cviu.1995. 1004. Citado na pág. 20

DCI (2013) Diário Comércio Indústria \& Serviços DCI. Mercado brasileiro de cosméticos deve ser vice-líder até 2017, aponta pesquisa, 2013. URL http://www. dci.com.br/comercio/mercado-brasileiro-de-cosmeticos-deve-ser-vicelider-ate-2017, -aponta-pesquisa-id353256.html. Citado na pág. 1

Dhall et al. (2009) Abhinav Dhall, Gaurav Sharma, Rajen Bhatt e Ghulam Khan. Adaptive digital makeup. Em Advances in Visual Computing, volume 5876 of Lecture Notes in Computer Science, páginas 728-736. Springer Berlin / Heidelberg. ISBN 978-3-642-105197. URL http://dx.doi.org/10.1007/978-3-642-10520-3_69. Citado na pág. 20, 28, 34

Donner et al. (2008) Craig Donner, Tim Weyrich, Eugene d'Eon, Ravi Ramamoorthi e Szymon Rusinkiewicz. A layered, heterogeneous reflectance model for acquiring and rendering human skin. Em ACM SIGGRAPH Asia 2008 papers, SIGGRAPH Asia '08, páginas 140:1-140:12, New York, NY, USA. ACM. doi: 10.1145/1457515.1409093. URL http://doi.acm.org/10.1145/1457515.1409093. Citado na pág. 30

Eisemann e Durand (2004) Elmar Eisemann e Frédo Durand. Flash photography enhancement via intrinsic relighting. ACM Trans. Graph., 23(3):673-678. ISSN 0730-0301. doi: 10.1145/1015706.1015778. URL http://doi.acm.org/10.1145/1015706.1015778. Citado na pág. 16

Farbman et al. (2008) Zeev Farbman, Raanan Fattal, Dani Lischinski e Richard Szeliski. Edge-preserving decompositions for multi-scale tone and detail manipulation. ACM Trans. Graph., 27(3):67:1-67:10. ISSN 0730-0301. doi: 10.1145/1360612.1360666. URL http: //doi.acm.org/10.1145/1360612.1360666. Citado na pág. 16

Foley et al. (1990) James D. Foley, Andries van Dam, Steven K. Feiner e John F. Hughes. Computer Graphics: Principles and Practice (2Nd Ed.). Addison-Wesley Longman Publishing Co., Inc., Boston, MA, USA. ISBN 0-201-12110-7. Citado na pág. 7

Gonzalez e Woods (2006) Rafael C. Gonzalez e Richard E. Woods. Digital Image Processing (3rd Edition). Prentice-Hall, Inc., Upper Saddle River, NJ, USA. ISBN 013168728X. Citado na pág. 6

Guo e Sim (2009) Dong Guo e T. Sim. Digital face makeup by example. Em Computer Vision and Pattern Recognition, 2009. CVPR 2009. IEEE Conference on, páginas $73-79$. doi: 10.1109/CVPR.2009.5206833. Citado na pág. ix, x, 13, 15, 16, 17, 18, 19, 20, 34 
Hanafusa et al. (2010) Akihiko Hanafusa, Shuri Terada, Yuuri Miki, Chiharu Sasagawa, Tomozumi Ikeda e Teruhiko Fuwa. Makeup support system for visually impaired persons: Overview of system functions. Em Klaus Miesenberger, Joachim Klaus, Wolfgang L. Zagler e Arthur I. Karshmer, editors, ICCHP (2), volume 6180 of Lecture Notes in Computer Science, páginas 338-345. Springer. ISBN 978-3-642-14099-0. URL http://dx.doi.org/10. 1007/978-3-642-14100-3_50. Citado na pág. x, 26, 27, 35, 36

Huang et al. (2013) Cheng-Guo Huang, Tsung-Shian Huang, Wen-Chieh Lin e Jung-Hong Chuang. Physically-based cosmetic rendering. Em International Conference on Computer Animation and Social Agents. Citado na pág. x, 21, 22, 30, 34

Iwabuchi et al. (2009) Eriko Iwabuchi, Maki Nakagawa e Itiro Siio. Smart makeup mirror: Computer-augmented mirror to aid makeup application. Em Proceedings of the 13th International Conference on Human-Computer Interaction. Part IV: Interacting in Various Application Domains, páginas 495-503, Berlin, Heidelberg. Springer-Verlag. ISBN 978-3-642-02582-2. doi: 10.1007/978-3-642-02583-9_54. URL http://dx.doi.org/10.1007/ 978-3-642-02583-9_54. Citado na pág. x, 22, 23, 35, 36

Jain e Bhatti (2010) Jhilmil Jain e Nina Bhatti. Snap and match: a case study of virtual color cosmetics consultation. Em Proceedings of the 28th of the international conference extended abstracts on Human factors in computing systems, CHI EA '10, páginas 47434754, New York, NY, USA. ACM. ISBN 978-1-60558-930-5. doi: 10.1145/1753846.1754224. URL http://doi.acm.org/10.1145/1753846.1754224. Citado na pág. x, 28, 29

Jimenez et al. (2010) J. Jimenez, D. Whelan, V. Sundstedt e D. Gutierrez. Real-time realistic skin translucency. Computer Graphics and Applications, IEEE, 30(4):32 -41. ISSN 0272-1716. doi: 10.1109/MCG.2010.39. Citado na pág. 30

Jimenez et al. (2009) Jorge Jimenez, Veronica Sundstedt e Diego Gutierrez. Screen-space perceptual rendering of human skin. ACM Transactions on Applied Perception (TAP), 6 (4):23. Citado na pág. 21

Khronos () Group Khronos. Opencl - open computing language - the open standard for parallel programming of heterogeneous systems. URL https://www.khronos.org/opencl/. Citado na pág. 55

Kim e Choi (2008) Jeong-Sik Kim e Soo-Mi Choi. Interactive cosmetic makeup of a $3 \mathrm{~d}$ point-based face model. IEICE Transactions on Information and Systems, E91.D(6): 1673-1680. Citado na pág. $\mathrm{x}, 21,22,30,33,34,35,36$

Kim et al. (2005) Sang Kim, Kyoung Seo e Sang Lee. Image-based generation of facial skin texture with make-up. Em Yo-Sung Ho e Hyoung Kim, editors, Advances in Multimedia Information Processing - PCM 2005, volume 3767 of Lecture Notes in Computer Science, páginas 350-360. Springer Berlin / Heidelberg. ISBN 978-3-540-30027-4. URL http: //dx.doi.org/10.1007/11581772_31. Citado na pág. 30

Kortüm e Lohr (1969) Gustav Kortüm e James E Lohr. Reflectance spectroscopy: principles, methods, applications. Springer New York. Citado na pág. 21

Kwatra et al. (2003) Vivek Kwatra, Arno Schödl, Irfan Essa, Greg Turk e Aaron Bobick. Graphcut textures: image and video synthesis using graph cuts. Em ACM SIGGRAPH 
2003 Papers, SIGGRAPH '03, páginas 277-286, New York, NY, USA. ACM. ISBN 158113-709-5. doi: 10.1145/1201775.882264. URL http://doi.acm.org/10.1145/1201775. 882264. Citado na pág. 10

Makino et al. (2005) Takao Makino, Toshiya Nakaguchi, Norimichi Tsumura e Yoichi Miyake. Virtual mirror based on 3d-shape reconstruction and real-time face tracking. páginas 252-259. doi: 10.1117/12.585841. URL +http://dx.doi.org/10.1117/12.585841. Citado na pág. x, 25

Microsoft () Microsoft. Kinect for windows sdk. URL http://www.microsoft.com/en-us/ kinectforwindowsdev/Downloads.aspx. Citado na pág. 47

Milborrow e Nicolls (2008) Stephen Milborrow e Fred Nicolls. Locating facial features with an extended active shape model. Em Proceedings of the 10th European Conference on Computer Vision: Part IV, ECCV '08, páginas 504-513, Berlin, Heidelberg. SpringerVerlag. ISBN 978-3-540-88692-1. doi: 10.1007/978-3-540-88693-8_37. URL http://dx. doi.org/10.1007/978-3-540-88693-8_37. Citado na pág. 16

Mori (1970) M. Mori. The uncanny valley. Energy, 7(4):33-35. URL http://www. androidscience.com/theuncannyvalley/proceedings2005/uncannyvalley.html. Citado na pág. 31

Nakagawa et al. (2011) Maki Nakagawa, Koji Tsukada e Itiro Siio. Smart makeup system: supporting makeup using lifelog sharing. Em Proceedings of the 13th international conference on Ubiquitous computing, UbiComp '11, páginas 483-484, New York, NY, USA. ACM. ISBN 978-1-4503-0630-0. doi: 10.1145/2030112.2030182. URL http: //doi.acm.org/10.1145/2030112.2030182. Citado na pág. x, 26, 28, 35, 36

Nars (2004) F. and Nars. Makeup your Mind. PowerHouse Books, hardcover edition ed. ISBN 9781576870990. Citado na pág. ix, 15

Rahman et al. (2010) A.S.M.M. Rahman, T.T. Tran, S.A. Hossain e A. El Saddik. Augmented rendering of makeup features in a smart interactive mirror system for decision support in cosmetic products selection. Em Distributed Simulation and Real Time Applications (DS-RT), 2010 IEEE/ACM 14th International Symposium on, páginas 203 -206. doi: 10.1109/DS-RT.2010.30. Citado na pág. x, 4, 25, 26, 35, 36

Scherbaum et al. (2011) Kristina Scherbaum, Tobias Ritschel, Matthias Hullin, Thorsten Thormahlen, Volker Blanz e Hans-Peter Seidel. Computer-suggested facial makeup. Computer Graphics Forum, 30(2):485-492. ISSN 1467-8659. doi: 10.1111/j.1467-8659. 2011.01874.x. URL http://dx.doi.org/10.1111/j.1467-8659.2011.01874.x. Citado na pág. 18, $20,29,30,34$

Taaz.com () Taaz.com. TAAZ virtual makeover \& hairstyles. URL http://www.taaz.com/. Citado na pág. 32

Tong et al. (2007) Wai-Shun Tong, Chi-Keung Tang, M.S. Brown e Ying-Qing Xu. Example-based cosmetic transfer. Em Computer Graphics and Applications, 200\%. PG '07. 15th Pacific Conference on, páginas 211 -218. doi: 10.1109/PG.2007.31. Citado na pág. ix, 10, 11, 12, 13, 14, 18, 19, 34 
Tsumura et al. (2003) Norimichi Tsumura, Nobutoshi Ojima, Kayoko Sato, Mitsuhiro Shiraishi, Hideto Shimizu, Hirohide Nabeshima, Syuuichi Akazaki, Kimihiko Hori e Yoichi Miyake. Image-based skin color and texture analysis/synthesis by extracting hemoglobin and melanin information in the skin. ACM Trans. Graph., 22(3):770-779. ISSN 0730-0301. doi: 10.1145/882262.882344. URL http://doi.acm.org/10.1145/882262.882344. Citado na pág. 11

Turk e Pentland (1991) M. A. Turk e A. P. Pentland. Face recognition using eigenfaces. Em Computer Vision and Pattern Recognition, 1991. Proceedings CVPR E\# 039;91., IEEE Computer Society Conference on, páginas 586-591. IEEE. ISBN 0-8186-2148-6. doi: 10.1109/cvpr.1991.139758. URL http://dx.doi.org/10.1109/cvpr.1991.139758. Citado na pág. 20

Viola e Jones (2001) P. Viola e M. Jones. Rapid object detection using a boosted cascade of simple features. Em CVPR 2001 - IEEE Conference on Computer Vision and Pattern Recognition. Citado na pág. 20

Zhang et al. (2008) X. Zhang, T. Sim e X. Miao. Enhancing photographs with near infrared images. Em Computer Vision and Pattern Recognition, 2008. CVPR 2008. IEEE Conference on, páginas 1-8. IEEE. Citado na pág. 16 